University of Rhode Island

DigitalCommons@URI

Open Access Dissertations

2013

\title{
Associations Between Patient Characteristics and Utilization in a Commercial Schizophrenia Population
}

Thomas Joseph Bunz

University of Rhode Island, thomasbunz@gmail.com

Follow this and additional works at: https://digitalcommons.uri.edu/oa_diss

\section{Recommended Citation}

Bunz, Thomas Joseph, "Associations Between Patient Characteristics and Utilization in a Commercial Schizophrenia Population" (2013). Open Access Dissertations. Paper 16.

https://digitalcommons.uri.edu/oa_diss/16

This Dissertation is brought to you for free and open access by DigitalCommons@URI. It has been accepted for inclusion in Open Access Dissertations by an authorized administrator of DigitalCommons@URI. For more information, please contact digitalcommons-group@uri.edu. 
ASSOCIATIONS BETWEEN PATIENT CHARACTERISTICS AND UTILIZATION IN A COMMERCIAL SCHIZOPHRENIA POPULATION

BY

THOMAS JOSEPH BUNZ

\begin{abstract}
A DISSERTATION SUBMITTED IN PARTIAL FULFILLMENT OF THE REQUIREMENTS FOR THE DEGREE OF

DOCTOR OF PHILOSOPHY
\end{abstract}

IN

PHARMACEUTICAL SCIENCES

UNIVERSITY OF RHODE ISLAND

2013 


\section{DOCTOR OF PHILOSOPHY DISSERTATION \\ OF}

THOMAS JOSEPH BUNZ

\section{APPROVED:}

Dissertation Committee:

Major Professor: Stephen Kogut, Ph.D.

E. Paul Larrat, Ph.D.

Brian Quilliam, Ph.D.

Marlene Dufault, Ph.D.

Nasser H. Zawia, Ph.D.

DEAN OF THE GRADUATE SCHOOL

University of Rhode Island

2013 


\section{Abstract:}

Background: Schizophrenia is a prevalent and costly condition in the United States. Many studies have been conducted on the schizophrenia populations receiving government sponsored insurance, but less is known about the $16 \%$ of the population that receives commercial insurance. A better understanding of the utilization and outcomes in this population is essential to ensure that outreach programs target the groups most in need, that these programs are aimed at the most important aspects of utilization, and that those factors are tied to meaningful clinical outcomes.

Objectives: The purpose of this research has been to better understand the patient characteristics, utilization patterns, and outcomes in patients with schizophrenia that participate in commercial insurance plans. Three studies have been completed to address the following specific aims: 1) To describe the schizophrenia population, 2) To determine if the sociodemographic, clinical, and employment characteristics of these patients are associated with their utilization patterns, and 3) To determine if adherence to therapy is associated with the rate of hospitalization for mental health conditions.

Methods: In order to accomplish these goals several studies have been completed utilizing claims data from calendar years 2000 and 2001 . The first is a retrospective cohort analysis identifying relationships between utilization of first and second generation antipsychotics, switching between therapies, and combination therapy and patient characteristics; the second study identifies the associations between patient characteristics and adherence; the final study 
utilizes a retrospective cohort design to determine the association between adherence and hospitalizations.

Results: Patient characteristics are a significant predictor of utilization, with individuals living in the North Central region and individuals with comorbid bipolar disorder significantly more likely to use second generation antipsychotics. Adherence was associated with comorbid diabetes and mental health disorders. Adherence as measured by an MPR greater than or equal to $80 \%$ was associated with a lower risk of hospitalization due to mental health conditions. Conclusion: This series of studies has identified significant associations between comorbidities and increased likelihood to switch medications, utilize a second generation antipsychotic, or combine therapies. Comorbidities also increase the likelihood that someone will not be adherent to their therapy. Low adherence to therapy in turn increases the likelihood of hospitalization. 


\section{Acknowledgements}

I would like to begin by acknowledging my major professor, Dr. Stephen Kogut, without whom these manuscripts would not exist. Dr. Kogut's mentorship and instruction directly lead to my decision to pursue postgraduate training in pharmacoeconomics. His consistent, thoughtful, and pragmatic advice helped to guide this work to its completion.

I would also like to acknowledge the unbelievably supportive and expert faculty in the College of Pharmacy, who have provided guidance and training for over a decade as an undergraduate and graduate student. Dr. Paul Larrat's support as a member of my committee and an instructor in several courses have taught me how to interpret and conduct pharmacoeconomic research, and also how to work with others with a sense of humility, patience, and humor. Dr. Brian Quilliam has also been an integral member of my committee, and a dedicated teacher. His generosity and instruction while I was an undergraduate and a graduate student provided me with the technical skill set that is now a cornerstone of my career, and was necessary to complete this dissertation. Dr. Cynthia Willey's training in study design and application of statistical analyses was also essential in being able to conduct these studies. 
I would also like to thank my outside committee members, Drs. Marlene Dufault and Elizabeth Fallon, for their generosity in taking the time to review this work and applying their expertise and diverse perspectives to make it better.

I would also like to thank the friends and colleagues that have supported this work through the years. Dr. Mark Regine provided great friendship, support, and just enough competition to make moving forward with this fun. Dr. Laura Pizzi, Mr. Neil Goldfarb, Dr. Therese Conner, and Mr. Jason Cooper have all provided strong encouragement, and the freedom to take the time necessary to complete this dissertation.

Finally, without the support of my family it would have been impossible to complete this dissertation. My wife, Megan, has been unwavering in her support of this work. My parents, Marc and Celeste have instilled in me the importance of education and continuously building new skills and knowledge. Finally, my children, Abigail, Thomas, and Evelyn, have been an inspiration in their constant desire to learn and discover. 


\section{Preface}

This dissertation was prepared following the manuscript format. 


\section{Table of Contents}

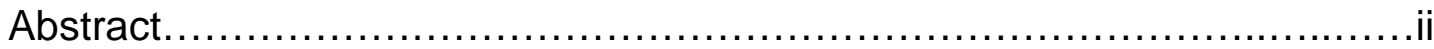

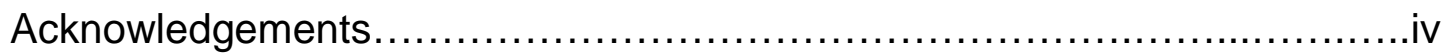

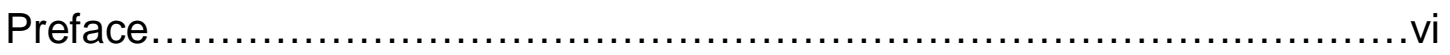

Table of Contents ...................................................................

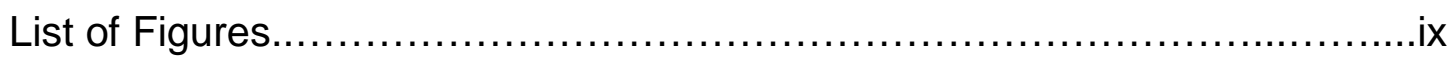

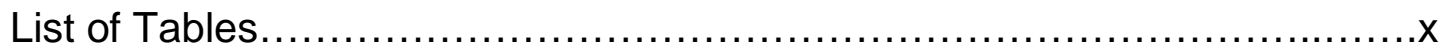

Chapter 1: Analysis of the demographic, employment, and clinical characteristics of antipsychotic utilizers in a commercially insured

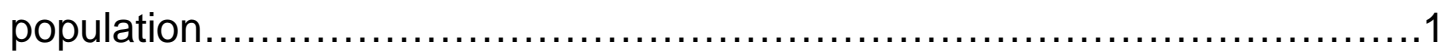

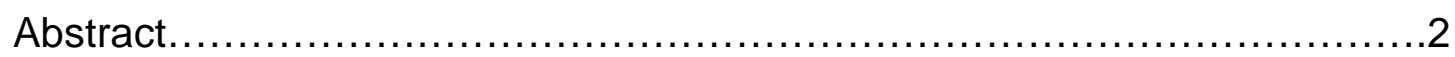

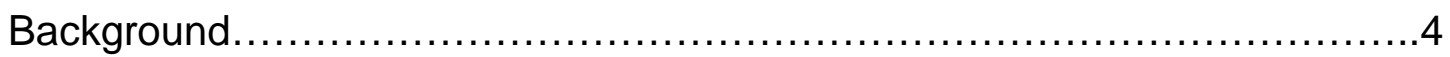

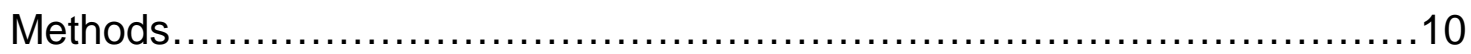

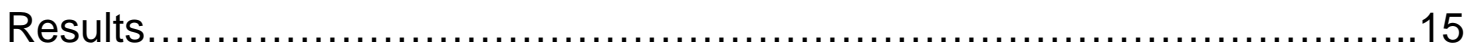

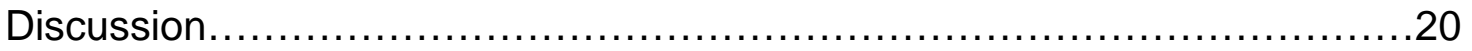

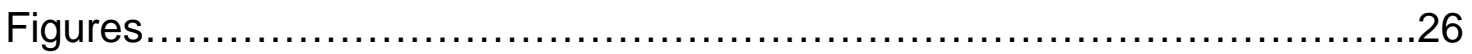

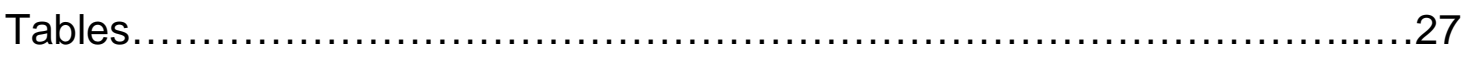

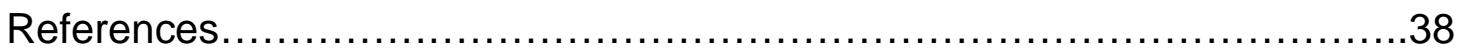

Chapter 2: Adherence to antipsychotic treatments in a commercially insured population diagnosed with schizophrenia............................42

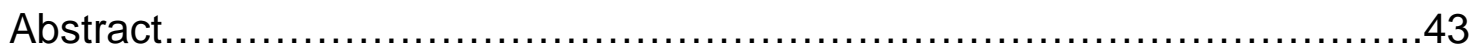

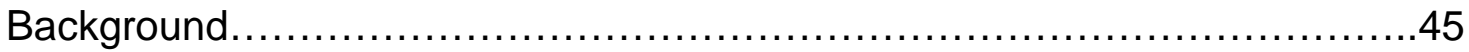




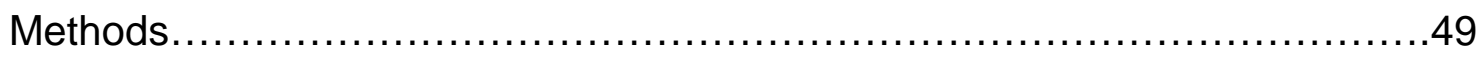

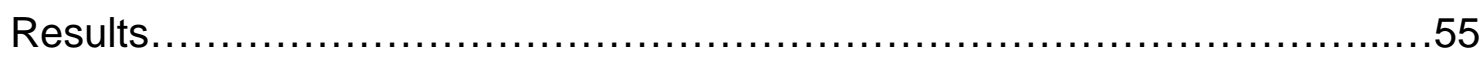

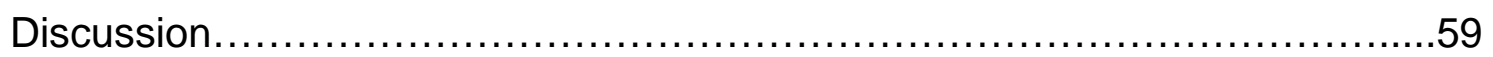

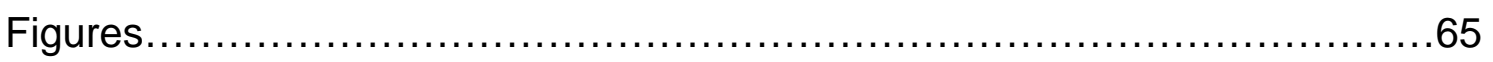

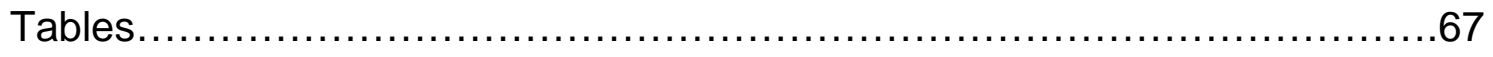

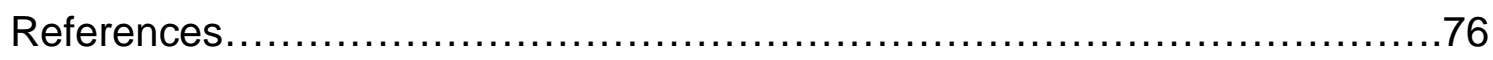

Chapter 3: Association between adherence and hospitalization in a commercially insured population receiving antipsychotics.....................8

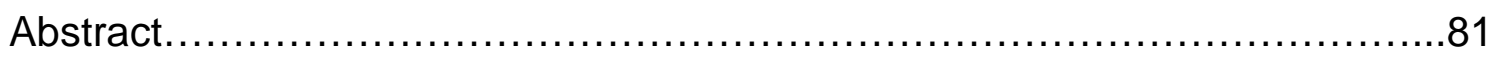

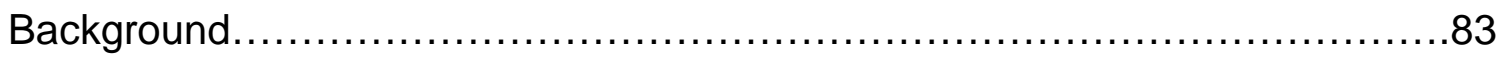

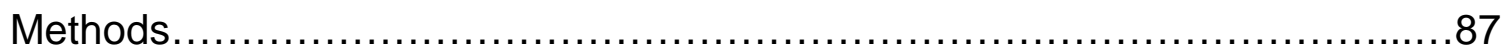

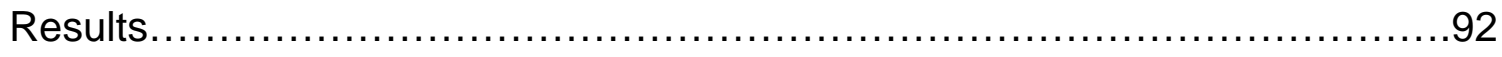

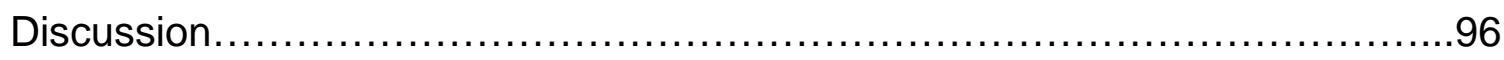

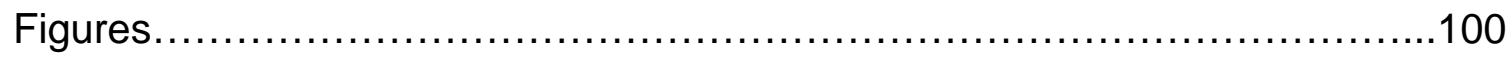

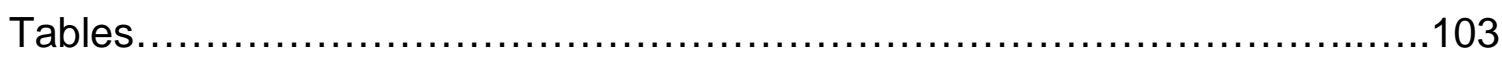

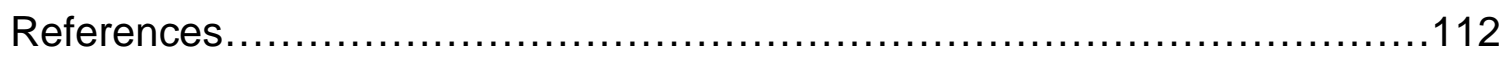




\section{List of Figures}

Figure I-1: Inclusion and exclusion criteria flowchart.........................26

Figure II-1: Inclusion and exclusion criteria flowchart.........................65

Figure II-2: Histogram of frequency of days of continual antipsychotic treatment among patients with a diagnosis of schizophrenia...........................66

Figure III-1: Inclusion and exclusion criteria flowchart.......................100

Figure III-2: Matching support for propensity scores in adherent vs. non-adherent

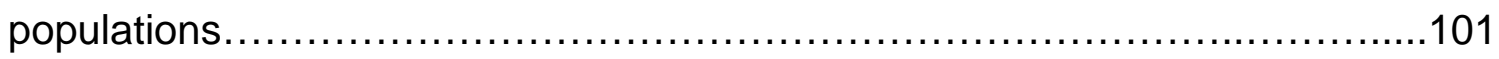

Figure III-3: Absolute standardized differences in matching variables before and

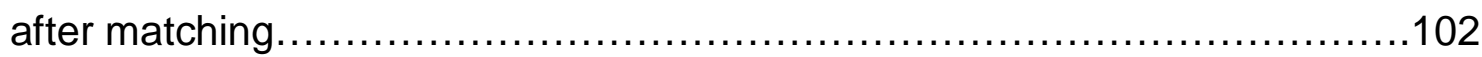




\section{List of Tables}

Table I-1: ICD-9 codes used for identifying diagnoses with primary conditions and comorbidities.

Table I-2: Demographics of patients with a diagnosis of schizophrenia 28

Table I-3: Frequency and percentage of the use of antipsychotic medications

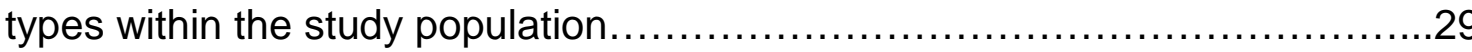

Table I-4: Antipsychotic medication switches................................30

Table I-5: Antipsychotic medication combinations.............................31

Table I-6: Bivariate analysis of demographic, clinical, and employment factors associated with use of a first or second generation antipsychotic in the population

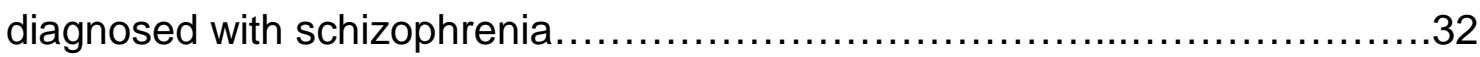

Table I-7: Bivariate analysis of demographic, clinical, and employment factors associated with switching between and combination of antipsychotics in the population diagnosed with schizophrenia 
Table I-8: Model fitting diagnostics for variables associated with the use of first or second generation antipsychotics, adherence, persistence, switching, and combination in the schizophrenia population

Table I-9: Odds ratios for the likelihood that a patient would receive a second generation antipsychotic as compared with a first generation antipsychotic.....35

Table 1-10: Odds ratios for the likelihood that a patient would switch treatments, according to selected demographic and clinical characteristics.................36

Table I-11: Odds ratios for the likelihood of combination antipsychotic medication treatment, according to selected demographic and clinical characterisitics.....37

Table II-1: ICD-9 codes used for identifying diagnoses with primary conditions

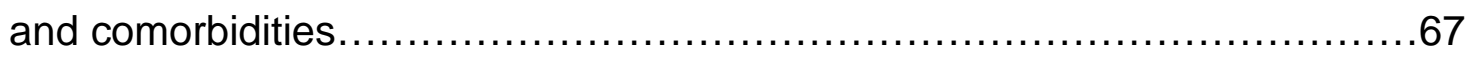

Table II-2: Demographic characteristics of the study population................68

Table II-3: Treatments observed in the study population........................69

Table II-4: Bivariate associations between adherence and demographic, clinical, and employment characteristics.............................................. 
Table II-5: Bivariate associations between discontinuation and demographic, clinical, and employment characteristics ................................... 71

Table II-6: Logistic regression model optimization for factors associated with

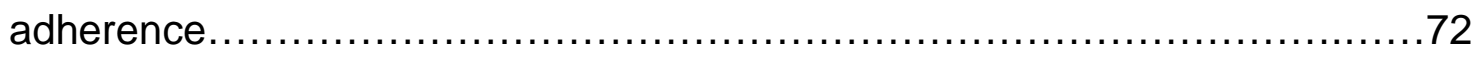

Table II-7: Odds ratios for the likelihood that an individual will be adherent to

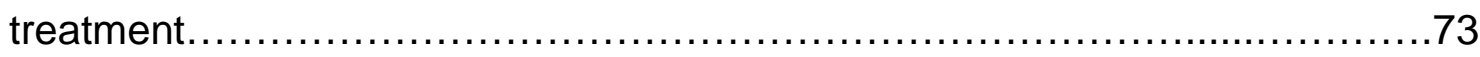

Table II-8: Logistic regression model optimization for factors associated with

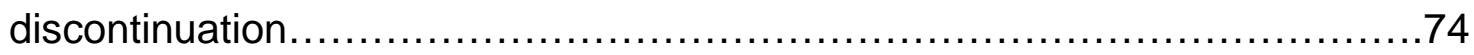

Table II-9: Odds ratios for the likelihood that an individual will be persistent on

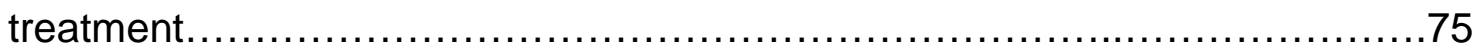

Table III-1: ICD-9 codes used for identifying diagnoses with primary conditions and comorbidities.............................................................

Table III-2: Bivariate analysis of clinical, demographic, and employment factors potentially associated with adherence before and after matching..............104 
Table III-3: Model fitting diagnostics for propensity score, modeling likelihood of hospitalization among adherent and non-adherent groups, controlling for other

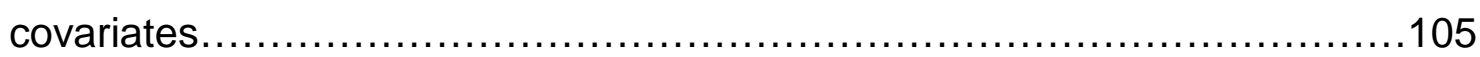

Table III-4: Hospitalization rates in the adherent and non-adherent populations

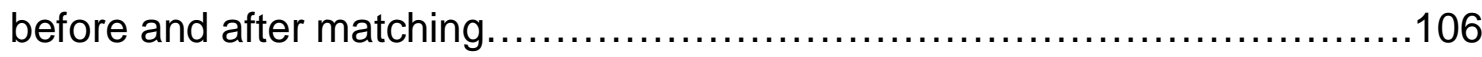

Table III-5: Demographic, clinical, and employment characteristics in the hospitalized and non-hospitalized populations before and after matching......107

Table III-6: Model fitting diagnostics for the likelihood of hospitalization........108

Table III-7: Odds ratios for the likelihood of hospitalization 109

Table III-8: Hospitalization rates in the adherent and non-adherent populations

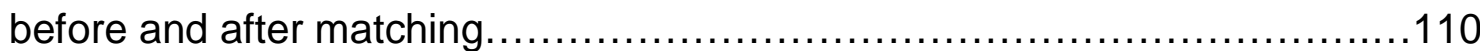

Table III-9: Odds of hospitalization based on analysis of the unmatched, matched, and matched with logistic regression populations 


\section{CHAPTER 1}

\section{ANALYSIS OF THE DEMOGRAPHIC, EMPLOYMENT, AND CLINICAL CHARACTERISTICS OF ANTIPSYCHOTIC UTILIZERS IN A COMMERCIALLY INSURED POPULATION}

Formatted for submission to the Journal of Managed Care Pharmacy (JMCP), not yet submitted. 


\section{Abstract:}

\section{Background}

Schizophrenia is a difficult and expensive condition to treat. In the United States, many individuals with this condition are managed by federal health insurance programs, as a result most database studies examine schizophrenia treatment at the VA, or in Medicare and Medicaid populations. The purpose of this analysis is to better understand treatment patterns in the commercial population, where $16 \%$ of the schizophrenia population is managed.

\section{Methods}

A retrospective cohort study was conducted utilizing data from the Thomson Marketscan database between January 1, 2000 and December 31, 2001. Individuals with schizophrenia were identified based on documentation of an ICD-9 (295.xx) code during year one. Three logistic regression models were then used to determine if there was an association between first and second generation antipsychotic use, switching, and combination of therapies; and demographic, clinical, and employment characteristics of the population. Results

Second generation antipsychotic use was associated with living in the North Central area of the United States (OR 1.3, 95\% Cl 1.053 - 1.603), comorbid bipolar disorder (OR 1.271, 95\% Cl 1.072 - 1.507), and switching (OR 1.937, $95 \% \mathrm{Cl} 1.568$ - 2.393). Individuals who switched therapy were nearly twice as likely to have been taking a first generation antipsychotic before the switch (OR $1.962,95 \% \mathrm{Cl} 1.583-2.431$ ) Combination therapies were less likely in the North 
Central $(0.727,95 \% \mathrm{Cl} 0.554-0.955)$ and Southern $(0.534,95 \% \mathrm{Cl} 0.411$ 0.694) regions as compared to the North East.

\section{Conclusion}

There were significant associations between certain demographic, clinical, and employment characteristics and the antipsychotic therapies received by individuals in the commercial population. 


\section{Background:}

Prevalence

Mental health disorders are prevalent in the United States, and treating these conditions can be difficult and expensive. A study conducted by Kessler et al, found that the lifetime prevalence of schizophrenia for adults in the United States is between $0.3 \%$ and $1.6 \%{ }^{1}$ A systematic review of the literature found that the period prevalence of schizophrenia is between $0.13 \%$ and $0.82 \% .{ }^{2}$ An evaluation of a commercially insured population found that the prevalence of schizophrenia in that group is near the lower end of the range, at about $0.13 \% .^{3}$ Despite being less prevalent in the commercial population, people in this group make up a significant portion (16\%) of the schizophrenic population. ${ }^{3}$

\section{Treatment Decisions}

Finding an appropriate treatment for schizophrenia is difficult. It can take up to sixteen weeks to see the positive effects of treatment, ${ }^{4}$ and even with effective treatment the negative symptoms of schizophrenia (such as social and emotional withdrawal, poor rapport, and blunted affect) are still common. ${ }^{5}$ As a result, roughly $74 \%$ of patients are expected to discontinue treatment during the first 18 months. ${ }^{6}$ In addition to difficulty finding and adjusting to a treatment, the adverse events associated with both first and second generation antipsychotics are associated with lower adherence. ${ }^{7}$ In first generation antipsychotics, the 
extrapyramidal side effects were closely associated with discontinuation, while metabolic effects lowered adherence in users of Second Generation Antipsychotics, ${ }^{6,8}$ A study by Staring, et al, found that high adherence was associated with decreased quality of life, as was low adherence due to the balance of symptoms and adverse events..$^{9}$ It has become clear that adequate treatment with antipsychotics will lower the mortality rate in the schizophrenia population, ${ }^{10}$ but there are also associations between antipsychotics and increased cardiovascular mortality that have yet to be fully understood. ${ }^{11}$

There are several studies that have tried to define the best strategy for selecting an initial antipsychotic. The CATIE and CutLASS studies were prospective open label trials, but the treatments included for study, population characteristics, and study limitations have limited the acceptance of their findings by clinicians. ${ }^{12}$ Several studies have provided support for the use of First Generation Antipsychotics. In a Medicare population, Second Generation Antipsychotic users were significantly more likely to be hospitalized as compared to non-users, while First Generation Antipsychotic users had roughly the same hospitalization rate as non-users. ${ }^{13}$ CATIE found that users of perphenazine saved roughly $\$ 300-600$ over users of Second Generation Antipsychotics. ${ }^{14}$ Amongst Second Generation Antipsychotics, a review of the literature found no clear benefit to any one choice..$^{15}$ Despite the limited support in the literature, and no preference in treatment guidelines, there has been a major shift in use of antipsychotics from the first to second generation agents. ${ }^{16}$ Race, age, and 
comorbidities were all factors closely associated with the decision to use a second generation antipsychotic in a Veteran population. ${ }^{16}$

The population utilizing antipsychotics is not limited to individuals with schizophrenia. In an analysis of a Veterans population, $60.2 \%$ of the population had no indication of a schizophrenia or bipolar diagnosis. ${ }^{17}$ The most common off label use in this population was Post Traumatic Stress Disorder (PTSD) (about $40 \%$ of the population had this diagnosis). In a Medicaid population in Oregon, only $15 \%$ of patients receiving had a documented diagnosis of schizophrenia. ${ }^{18}$

In addition to adverse events, comorbidities complicate the treatment of schizophrenia. It has been found that despite physician knowledge of the problem, schizophrenic patients still do not receive appropriate treatments for their comorbid conditions. ${ }^{19}$ Patients with these conditions are often diagnosed with both mental health and general health issues, with one of the most common in schizophrenics being bipolar disorder. ${ }^{20}$ In schizophrenia, comorbid depression is closely linked to relapses, ${ }^{21}$ and anxiety is diagnosed in roughly $60 \%$ of the population. ${ }^{22}$ The major general comorbidities driving treatment decisions are diabetes and cardiovascular disease. ${ }^{23,24}$ Diabetes occurs in $10.3 \%$ of schizophrenics, as compared to $5.6 \%$ of the general population. ${ }^{25}$ In the schizophrenic population, these increased risks are associated with greater risk of death from comorbidities, ${ }^{26}$ and a nursing home admission rate in 40-64 year olds that is 3.9 times higher than the general population. ${ }^{27}$ 


\section{Switching and Combinations}

Switching between antipsychotics is a fairly common practice. The CATIE trial found that in the best case scenario, $36 \%$ of patients taking olanzapine remained on treatment at 18 months. Only $17 \%$ of quetiapine patients, $26 \%$ of risperidone patients, and $20 \%$ of ziprasidone patients remained on these second generation antipsychotics at 18 months. Perphenazine represented first generation antipsychotics in this trial, and $25 \%$ of patients remained persistent at 18 months. ${ }^{14}$ In almost all cases patients switched to a second generation antipsychotic, in only $1.2 \%$ of treatment episodes did an individual move from second generation to first generation. An earlier study by Menzin, et al, found that $58 \%$ of first generation antipsychotic users switched to another antipsychotic (most often a second generation antipsychotic) while only $33 \%$ of second generation antipsychotic users switched to another antipsychotic (also most often a new second generation antipsychotic) ${ }^{28}$

The use of combination therapy is highly controversial. The practice has been observed in between $5 \%$ and $18 \%$ of the population according to a review of the literature. ${ }^{4}$ There is scant evidence that polypharmacy results in better outcomes for individuals, ${ }^{4}$ although patients taking multiple medications do demonstrate poorer adherence..$^{29}$ The most common combinations seen in database analyses involve two second generation antipsychotics, or a first and a second generation medication. ${ }^{30}$ The Joint Commission for Quality Improvement has laid out a set of narrow guidelines where combinations of two or more 
antipsychotics might be reasonable, such as in patients utilizing Clozapine, multiple failed trials of monotherapy, or if discharged from a hospitalization with two or more medications. ${ }^{31}$

Study Purpose and Justification

There have been many studies conducted to better understand the populations utilizing antipsychotics. The vast majority of the literature identified above focuses on specific populations with a high incidence of schizophrenia, those individuals utilizing Medicaid and VA programs. The commercial population likely differs significantly from the Medicaid and VA groups where patients are typically older, and (especially in the VA) more likely to be male..$^{16,28}$ This population is also different from the CATIE population, in which $85 \%$ of the population was unemployed. ${ }^{6}$ A better understanding of how antipsychotic medications are utilized within commercial populations is critical. Sixteen percent of schizophrenics receive services through private insurance. ${ }^{3}$ Programs designed to better manage these populations will utilize the improved information to better understand their participants..$^{32,33}$

The goal of this analysis is to describe the primary medication taking characteristics of commercially insured patients utilizing antipsychotic medications; these characteristics are: the use of first or second generation agents, switching treatments, and combination of treatments. These 
characteristics will be examined in relationship to the demographic, clinical, and employment characteristics of the patients. 


\section{Methods:}

Study Design:

A retrospective cohort study was conducted utilizing the Thompson MarketScan database. Those individuals utilizing antipsychotic medications, and diagnosed with schizophrenia were identified. The primary treatment outcomes studied were choice of first or second generation antipsychotic, switching of treatments, and use of combination treatment. Associations between these outcomes and the demographic, clinical, and employment characteristics of the populations were assessed.

Data:

Data for this analysis was made available through the Thomson Medstat dissertation support program. This program provides access to de-identified data in the MarketScan database from years 2000 and 2001. This database contains enrollment and demographics data, as well as medical and pharmacy claims for nearly 5.9 million individuals, including employees and their dependents working for large companies spread across the United States, and insured by roughly 100 different payers. 
Inclusion Criteria:

Continuous enrollment is a key criterion for inclusion in this analysis. Although this requirement narrows the study population significantly, it is essential to ensure that key events such as prescription dispensings and encounters with medical professionals are recorded in the database, and available for the description of the population. Individuals over 65 years of age during the study period were also excluded from the study population in order to avoid biases resulting from missing data associated with the coordination of benefits between Medicare and commercial insurers. Individuals under the age of 18 were excluded in order to avoid similar benefit coordination issues in a pediatric environment. Patients also had to have at least one diagnosis code indicating schizophrenia during the 2 year study period (Table I-1).

\section{Operational Definitions:}

Continuous enrollment was defined as having 366 days of continuous enrollment in 2000, and 365 days of continuous enrollment in 2001 with both medical and pharmacy coverage. This data was abstracted from the enrollment data sets provided.

Diagnoses for specific conditions were identified through the presence of one or more ICD-9 codes in the inpatient or outpatient records between January 1, 2000 and December 31, 2001. Anxiety, Bipolar Disorder, Depression, 
Schizophrenia, Other Mental Health Disorders not included above, and Diabetes were all identified. The specific list of ICD-9 codes used to identify these conditions is provided in table $\mathrm{I}-1$. This methodology is similar to that used in a variety of other studies,,$^{3,34-36}$ and validated by Rawson, et al, in $1997 . .^{36}$

A treatment episode with a given therapy was defined as receipt of at least 2 dispensings on different days within the study period. Individuals with no treatment episodes were excluded from the bivariate and multivariate analyses. Therapies were defined as a "new treatment" if there was no record of that treatment being received during the six months preceding the first fills. The "therapeutic period" for a treatment was defined as the time from the first fill, to the date of the last fill plus the last days supply. "Combination Therapy" was defined as two treatments overlapping by a minimum of 90 consecutive days. A "switch" in therapy is defined as a change from one treatment to another where there is no more than a 90 day gap in therapy, and no more than 90 days of overlap in therapy. A "gap" in treatment is defined as a period of 90 days or more following the end of a therapeutic period. Studies have typically used periods of 30 to 90 days to define gaps in therapy. ${ }^{34,35,37}$ This study utilized the 90 day period to match the longest days supply routinely received by patients.

Demographic variables were examined for missing or obviously erroneous data through examination of distributions and outliers. An individual's age was defined as the difference between their birth year, and the year 2000. There were no instances in the data where an individual had more than 1 gender on record. Descriptions of employment type (primary vs. secondary policy holder, 
full time vs. part time, and hourly vs. salaried) and geographic variables were defined for each individual as the value that turned up most often for that individual (if more than one value was available).

Bivariate Statistical Analysis:

Bivariate analyses were conducted in order to determine the associations between the three outcomes (antipsychotic generation choice, switching, and combination use) and the demographic, clinical, and employment variables. The students t-test was utilized for age, the only normally distributed continuous variable. Chi-square analysis was conducted for the binomial and categorical variables.

Multivariate Statistical Analysis:

Because of the potential for strong relationships between many of the explanatory variables explored in the bivariate statistical analysis, logistic regression was also used in each of the populations to examine the following:

1. Factors associated with the decision to use a second generation antipsychotic or a first generation antipsychotic

2. Factors associated with switching

3. Factors associated with combination use

The dependent variables tested were: type of antipsychotic, switch, and combination. The independent variables included in each model were: age, gender, region, rural / urban, full time employment, employee or dependent, 
industry, and comorbidies (schizophrenia, bipolar disorder, depression, anxiety, other mental health, and diabetes). Variables were included in the model if they were found to be associated with the outcome variable in bivariate testing $(\mathrm{p}<$ 0.2). The exceptions are age and gender, which were included regardless due to their importance in understanding the make-up of the population. Interaction terms including the various combinations of age group, gender, and comorbidities were also included if they were associated with the dependent variable as measured by the chi-square test with a significant $p$-value $(<0.2)$. Chi-square analysis was also used to assess several potential associations amongst independent variables to determine if they were independent. If the variables were not independent (chi-square value was less than 0.05 ), the less important variable was dropped from consideration for the model. Stepwise backwards elimination was used to optimize the model, using the -2 log likelihood to test the significance of changes. Multicollinearity was assessed based on the variation inflation factor (VIF), and eignevalues. These were calculated utilizing a separate model with the proc reg function in SAS with the VIF, TOL, and collin options. Hosmer-Lemeshow was used to assess goodness of fit. 


\section{Results:}

\section{Study Population}

A diagnosis for schizophrenia was recorded for 2,156 individuals $(0.15 \%$ of the eligible population) between 2000 and 2001; table I-2 describes their demographic characteristics. Of the 2,156 , a total of $1,517(70.4 \%)$ received at least 2 dispensings for the same antipsychotic. Figure I-1 describes the population waterfall. A majority of this population was female $(\mathrm{N}=1,244[57.7 \%])$. The biggest group of schizophrenic patients lived in the south (43.7\%), with $27.1 \%$ in North Central, $24.7 \%$ in the North East, and the remaining $4.4 \%$ in the West. $19.3 \%$ of the population lived in a rural setting. This reflects the general distribution of the population in the database. Of the population eligible for inclusion in this study, $0.15 \%$ had one or more documented ICD-9 codes indicating schizophrenia.

A majority of this population (56.3\%) were active full time employees. Manufacturing was the most common known industry, with $32.0 \%(\mathrm{~N}=690)$ of individuals employed. Approximately half of the individuals in this population were spouses or dependents (1098 [50.9\%]). There were more hourly workers than salary workers in this population ( $\mathrm{N}=593$ and 470 respectively). Details regarding employment in this population are in table I-2.

Comorbid conditions are described in table I-2. Bipolar disorder was identified in $29 \%$ ( $N=637$ ) of this population, depression was documented in 489 $(22.7 \%)$ individuals, and anxiety was documented in 245 (11.4\%). Other mental 
health disorders not listed above were identified in claims for 1,181 (54.8\%) people. Diabetes was documented in 355 (16.5\%) of individuals identified in this group.

There were 3,239 individual treatment episodes for antipsychotics in the schizophrenic population (table I-3), which averages to 1.5 per patient or 2.1 for each patient that used at least 2 fills of an antipsychotic. Second generation antipsychotics were utilized by $56.2 \%(\mathrm{~N}=1212)$ of the population, and first generation antipsychotics are used by $27.4 \%(\mathrm{~N}=591)$ of the schizophrenic population identified. Records indicating 2 or more dispensings of an antipsychotic are absent in $29.6 \%(\mathrm{~N}=639)$ of the population with documentation of schizophrenia, indicating that they are either untreated during this study period, or are receiving treatment through a source that is not recorded in the claims. The most commonly received antipsychotics were olanzapine and risperidone (received by $27.1 \%$ and $25.2 \%$ of the population respectively), table I-3 describes the rate of use for the remaining treatments.

Switching between one or more antipsychotics occurred prior to $21.7 \%$ ( $\mathrm{N}=702)$ of the treatment episodes (in $13.6 \%$ of the population), while combination therapy was observed in 421 (13.0\%) treatment episodes (in 12.9\% of the population). The most common switches were between second generation antipsychotics. Table I-4 demonstrates the switches identified in the antipsychotic users. The majority of combinations were with first and second generation antipsychotics ( $\mathrm{N}=262)$, with combinations of two second generation 
antipsychotics also common ( $\mathrm{N}=136)$. Table $\mathrm{l}-5$ demonstrates the combinations utilized by this population.

\section{Bivariate Analysis}

First generation antipsychotic users were on average 3.1 years older than those using second generation antipsychotics in this population (table I-6), and $3.6 \%$ more individuals in the North East received a first generation antipsychotic than individuals living elsewhere; 9.2\% more individual patients diagnosed with comorbid bipolar disorder received a second generation antipsychotic than those who were not diagnosed. After switching medications, the frequency of second generation antipsychotic use was $14.5 \%$ higher than if they were treatment naïve or starting on a therapy after a long gap.

Patients switching medications were on average, younger than those who did not switch, although there was no difference in age for those using combination treatments. Table I-7 describes associations with switching and combination use in this population. Patients with bipolar disorder in addition to schizophrenia were more likely to switch medications $(p<0.0001)$. Those with anxiety were more likely to switch $(p<0.001)$, but less likely to use combinations $(p=0.004)$. Type of employment was not associated with the rate of switching. 


\section{Multivariate Analysis:}

In this population antipsychotic type was modeled against age, gender, region, comorbid diagnoses (bipolar disorder, depression, anxiety, and diabetes), switching, combination use, and employment variables for the full model. Salary, full time employment, combinations, and anxiety and depression diagnoses did not contribute significantly to the model (see table I-8). The final model had a reasonable goodness-of-fit with $\mathrm{c}=0.839$, and the Hosmer-Lemeshow $p$-value of 0.353. The model indicated that as compared with residents of the North East region, individuals in the North Central region were more likely to receive a second generation antipsychotic (OR $1.3,95 \% \mathrm{Cl} 1.053-1.603)$. In this population, individuals with a comorbid diagnosis of bipolar disorder were $27.1 \%$ (OR $1.271,95 \% \mathrm{Cl} 1.072 \%-1.507 \%$ ), and individuals with other mental health conditions were $48.9 \%(\mathrm{OR} 1.489,95 \% \mathrm{Cl} 1.266$ - 1.750) more likely to receive a second generation antipsychotic as compared with patients without the condition. Individuals who had switched from another medication were nearly twice as likely as those who had not switched to receive a second generation antipsychotic (OR $1.937,95 \% \mathrm{Cl} 1.568-2.393)$. Age, gender, and comorbid diabetes were not significant (table I-9).

Switching therapy was modeled against age, gender, region, diagnoses, use of a second generation antipsychotic, combination use, and responsibility for insurance coverage. Responsibility for coverage was removed in the final model due to lack of significance (table I-8). This had a reasonable goodness-of-fit with 
$\mathrm{c}=0.848$, and the Hosmer-Lemeshow $\mathrm{p}$-value of 0.275 . Prior to switching, individuals were nearly twice as likely to have received first generation antipsychotics, as compared to a second generation antipsychotic (OR1.929, $95 \%$ Cl $1.561-2.384$ ) (table I-10). Individuals with comorbid bipolar disorder were $39 \%$ (OR $1.39395 \% \mathrm{Cl} 1.163-1.668)$ more likely than those without a bipolar diagnosis to switch antipsychotics.

Use of combinations of treatments in the schizophrenia population was modeled against age, gender, rural location, region, diagnoses, use of a second generation antipsychotic, switching, and employment variables. Rural location, use of a second generation antipsychotic, and diagnoses besides anxiety were removed from the model because they did not make a significant contribution to the model (table I-8). The model had a good fit with $\mathrm{c}=0.895$, and the HosmerLemeshow $p$-value $=0.926$. Individuals in the North East were more likely to receive medications in combination as compared with patients in the North Central and South regions (table I-11). Full time workers (OR 0.653, 95\% Cl $0.523-0.989$ ), and those listed as primary on their insurance coverage (OR $0.785,95 \% \mathrm{Cl} 0.623-0.815)$ were less likely than others to have combination therapies. 


\section{Discussion:}

The results of this study draw some significant distinctions between the commercially insured and government insured populations receiving antipsychotic therapy for schizophrenia. Understanding these differences will improve the ability of the commercial managed care organizations to direct resources and focus on ensuring appropriate care for those individuals most likely to be switching or combining therapy, and help to ensure that those prescribing decisions are appropriate. The ability to do this could lead to improved quality of care and lower overall costs for both the payors and patients.

\section{Utilization of First vs. Second Generation Antipsychotics}

Age was a significant predictor of medication choice, with older individuals more likely to receive first generation antipsychotics than younger patients. One other study was identified that has used claims data to identify factors associated with utilization of antipsychotics. The association between older age and lower frequency of second generation antipsychotic use was similar to that identified in a Texas Veteran's population by Yang, et al. ${ }^{16}$ In agreement with our findings Yang et al reported that patients having a documented diagnosis of bipolar disorder or other mental health disorders had an increased likelihood of receiving a second generation antipsychotic. However, the Yang et al study did not assess 
the influence of a diagnosis of diabetes, region, or switching between medications.

The differences identified in prescribing by region between the North East and North Central areas of the country are supported by a variety of literature describing differences in medical costs and quality throughout the United States. Some of the most described examples of this are the regional differences in cost and quality in Medicare. Zhang et al found that in the South East there are significantly higher rates (up to $44 \%$ ) of potentially inappropriate prescribing to the elderly, compared to New England where the highest rates observed were below $21 \% .^{38}$

\section{Switching Rates}

Individuals can switch between antipsychotics for a variety of reasons, including adverse events, lack of effectiveness, or concerns about cost. Although patients are commonly more adherent to treatment after a switch, there are potential adverse events associated with switching, especially if patients do not titrate propperly. ${ }^{39}$ The results of this study are useful in establishing a baseline switch rate for individuals in a commercial population.

The likelihood of having switched therapies was twice as high among those individuals currently using second generation antipsychotics, and roughly $40 \%$ higher in those with bipolar disorder or depression. Age and gender were not significant influences on medication switching. Although having a comorbid 
diagnosis of diabetes was associated with increased use of first generation antipsychotics, those with diabetes were also $34.5 \%$ more likely to switch medications. The increased rate of switching makes sense in those individuals with a more complex clinical situation due to the increased likelihood of adverse events and poorer adherence leading to inadequate outcomes, ${ }^{28}$ and these trends are also supported by literature evaluating a Medicaid population..$^{28,39}$ The rate of switching from first generation antipsychotics to second generation antipsychotics was also similar to that seen in the CATIE trial, which found that $18 \%$ of patients switched medications during an 18 month time period. ${ }^{14}$

\section{Use of combination therapy}

The frequency of combinations between first generation antipsychotics and second generation antipsychotics, as well as multiple second generation antipsychotics seen in our population was similar to that seen in the literature. ${ }^{30}$ The overall combination rate of $12.9 \%$ was in the range identified in a review by Stahl, et al, which was $5-18 \%$ of all users of these medications within outpatient populations. ${ }^{4}$ Combination therapy was significantly less common in individuals working full time, or currently responsible for providing insurance coverage.

These factors are likely to be closely associated with disease severity, although given the short time period studied, it cannot be determined whether they simply are better responders to monotherapy, or if this group has a less severe underlying condition overall. Generally, the existing literature does not support 
the utilization of polypharmacy, due to a lack of improved outcomes, increased adverse events, and higher costs, ${ }^{4}$ although there are narrow circumstances in which combining multiple medications may be necessary and acceptable, such as after failure to respond in 3 or more trials of monotherapy, individuals using Clozapine, and those released from inpatient treatment with combination therapy. ${ }^{31}$

Combination therapy was also less common in individuals living in the North Central and Southern regions as compared to the North East. Further study is needed to understand why these regional differences exist, and no other studies conducted in the United States have been identified that address this discrepancy in therapy across regions. A Danish study identified regional differences in the understanding of clinical guidelines as one possible reason for differences in polypharmacy. ${ }^{40}$

\section{Limitations}

Although the goal of this analysis was to ensure generalizability to the commercially insured US population, the requirement of 2 years continuous data may have limited the inclusion of some of the more severe patients that were not enrolled for the entire study period. However, the proportion of schizophrenic individuals excluded from the study population due to our continuous enrollment requirement was smaller than the proportion of the overall population. Because the time available in the data set is relatively short, it was not possible to reliably 
establish a temporal sequence, limiting the ability to understand the relationships between the observed factors and medication choice, switching, or combination use. The age of the data also limits generalizability due to the addition of new treatments and guidelines that may have subsequently changed practice over time.

This study is reliant on claims data submitted by physicians and pharmacies for the purposes of billing, therefore there are some limitations seen across retrospective database analyses. Pharmacy data indicating a medication is dispensed do not ensure that the medications are actually consumed, additionally individuals paying cash or receiving samples of their medication from their physician will not have records. Finally, diagnosis coding can be inaccurate, with some individuals with documentation of schizophrenia not having the condition, as well as the reverse, individuals diagnosed that do not have full documentation.

Smoking and obesity are confounders in the schizophrenia population that could not be addressed. Because of the metabolic side effects of second generation antipsychotics, obesity may have been an unobserved factor influencing an increased use of first generation antipsychotics. Smoking has been associated with lower adherence to medications, ${ }^{41}$ but it is not clear whether it would impact combination therapy, switching, or the choice between first and second generation antipsychotics.

\section{Conclusions}


This analysis demonstrates the significant differences between a commercially insured schizophrenia population and the more commonly evaluated populations in federally insured programs. Comorbidities with diabetes and bipolar disorder were key drivers of increased therapy switches, while age and gender played a smaller role than that observed in other populations. Additional study is necessary to determine if these factors also impact an individual's ability to adhere to therapy. 
Figures:

Figure 1-1: Inclusion / Exclusion Criteria Flowchart

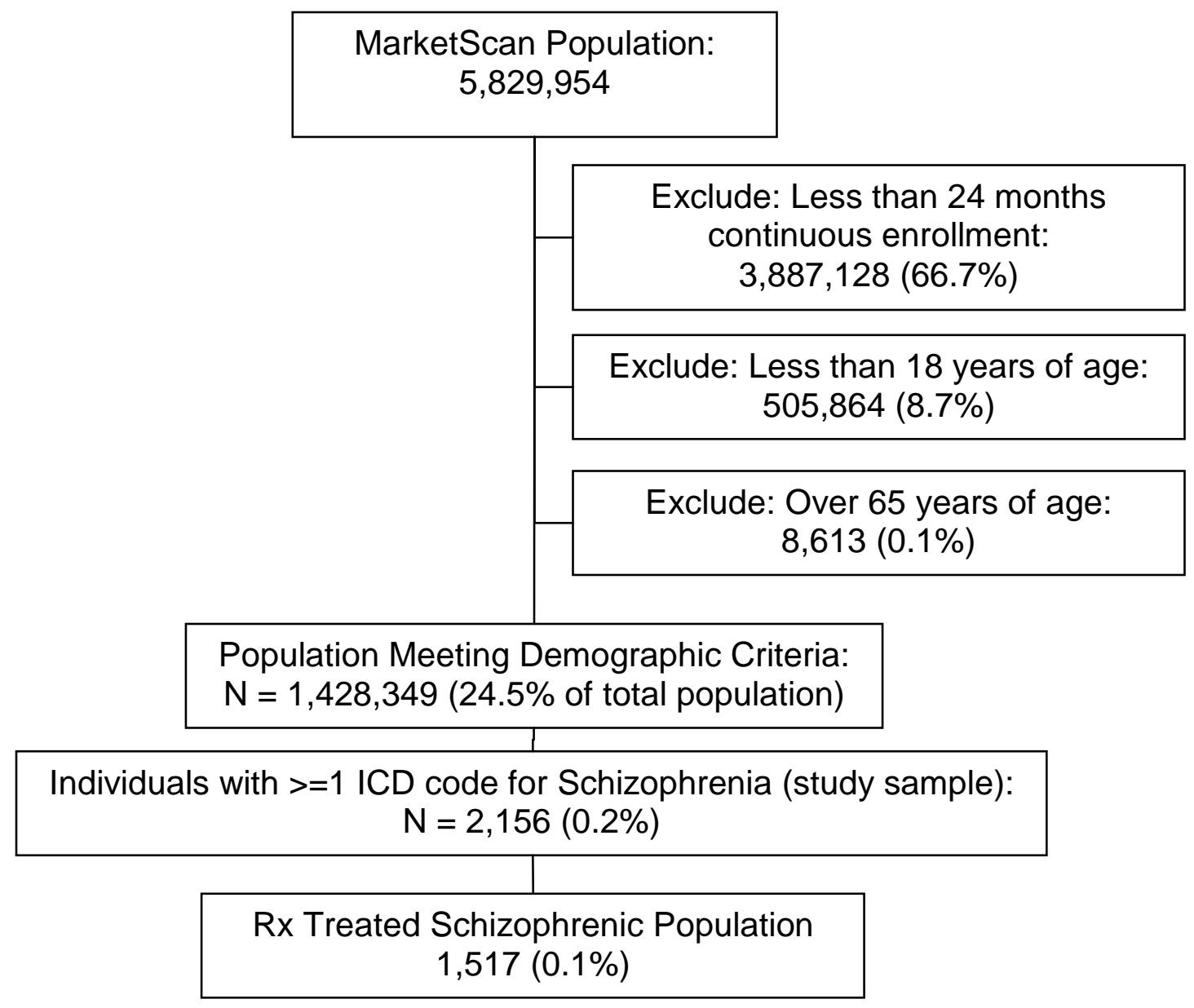




\section{Tables:}

Table l-1: ICD-9 Codes used for identifying diagnoses with primary conditions and comorbidities

\begin{tabular}{lc}
\hline Condition & ICD-9 Codes Included \\
\hline Schizophrenia & $295-295.95$ \\
\hline Bipolar Disorder & $296-296.99$ \\
\hline Anxiety & $300-300.09$ \\
\hline Depression & $311,300.4$ \\
\hline Other Mental Health & $290-319$, except for those listed above \\
\hline Diabetes & $250.00-250.99$ \\
\hline
\end{tabular}


Table I-2: Demographics of patients with a diagnosis for schizophrenia

\begin{tabular}{|c|c|c|c|c|}
\hline \multirow{2}{*}{\multicolumn{3}{|c|}{ Total Population N }} & \multirow{2}{*}{$\begin{array}{c}\mathbf{N} / \text { Mean } \\
2,156 \\
\end{array}$} & \multirow{2}{*}{$\frac{\% / S D}{100.0 \%}$} \\
\hline & & & & \\
\hline \multirow[t]{6}{*}{ Demographic } & Age & Mean (SD) & 45.5 & 11.9 \\
\hline & \multirow[t]{5}{*}{ Region } & Northeast & 533 & $24.7 \%$ \\
\hline & & North Central & 584 & $27.1 \%$ \\
\hline & & South & 942 & $43.7 \%$ \\
\hline & & West & 95 & $4.4 \%$ \\
\hline & & Unknown & 2 & $0.1 \%$ \\
\hline \multirow[t]{5}{*}{ Comorbidities } & \multirow{4}{*}{$\begin{array}{l}\text { Mental Health } \\
\text { Conditions }\end{array}$} & Bipolar & 637 & $29.5 \%$ \\
\hline & & Depression & 489 & $22.7 \%$ \\
\hline & & Anxiety & 245 & $11.4 \%$ \\
\hline & & Other Mental Health & 1,181 & $54.8 \%$ \\
\hline & Others & Diabetes & 355 & $16.5 \%$ \\
\hline \multirow[t]{28}{*}{ Employment } & \multirow{9}{*}{$\begin{array}{l}\text { Employment } \\
\text { Status }\end{array}$} & Active Full Time & 1,213 & $56.3 \%$ \\
\hline & & Active Part Time or Seasonal & 25 & $1.2 \%$ \\
\hline & & Early Retiree & 800 & $37.1 \%$ \\
\hline & & Medicare Eligible Retiree & 13 & $0.6 \%$ \\
\hline & & Retiree (status unknown) & 34 & $1.6 \%$ \\
\hline & & COBRA Continuee & 19 & $0.9 \%$ \\
\hline & & Long Term Disability & 18 & $0.8 \%$ \\
\hline & & Surviving Spouse/Depend. & 12 & $0.6 \%$ \\
\hline & & Other/Unknown & 22 & $1.0 \%$ \\
\hline & \multirow[t]{7}{*}{ Industry } & Oil \& Gas Extraction, Mining & 0 & $0.0 \%$ \\
\hline & & Manufacturing, Durable Goods & 514 & $23.8 \%$ \\
\hline & & $\begin{array}{l}\text { Manufacturing, Nondurable } \\
\text { Goods }\end{array}$ & 176 & $8.2 \%$ \\
\hline & & $\begin{array}{l}\text { Transportation, } \\
\text { Communications, Utilities }\end{array}$ & 392 & $18.2 \%$ \\
\hline & & $\begin{array}{l}\text { Finance, Insurance, Real } \\
\text { Estate }\end{array}$ & 43 & $2.0 \%$ \\
\hline & & Services & 273 & $12.7 \%$ \\
\hline & & Unknown / Missing & 758 & $35.2 \%$ \\
\hline & \multirow{3}{*}{$\begin{array}{l}\text { Relationship to } \\
\text { Employee }\end{array}$} & Employee & 1,058 & $49.1 \%$ \\
\hline & & Spouse & 708 & $32.8 \%$ \\
\hline & & Child/Other & 390 & $18.1 \%$ \\
\hline & \multirow{9}{*}{$\begin{array}{l}\text { Employment } \\
\text { Class }\end{array}$} & Salary Non-union & 146 & $6.8 \%$ \\
\hline & & Salary Union & 166 & $7.7 \%$ \\
\hline & & Salary Other & 158 & $7.3 \%$ \\
\hline & & Hourly Non-union & 47 & $2.2 \%$ \\
\hline & & Hourly Union & 171 & $7.9 \%$ \\
\hline & & Hourly Other & 375 & $17.4 \%$ \\
\hline & & Non-union & 175 & $8.1 \%$ \\
\hline & & Union & 51 & $2.4 \%$ \\
\hline & & Unknown & 857 & $39.7 \%$ \\
\hline
\end{tabular}


Table 1-3: Frequency and percentage of the use of antipsychotic medication types within the study population

\begin{tabular}{|c|c|c|c|}
\hline & $\mathbf{N}^{*}$ & $\%$ \\
\hline \multicolumn{2}{|c|}{ Total Population } & 2156 & $100.0 \%$ \\
\hline \multicolumn{2}{|c|}{ No Treatment } & 639 & $29.6 \%$ \\
\hline \multirow{6}{*}{$\begin{array}{l}\text { Second } \\
\text { Generation }\end{array}$} & Any Second Generation & 1212 & $56.2 \%$ \\
\hline & Clozapine (Clozaril) & 112 & $5.2 \%$ \\
\hline & Ziprasidone (Geodon) & 207 & $9.6 \%$ \\
\hline & Risperidone (Risperdal) & 544 & $25.2 \%$ \\
\hline & Quetiapine (Seroquel) & 294 & $13.6 \%$ \\
\hline & Olanzapine (Zyprexa) & 584 & $27.1 \%$ \\
\hline \multirow{12}{*}{$\begin{array}{l}\text { First } \\
\text { Generation }\end{array}$} & Any First Generation & 591 & $27.4 \%$ \\
\hline & Haloperidol (Haldol) & 163 & $7.6 \%$ \\
\hline & Loxapine (Loxitane) & 35 & $1.6 \%$ \\
\hline & Thioridazine (Mellaril) & 61 & $2.8 \%$ \\
\hline & Molindone (Mobane) & 12 & $0.6 \%$ \\
\hline & Thiothixene (Navane) & 75 & $3.5 \%$ \\
\hline & Pimozide (Orap) & 3 & $0.1 \%$ \\
\hline & Fluphenazine (Prolixin) & 80 & $3.7 \%$ \\
\hline & Mesoridazine (Serentil) & 7 & $0.3 \%$ \\
\hline & Trifluoperazine (Stelazine) & 93 & $4.3 \%$ \\
\hline & Chlorpromazine (Thorazine) & 59 & $2.7 \%$ \\
\hline & Perphenazine (Trilafon) & 65 & $3.0 \%$ \\
\hline
\end{tabular}

*Total $\mathrm{N}$ does not sum due to use of combination therapies 


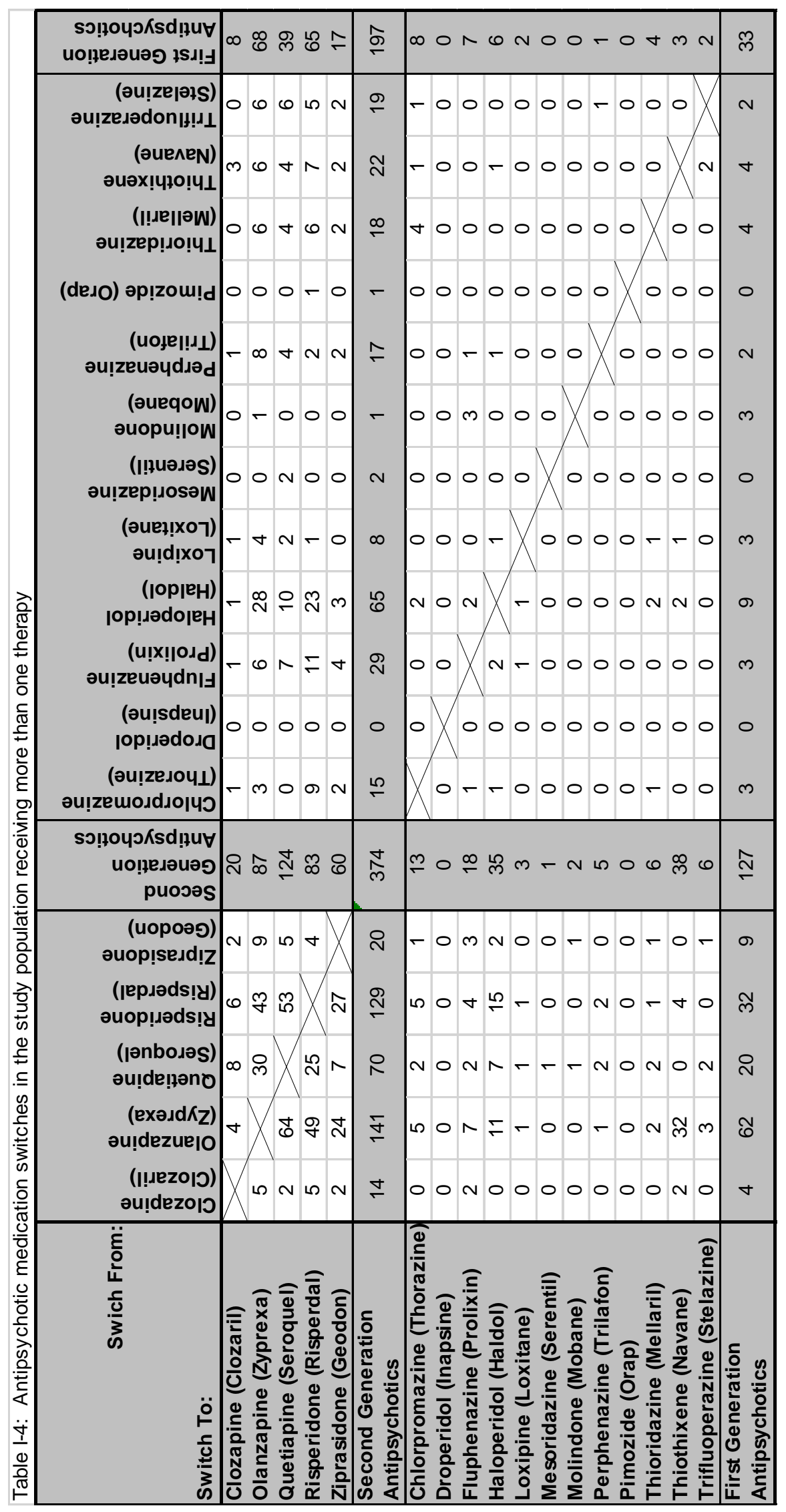




\begin{tabular}{|c|c|c|c|c|c|c|c|c|c|c|c|c|c|c|c|c|c|c|c|c|}
\hline & 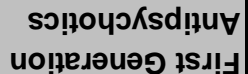 & $\infty$ & & ले & $\bar{m}$ & & $\stackrel{\text { ิ }}{\sim}$ & 10 & 0 & $\tau$ & 0 & - & 0 & 0 & $\sim$ & 0 & & $\sim$ & $m$ & ని \\
\hline & 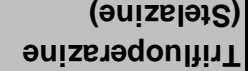 & - & $m$ & $\nabla$ & - & $\tau$ & 으 & $m$ & 0 & 0 & 0 & 0 & 0 & 0 & 0 & 0 & - & 0 & X & $\nabla$ \\
\hline & 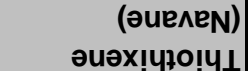 & - & 0 & $m$ & $\sim$ & 0 & 0 & 0 & 0 & 0 & - & 0 & 0 & 0 & 0 & 0 & 0 & $\lambda$ & 0 & - \\
\hline & 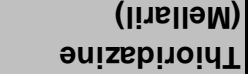 & o & $\nabla$ & - & $\forall$ & 0 & の & 0 & 0 & 0 & の & 0 & 0 & 0 & 0 & 0 & $X$ & $\sigma$ & - & 10 \\
\hline & (deso) әр!zou!d & 0 & 0 & 0 & 0 & 0 & 0 & 0 & 0 & 0 & 0 & 0 & 0 & 0 & 0 & $X$ & 0 & 0 & 0 & 0 \\
\hline & $\begin{array}{r}\text { (uoje!!ı卫) } \\
\text { әu!zeuәчdıәd }\end{array}$ & o & $\nabla$ & $\infty$ & N & 0 & さ & - & 0 & 0 & 0 & 0 & 0 & 0 & & 0 & 0 & 0 & 0 & - \\
\hline & $\begin{array}{r}\text { (әueqow) } \\
\text { әuopu!ןow }\end{array}$ & 0 & $\sim$ & - & - & 0 & $\forall$ & 0 & 0 & 0 & - & 0 & 0 & $X$ & - & 0 & 0 & 0 & 0 & $\sim$ \\
\hline$\stackrel{\frac{N}{\Phi}}{\risingdotseq}$ & $\begin{array}{r}\text { (I!!uәләS) } \\
\text { әuाzzрıоsән }\end{array}$ & 0 & 0 & 0 & $\tau$ & 0 & - & 0 & 0 & 0 & 0 & 0 & $X$ & 0 & 0 & 0 & 0 & 0 & 0 & 0 \\
\hline$\stackrel{\frac{c}{\sqrt{0}}}{=}$ & $\begin{array}{r}\text { (әuei!xoา) } \\
\text { əuाd।xo7 }\end{array}$ & $m$ & $\sim$ & 0 & $m$ & - & $\sigma$ & 0 & 0 & 0 & 0 & $X$ & 0 & 0 & 0 & 0 & 0 & 0 & 0 & 0 \\
\hline ธั & $\begin{array}{r}\text { (јорןен) } \\
\text { јорцәdојен }\end{array}$ & $\sim$ & $\stackrel{\text { の }}{\square}$ & の & 0 & 0 & ले & 0 & 0 & 0 & $X$ & 0 & 0 & 0 & - & 0 & 0 & 0 & 0 & - \\
\hline $\begin{array}{l}\overline{0} \\
\frac{1}{\widetilde{D}}\end{array}$ & $\begin{array}{r}\text { (u!X!|Odd) } \\
\text { әu!̨zeuәчdn|ヨ }\end{array}$ & - & 으 & 0 & $\nabla$ & 0 & $\bar{N}$ & - & 0 & X & 0 & - & 0 & 0 & 0 & 0 & - & 0 & 0 & $m$ \\
\hline 일 & 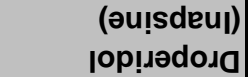 & 0 & 0 & 0 & 0 & 0 & 0 & 0 & & 0 & 0 & 0 & 0 & 0 & 0 & 0 & 0 & 0 & 0 & 0 \\
\hline$:=\frac{.}{0}$ & 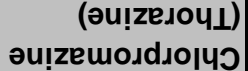 & 0 & - & $\sim$ & N & 0 & 으 & X & 0 & $\tau$ & - & 0 & 0 & 0 & 0 & 0 & - & - & $\sim$ & 0 \\
\hline 文 & 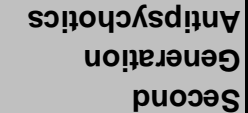 & શิ & ষ & $\stackrel{\llcorner}{\sim}$ & ร & $\checkmark$ & $\stackrel{\text { m }}{\leftarrow}$ & 음 & 0 & N & 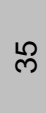 & م & $N$ & $\sim$ & $\stackrel{n}{\leftarrow}$ & 0 & & $\stackrel{\infty}{-}$ & $\stackrel{\infty}{\leftarrow}$ & $\underset{y}{\mathscr{y}}$ \\
\hline a & $\begin{array}{r}\text { (uopoәэ) } \\
\text { әuop!̣e.d!!Z }\end{array}$ & $\sim$ & $\mp$ & $\nabla$ & $\tau$ & $X$ & $\stackrel{\infty}{\leftarrow}$ & 0 & 0 & 0 & $\sim$ & - & 0 & 0 & 0 & 0 & 0 & 0 & $\tau$ & $\nabla$ \\
\hline $\begin{array}{l}\infty \\
0 \\
\stackrel{0}{+}\end{array}$ & $\begin{array}{l}\text { (ןepıәds!y) } \\
\text { әuop!ıəds!y }\end{array}$ & 入 & $\stackrel{\infty}{\square}$ & 음 & $X$ & $\tau$ & m & $m$ & 0 & $\nabla$ & $\stackrel{m}{-}$ & 0 & 0 & $\sim$ & の & 0 & $\infty$ & 10 & $\sim$ & 우 \\
\hline 등 & 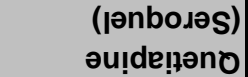 & $\checkmark$ & $\stackrel{n}{\square}$ & $X$ & $\stackrel{\nabla}{\square}$ & - & ले & - & 0 & $\infty$ & $\infty$ & $\nabla$ & $\tau$ & 0 & 0 & 0 & - & $m$ & $\infty$ & மூ \\
\hline 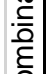 & $\begin{array}{r}\text { (exə,d/Kz) } \\
\text { əu!̣dezue।o }\end{array}$ & $\Lambda$ & $X$ & $\infty$ & $\stackrel{\sim}{N}$ & N & テ & $\bullet$ & 0 & 으 & $\cong$ & 0 & - & 0 & 0 & 0 & 0 & 으 & $\cong$ & అొ \\
\hline 든 & $\begin{array}{l}\text { (I!lezolO) } \\
\text { әu!̣dezolo }\end{array}$ & X & ल) & $m$ & $\checkmark$ & 0 & 으 & 0 & 0 & 0 & 0 & 0 & 0 & 0 & 0 & 0 & 0 & 0 & 0 & 0 \\
\hline 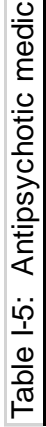 & $\begin{array}{l}\bar{r} \\
\text { 올 } \\
\text { Dे }\end{array}$ & 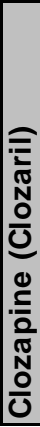 & 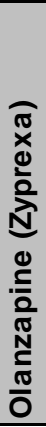 & 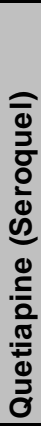 & 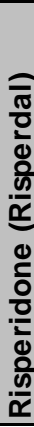 & & 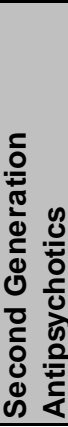 & 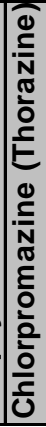 & 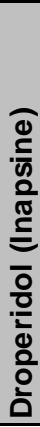 & 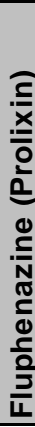 & 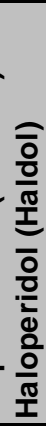 & 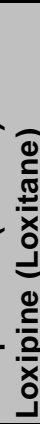 & 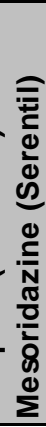 & 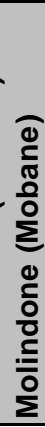 & 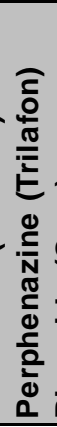 & 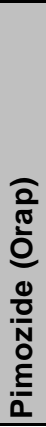 & 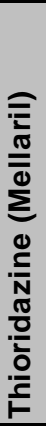 & 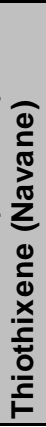 & 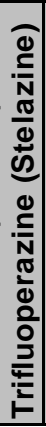 & 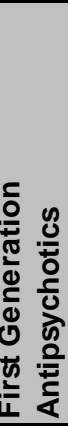 \\
\hline
\end{tabular}


Table I-6: Bivariate analysis of demographic, clinical, and employment factors associated with use of a first or second generation antipsychotic in the population diagnosed with schizophrenia

\begin{tabular}{|c|c|c|c|c|c|c|}
\hline & & \multicolumn{2}{|c|}{$\begin{array}{c}\text { First } \\
\text { Generation } \\
\text { Antipsychotic }\end{array}$} & \multicolumn{2}{|c|}{$\begin{array}{c}\text { Second } \\
\text { Generation } \\
\text { Antipsychotic }\end{array}$} & \multirow[t]{2}{*}{$\mathrm{p}$-value } \\
\hline & & $\mathrm{N}$ & $\%$ & $\mathrm{~N}$ & $\%$ & \\
\hline Age & mean (SD) & 47.1 & 10.8 & 44 & 12.4 & $<0.0001$ \\
\hline \multirow[t]{2}{*}{ Gender } & Male & 404 & 30.2 & 932 & 69.8 & \multirow{2}{*}{0.836} \\
\hline & Female & 569 & 29.9 & 1,334 & 70.1 & \\
\hline \multirow[t]{10}{*}{ Location } & Rural & 186 & 30.7 & 419 & 69.3 & \multirow{2}{*}{0.676} \\
\hline & Non-Rural & 787 & 29.9 & 1,847 & 70.1 & \\
\hline & North East & 275 & 32.7 & 565 & 67.3 & \multirow{2}{*}{0.048} \\
\hline & Not North East & 698 & 29.1 & 1,701 & 70.9 & \\
\hline & North Central & 248 & 27.0 & 669 & 73.0 & \multirow{2}{*}{0.019} \\
\hline & Not North Central & 725 & 31.2 & 1,597 & 68.8 & \\
\hline & South & 401 & 30.4 & 920 & 69.6 & \multirow{2}{*}{0.745} \\
\hline & Not South & 572 & 29.8 & 1,346 & 70.2 & \\
\hline & West & 46 & 30.3 & 106 & 69.7 & \multirow{2}{*}{0.951} \\
\hline & Not West & 927 & 30.0 & 2,160 & 70.0 & \\
\hline \multirow[t]{10}{*}{ Diagnoses } & Bipolar Disorder & 295 & 24.3 & 917 & 75.7 & \multirow{2}{*}{$<0.0001$} \\
\hline & No Bipolar Disorder & 678 & 33.5 & 1,349 & 66.5 & \\
\hline & Anxiety & 103 & 25.8 & 297 & 74.2 & \multirow{2}{*}{0.046} \\
\hline & No Anxiety & 870 & 30.6 & 1,969 & 69.4 & \\
\hline & Depression & 211 & 24.2 & 622 & 75.8 & \multirow{2}{*}{$<0.0001$} \\
\hline & No Depression & 762 & 32.2 & 1,604 & 67.8 & \\
\hline & Other Mental Health & 495 & 25.2 & 1,468 & 74.8 & \multirow{2}{*}{$<0.0001$} \\
\hline & No Other Mental Health & 478 & 37.5 & 798 & 62.5 & \\
\hline & Diabetes & 203 & 34.9 & 379 & 65.1 & \multirow{2}{*}{0.005} \\
\hline & No Diabetes & 770 & 29.0 & 1,887 & 71.0 & \\
\hline \multirow[t]{2}{*}{ Switching } & Switched To & 131 & 18.7 & 571 & 81.3 & \multirow{2}{*}{$<0.0001$} \\
\hline & Not post switch & 842 & 33.2 & 1,695 & 66.8 & \\
\hline \multirow[t]{2}{*}{ Combinations } & Combined & 143 & 34.0 & 278 & 66.0 & \multirow{2}{*}{0.060} \\
\hline & Not Combined & 830 & 29.5 & 1,988 & 70.5 & \\
\hline \multirow[t]{8}{*}{ Employment } & Full Time & 1,013 & 44.7 & 1,253 & 55.3 & \multirow[b]{2}{*}{0.146} \\
\hline & $\begin{array}{l}\text { Part Time / Retired / } \\
\text { Unemployed }\end{array}$ & 462 & 47.5 & 511 & 52.5 & \\
\hline & $\begin{array}{l}\text { Responsible for } \\
\text { Coverage }\end{array}$ & 1,200 & 53.0 & 1,066 & 47.0 & \multirow[t]{2}{*}{0.696} \\
\hline & Dependent & 508 & 52.2 & 465 & 47.8 & \\
\hline & Salary & 1,754 & 77.4 & 512 & 22.6 & \multirow{2}{*}{0.038} \\
\hline & Non-Salary / Unknown & 785 & 80.7 & 188 & 19.3 & \\
\hline & Hourly & 1,643 & 72.5 & 623 & 27.5 & \multirow{2}{*}{0.090} \\
\hline & Non-Hourly / Unknown & 677 & 69.6 & 296 & 30.4 & \\
\hline
\end{tabular}


Table I-7: Bivariate analysis of demographic, clinical, and employment factors associated with switching between and combinations of antipsychotics in the population diagnosed with schizophrenia

\begin{tabular}{|c|c|c|c|c|c|c|c|c|c|c|c|}
\hline & & \multicolumn{5}{|c|}{ Switching } & \multicolumn{5}{|c|}{ Combination } \\
\hline & & \multicolumn{2}{|c|}{ Switch } & \multicolumn{2}{|c|}{ Non-Switch } & \multirow{2}{*}{$p$-value } & \multicolumn{2}{|c|}{ Combination } & \multicolumn{2}{|c|}{$\begin{array}{c}\text { Non- } \\
\text { Combination }\end{array}$} & \multirow{2}{*}{$p$-value } \\
\hline & & $\mathrm{N}$ & $\%$ & $\mathrm{~N}$ & $\%$ & & $\mathrm{~N}$ & $\%$ & $\mathrm{~N}$ & $\%$ & \\
\hline Age & mean (SD) & 43.3 & 12.3 & 45.2 & 12.0 & 0.000 & 44.9 & 11.6 & 44.8 & 12.1 & 0.857 \\
\hline \multirow[t]{2}{*}{ Gender } & Male & 272 & 20.4 & 1,064 & 79.6 & \multirow{2}{*}{0.128} & 172 & 12.9 & 1,164 & 87.1 & \multirow{2}{*}{0.861} \\
\hline & Female & 430 & 22.6 & 1,473 & 77.4 & & 249 & 13.1 & 1,654 & 86.9 & \\
\hline \multirow[t]{10}{*}{ Location } & Rural & 128 & 21.2 & 477 & 78.8 & \multirow{2}{*}{0.733} & 69 & 11.4 & 536 & 88.6 & \multirow{2}{*}{0.196} \\
\hline & Non-Rural & 574 & 21.8 & 2,060 & 78.2 & & 352 & 13.4 & 2,282 & 86.6 & \\
\hline & North East & 172 & 20.5 & 668 & 79.5 & \multirow{2}{*}{0.328} & 140 & 16.7 & 700 & 83.3 & \multirow{2}{*}{0.000} \\
\hline & Not North East & 530 & 22.1 & 1,869 & 77.9 & & 281 & 11.7 & 2,118 & 88.3 & \\
\hline & North Central & 197 & 21.5 & 720 & 78.5 & \multirow{2}{*}{0.869} & 124 & 13.5 & 793 & 86.5 & \multirow{2}{*}{0.577} \\
\hline & Not North Central & 505 & 21.7 & 1,817 & 78.3 & & 297 & 12.8 & 2,025 & 87.2 & \\
\hline & South & 285 & 21.6 & 1,036 & 78.4 & \multirow{2}{*}{0.910} & 132 & 10.0 & 1,189 & 90.0 & \multirow{2}{*}{$<0.0001$} \\
\hline & Not South & 417 & 21.7 & 1,501 & 78.3 & & 289 & 15.1 & 1,629 & 84.9 & \\
\hline & West & 43 & 28.3 & 109 & 71.7 & \multirow{2}{*}{0.043} & 23 & 15.1 & 129 & 84.9 & \multirow{2}{*}{0.423} \\
\hline & Not West & 659 & 21.3 & 2,428 & 78.7 & & 398 & 12.9 & 2,689 & 87.1 & \\
\hline \multirow[t]{10}{*}{ Diagnoses } & Bipolar Disorder & 337 & 27.8 & 875 & 72.2 & \multirow{2}{*}{$<0.0001$} & 145 & 12.0 & 1,067 & 88.0 & \\
\hline & No Bipolar Disorder & 365 & 18.0 & 1,662 & 82.0 & & 276 & 13.6 & 1,751 & 86.4 & 0.176 \\
\hline & Anxiety & 115 & 28.8 & 285 & 71.3 & חمח & 34 & 8.5 & 366 & 91.5 & ח $\cap 04$ \\
\hline & No Anxiety & 587 & 20.7 & 2,252 & 79.3 & 0.000 & 387 & 13.6 & 2,452 & 86.4 & 0.004 \\
\hline & Depression & 263 & 30.1 & 610 & 69.9 & & 96 & 11.0 & 777 & 89.0 & 040 \\
\hline & No Depression & 439 & 18.6 & 1,927 & 81.4 & & 325 & 13.7 & 2,041 & 86.3 & 0.040 \\
\hline & Other Mental Health & 517 & 26.3 & 1,446 & 73.7 & & 248 & 12.6 & 1,715 & 87.4 & \\
\hline & No Other Mental Health & 185 & 14.5 & 1,091 & 85.5 & & 173 & 13.6 & 1,103 & 86.4 & 0.445 \\
\hline & Diabetes & 139 & 23.9 & 443 & 76.1 & 0153 & 80 & 13.7 & 502 & 86.3 & 0554 \\
\hline & No Diabetes & 563 & 21.2 & 2,094 & 78.8 & 0.153 & 341 & 12.8 & 2,316 & 87.2 & 0.554 \\
\hline Switching & Switched To & $\mathrm{N} / \mathrm{A}$ & $\mathrm{N} / \mathrm{A}$ & $\mathrm{N} / \mathrm{A}$ & $\mathrm{N} / \mathrm{A}$ & $N / A$ & 3 & 0.4 & 699 & 99.6 & 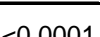 \\
\hline & Not post switch & $\mathrm{N} / \mathrm{A}$ & $\mathrm{N} / \mathrm{A}$ & $\mathrm{N} / \mathrm{A}$ & $\mathrm{N} / \mathrm{A}$ & $\mathrm{IV} / \mathrm{A}$ & 418 & 16.5 & 2,119 & 83.5 & .000 \\
\hline Combinations & Combined & 3 & 0.7 & 418 & 99.3 & & $\mathrm{~N} / \mathrm{A}$ & $\mathrm{N} / \mathrm{A}$ & $\mathrm{N} / \mathrm{A}$ & $\mathrm{N} / \mathrm{A}$ & N/A \\
\hline & Not Combined & 699 & 24.8 & 2,119 & 75.2 & & $\mathrm{~N} / \mathrm{A}$ & $\mathrm{N} / \mathrm{A}$ & $\mathrm{N} / \mathrm{A}$ & $\mathrm{N} / \mathrm{A}$ & $\mathrm{IN} / \mathrm{A}$ \\
\hline Employment & Full Time & 394 & 22.3 & 1,370 & 77.7 & & 198 & 11.2 & 1,566 & 88.8 & \\
\hline & $\begin{array}{l}\text { Part Time / Retired / } \\
\text { Unemployed } \\
\end{array}$ & 308 & 20.9 & 1,167 & 79.1 & 0.317 & 223 & 15.1 & 1,252 & 84.9 & 0.001 \\
\hline & Primary Policy Holder & 316 & 20.6 & 1,215 & 79.4 & 177 & 181 & 11.8 & 1,350 & 88.2 & م060 \\
\hline & Dependent & 386 & 22.6 & 1,322 & 77.4 & 0.177 & 240 & 14.1 & 1,468 & 85.9 & 0.060 \\
\hline & Salary & 152 & 21.7 & 548 & 78.3 & & 100 & 14.3 & 600 & 85.7 & 252 \\
\hline & Hourly / Unknown & 550 & 21.7 & 1,989 & 78.3 & .916 & 321 & 12.6 & 2,218 & 87.4 & 0.252 \\
\hline & Hourly & 189 & 20.6 & 730 & 79.4 & 0336 & 114 & 12.4 & 805 & 87.6 & 0.528 \\
\hline & Salary/Unknown & 513 & 22.1 & 1,807 & 77.9 & 0.330 & 307 & 13.2 & 2,013 & 86.8 & $0.5<0$ \\
\hline
\end{tabular}


Table I-8: Model fitting diagnostics for variables associated with the use of first or second generation antipsychotics, adherence, persistence, switching, and combination in the schizophrenia population

\begin{tabular}{|c|c|c|c|c|c|c|c|c|}
\hline $\begin{array}{l}\text { Dependent } \\
\text { Variable }\end{array}$ & Iteration & Description & $\begin{array}{c}\text { Log } \\
\text { Likelihood }\end{array}$ & $\begin{array}{c}-2 \text { Log } \\
\text { Likelihood }\end{array}$ & Model DF & $\begin{array}{c}\text { DF from } \\
\text { previous model }\end{array}$ & $\begin{array}{l}\text { chi-square } \\
\text { critical value }\end{array}$ & P-value \\
\hline \multirow{7}{*}{$\begin{array}{l}\text { Second } \\
\text { Generation } \\
\text { Antipsychotic } \\
\text { Use }\end{array}$} & 1 & Full Model $^{*}$ & 3800.453 & & 14 & & & \\
\hline & $\overline{2}$ & Full Model - Salary & 3800.474 & 0.042 & 13 & 1 & 3.84 & $>0.05$ \\
\hline & $\overline{3}$ & Full Model - Salary, Full & 3801.677 & 2.406 & 12 & 1 & 3.84 & $>0.05$ \\
\hline & 4 & $\begin{array}{l}\text { Full Model - Salary, Full } \\
\text { Time, Comb }\end{array}$ & 3801.83 & 0.306 & 11 & 1 & 3.84 & $>0.05$ \\
\hline & 5 & $\begin{array}{l}\text { Full Model - Salary, Full } \\
\text { Time, Comb, Anxiety }\end{array}$ & 3801.83 & 0 & 10 & 1 & 3.84 & $>0.05$ \\
\hline & 6 & $\begin{array}{l}\text { Full Model - Salary, Full } \\
\text { Time, Comb, Anxiety, }\end{array}$ & 3803.586 & 3.512 & 9 & 1 & 3.84 & $>0.05$ \\
\hline & 7 & $\begin{array}{l}\text { Full Model - Salary, Full } \\
\text { Time, Comb, Anxiety, } \\
\text { Depression, Region }\end{array}$ & 3811.36 & 15.548 & 6 & 3 & 7.81 & $<0.05$ \\
\hline
\end{tabular}

${ }^{*}$ Full model includes: Age, gender, region, diagnoses, switching, combination, and employment variables

${ }^{\star \star}$ Final model includes: Age, gender, region, diagnosis, and combination

\begin{tabular}{|c|c|c|c|c|c|c|c|c|}
\hline $\begin{array}{l}\text { Dependent } \\
\text { Variable }\end{array}$ & Iteration & Description & $\begin{array}{c}\text { Log } \\
\text { Likelihood }\end{array}$ & $\begin{array}{c}-2 \text { Log } \\
\text { Likelihood }\end{array}$ & Model DF & $\begin{array}{c}\text { DF from } \\
\text { previous model }\end{array}$ & $\begin{array}{l}\text { chi-square } \\
\text { critical value }\end{array}$ & P-value \\
\hline \multirow[t]{3}{*}{ Switching } & 1 & Full Model $^{\star}$ & 3224.655 & & 14 & & & \\
\hline & 2 & Full Model - Covered ${ }^{\star \star}$ & 3225.013 & 0.716 & 13 & 1 & 3.84 & $>0.05$ \\
\hline & 3 & $\begin{array}{l}\text { Full Model - Covered, } \\
\text { Region }\end{array}$ & 3229.903 & 9.78 & 10 & 3 & 7.81 & $<0.05$ \\
\hline
\end{tabular}

*Full model includes: Age, gender, region, diagnoses, use of second generation antipsychotic, combination, and responsibility for co ${ }^{\star \star}$ Final model includes: Age, gender, region, diagnoses, use of second generation antipsychotic, and combination

\begin{tabular}{|c|c|c|c|c|c|c|c|c|}
\hline $\begin{array}{l}\text { Dependent } \\
\text { Variable }\end{array}$ & Iteration & Description & $\begin{array}{c}\text { Log } \\
\text { Likelihood }\end{array}$ & $\begin{array}{l}\text { Difference in } \\
\quad-2 \text { Log } \\
\text { Likelihood }\end{array}$ & Model DF & $\begin{array}{l}\text { Difference in } \\
\text { DF from } \\
\text { previous model }\end{array}$ & $\begin{array}{c}\text { chi-square } \\
\text { critical value }\end{array}$ & P-value \\
\hline \multirow[t]{8}{*}{ Combination } & 1 & Full Model ${ }^{*}$ & 2259.84 & & 17 & & & \\
\hline & 2 & Full Model - Rural & 2259.84 & 0 & 16 & 1 & 3.84 & $>0.05$ \\
\hline & 3 & Full Model - Rural, SGA & 2260.001 & 0.322 & 15 & 1 & 3.84 & $>0.05$ \\
\hline & 4 & $\begin{array}{l}\text { Full Model - Rural, SGA, } \\
\text { Depression }\end{array}$ & 2260.152 & 0.302 & 14 & 1 & 3.84 & $>0.05$ \\
\hline & 5 & $\begin{array}{l}\text { Full Model - Rural, SGA, } \\
\text { Depression, Other Mental } \\
\text { Health }\end{array}$ & 2261.22 & 2.136 & 13 & 1 & 3.84 & $>0.05$ \\
\hline & 6 & $\begin{array}{l}\text { Full Model - Rural, SGA, } \\
\text { Depression, Other Mental } \\
\text { Health, Bipolar Disorder }\end{array}$ & 2261.257 & 0.074 & 12 & 1 & 3.84 & $>0.05$ \\
\hline & 7 & $\begin{array}{l}\text { Full Model - Rural, SGA, } \\
\text { Depression, Other Mental } \\
\text { Health, Bipolar Disorder, } \\
\text { Diabetes }^{\star *}\end{array}$ & 2262.092 & 1.67 & 11 & 1 & 3.84 & $>0.05$ \\
\hline & 8 & $\begin{array}{l}\text { Full Model - Rural, SGA, } \\
\text { Depression, Other Mental } \\
\text { Health, Bipolar Disorder, } \\
\text { Diabetes, Region }\end{array}$ & 2285.674 & 47.164 & 8 & 3 & 7.81 & $<0.05$ \\
\hline
\end{tabular}

${ }^{*}$ Full model includes: Age, gender, rural / non-rural, region, diagnoses, use of second generation antipsychotic, switching, and emplo ${ }^{\star \star}$ Final model includes: Age, gender, region, diagnosis of anxiety, switching, and employment variables 
Table 1-9: Odds Ratios for the likelihood that a patient would receive a second generation antipsychotic as compared with a first generation antispychotic

\begin{tabular}{lllcc}
\hline \multirow{2}{*}{ Demographic } & \multicolumn{1}{c}{$\begin{array}{c}\text { Point } \\
\text { Estimate }\end{array}$} & 95\%Confidence Limits \\
& Male & 0.919 & 0.783 & 1.08 \\
\cline { 2 - 5 } Region & Age & 0.981 & 0.974 & 0.988 \\
\cline { 2 - 5 } & North East & Reference & & \\
\cline { 2 - 5 } & North Central & 1.3 & 1.053 & 1.603 \\
\cline { 2 - 5 } & South & 1.188 & 0.982 & 1.439 \\
\cline { 2 - 5 } & West & 0.919 & 0.624 & 1.354 \\
\hline Clinical & Bipolar & 1.271 & 1.072 & 1.507 \\
\cline { 2 - 5 } & Other Mental & 1.489 & 1.266 & 1.75 \\
\cline { 2 - 5 } & Health & & & \\
\cline { 2 - 5 } & Diabetes & 0.852 & 0.698 & 1.039 \\
\cline { 2 - 5 } & Switch & 1.937 & 1.568 & 2.393 \\
\hline
\end{tabular}


Table I-10: Odds Ratios for the likelihood that a patient would switch treatments, according to selected demographic and clinical characteristics.

\begin{tabular}{llccc}
\hline & & Point Estimate & \multicolumn{2}{c}{$\begin{array}{c}\text { 95\%Confidence } \\
\text { Limits }\end{array}$} \\
\hline Demographic & Male & 0.93 & 0.774 & 1.116 \\
\cline { 2 - 5 } & Age & 0.993 & 0.986 & 1.001 \\
\hline \multirow{2}{*}{ Region } & North East & Reference & & \\
\cline { 2 - 5 } & North Central & 1.053 & 0.832 & 1.333 \\
\cline { 2 - 5 } & South & 1.145 & 0.92 & 1.425 \\
\cline { 2 - 5 } & West & 1.539 & 1.027 & 2.306 \\
\hline Clinical & Second Generation & 1.929 & 1.561 & 2.384 \\
& Antipsychotic & 1.17 & 0.912 & 1.501 \\
\cline { 2 - 5 } & Anxiety & 1.393 & 1.163 & 1.668 \\
\cline { 2 - 5 } & Bipolar & 1.435 & 1.181 & 1.744 \\
\cline { 2 - 5 } & Depression & 1.592 & 1.301 & 1.949 \\
\cline { 2 - 5 } & Other Mental Health & 1.345 & 1.081 & 1.695 \\
\cline { 2 - 5 } & Diabetes & & & \\
& & & & \\
\end{tabular}


Table 1-11: Odds Ratios for the likelihood of combination antipsychotic medication treatment, according to selected demographic and clinical characteristics.

\begin{tabular}{llccc}
\hline \multirow{2}{*}{ Demographic } & Male & Point Estimate & \multicolumn{2}{c}{$\begin{array}{c}\text { 95Confidence } \\
\text { Limits }\end{array}$} \\
\cline { 2 - 5 } & Age & 0.94 & 0.748 & 1.182 \\
\hline \multirow{2}{*}{ Region } & North East & 0.995 & 0.985 & 1.005 \\
\cline { 2 - 5 } & North Central & Reference & & \\
\cline { 2 - 5 } & South & 0.727 & 0.554 & 0.955 \\
\cline { 2 - 5 } & West & 0.534 & 0.411 & 0.694 \\
\hline Clinical & Anxiety & 0.958 & 0.58 & 1.582 \\
\cline { 2 - 5 } & Switch & 0.643 & 0.44 & 0.94 \\
\hline \multirow{3}{*}{ Employment } & Full Time & 0.021 & 0.007 & 0.067 \\
\cline { 2 - 5 } & Responsible for & 0.653 & 0.523 & 0.989 \\
\hline & Coverage & 0.785 & 0.623 & 0.815 \\
\hline
\end{tabular}




\section{References:}

1. Kessler RC, Birnbaum H, Demler O, Falloon IR, Gagnon E, Guyer M et al. The prevalence and correlates of nonaffective psychosis in the National Comorbidity Survey Replication (NCS-R). Biol Psychiatry 2005;58(8):66876.

2. Saha S, Chant D, Welham J, McGrath J. A systematic review of the prevalence of schizophrenia. PLoS Med 2005;2(5):e141.

3. Wu EQ, Shi L, Birnbaum H, Hudson T, Kessler R. Annual prevalence of diagnosed schizophrenia in the USA: a claims data analysis approach. Psychol Med 2006;36(11):1535-40.

4. Stahl SM, Grady MM. A critical review of atypical antipsychotic utilization: comparing monotherapy with polypharmacy and augmentation. Curr Med Chem 2004;11(3):313-27.

5. Bobes J, Arango C, Garcia-Garcia M, Rejas J, for the CLAMORS Study Collaborative Group. Prevalence of negative symptoms in outpatients with schizophrenia spectrum disorders treated with antipsychotics in routine clinical practice: findings from the CLAMORS study. J Clin Psychiatry 2009;

6. Lieberman JA, Stroup TS, McEvoy JP, Swartz MS, Rosenheck RA, Perkins DO et al. Effectiveness of antipsychotic drugs in patients with chronic schizophrenia. N Engl J Med 2005;353(12):1209-23.

7. Ascher-Svanum H, Zhu B, Faries DE, Furiak NM, Montgomery W. Medication adherence levels and differential use of mental-health services in the treatment of schizophrenia. BMC Res Notes 2009;2:6.

8. Flanagan RJ. Side effects of clozapine and some other psychoactive drugs. Curr Drug Saf 2008;3(2):115-22.

9. Staring AB, Mulder CL, Duivenvoorden HJ, De Haan L, Van der Gaag M. Fewer symptoms vs. more side-effects in schizophrenia? Opposing pathways between antipsychotic medication compliance and quality of life. Schizophr Res 2009;113(1):27-33.

10. Tiihonen J, Lonnqvist J, Wahlbeck K, Klaukka T, Niskanen L, Tanskanen A et al. 11-year follow-up of mortality in patients with schizophrenia: a population-based cohort study (FIN11 study). Lancet 2009;374(9690):6207. 
11. Weinmann S, Read J, Aderhold V. Influence of antipsychotics on mortality in schizophrenia: systematic review. Schizophr Res 2009;113(1):1-11.

12. Naber D, Lambert M. The CATIE and CUtLASS studies in schizophrenia: results and implications for clinicians. CNS Drugs 2009;23(8):649-59.

13. Kennedy J, Tien YY, Cohen LJ, Sclar DA, Liu D, Blodgett EG et al. The association between class of antipsychotic and rates of hospitalization: results of a retrospective analysis of data from the 2005 medicare current beneficiary survey. Clin Ther 2009;31(12):2931-9.

14. Rosenheck RA, Leslie DL, Sindelar J, Miller EA, Lin H, Stroup TS et al. Cost-effectiveness of second-generation antipsychotics and perphenazine in a randomized trial of treatment for chronic schizophrenia. Am J Psychiatry 2006;163(12):2080-9.

15. Johnsen E, Jorgensen HA. Effectiveness of second generation antipsychotics: a systematic review of randomized trials. BMC Psychiatry 2008;8:31.

16. Yang M, Barner JC, Lawson KA, Rascati KL, Wilson JP, Crismon ML et al. Antipsychotic medication utilization trends among Texas veterans: 19972002. Ann Pharmacother 2008;42(9):1229-38.

17. Leslie DL, Mohamed S, Rosenheck RA. Off-label use of antipsychotic medications in the department of Veterans Affairs health care system. Psychiatr Serv 2009;60(9):1175-81.

18. Hartung DM, Wisdom JP, Pollack DA, Hamer AM, Haxby DG, Middleton L et al. Patterns of atypical antipsychotic subtherapeutic dosing among Oregon Medicaid patients. J Clin Psychiatry 2008;69(10):1540-7.

19. McIntyre RS. Understanding needs, interactions, treatment, and expectations among individuals affected by bipolar disorder or schizophrenia: the UNITE global survey. J Clin Psychiatry 2009;70 Suppl 3:5-11.

20. Laursen TM, Agerbo E, Pedersen CB. Bipolar disorder, schizoaffective disorder, and schizophrenia overlap: a new comorbidity index. J Clin Psychiatry 2009;70(10):1432-8.

21. Romm KL, Rossberg JI, Berg AO, Barrett EA, Faerden A, Agartz I et al. Depression and depressive symptoms in first episode psychosis. J Nerv Ment Dis 2010;198(1):67-71. 
22. Dernovsek MZ, Sprah L. Comorbid anxiety in patients with psychosis. Psychiatr Danub 2009;21 Suppl 1:43-50.

23. Medved V, Jovanovic N, Knapic VP. The comorbidity of diabetes mellitus and psychiatric disorders. Psychiatr Danub 2009;21(4):585-8.

24. Newcomer JW. Comparing the safety and efficacy of atypical antipsychotics in psychiatric patients with comorbid medical illnesses. $\mathrm{J}$ Clin Psychiatry 2009;70 Suppl 3:30-6.

25. Bresee LC, Majumdar SR, Patten SB, Johnson JA. Prevalence of cardiovascular risk factors and disease in people with schizophrenia: A population-based study. Schizophr Res 2010;

26. Fagiolini A, Goracci A. The effects of undertreated chronic medical illnesses in patients with severe mental disorders. J Clin Psychiatry 2009;70 Suppl 3:22-9.

27. Andrews AO, Bartels SJ, Xie H, Peacock WJ. Increased risk of nursing home admission among middle aged and older adults with schizophrenia. Am J Geriatr Psychiatry 2009;17(8):697-705.

28. Menzin J, Boulanger L, Friedman M, Mackell J, Lloyd JR. Treatment adherence associated with conventional and atypical antipsychotics in a large state Medicaid program. Psychiatr Serv 2003;54(5):719-23.

29. Gianfrancesco FD, Sajatovic M, Tafesse E, Wang RH. Association between antipsychotic combination therapy and treatment adherence among individuals with bipolar disorder. Ann Clin Psychiatry 2009;21(1):316.

30. Ranceva N, Ashraf W, Odelola D. Antipsychotic Polypharmacy in Outpatients at Birch Hill Hospital: Incidence and Adherence to Guidelines. J Clin Pharmacol 2010;

31. Specifications Manual for Joint Commission National Quality Measures (v2012A)

Discharges 01-01-12 (1Q12) through 06-30-12 (2Q12) downloaded from: http://manual.jointcommission.org/releases/TJC2013A on: February 9, 2012.

32. Valenstein M, Kavanagh J, Lee T, Reilly P, Dalack GW, Grabowski J et al. Using A Pharmacy-Based Intervention To Improve Antipsychotic Adherence Among Patients With Serious Mental Illness. Schizophr Bull 2009; 
33. Constantine RJ, Andel R, Tandon R. Trends in Adult Antipsychotic Polypharmacy: Progress and Challenges in Florida's Medicaid Program. Community Ment Health J 2010;

34. Gianfrancesco FD, Rajagopalan K, Sajatovic M, Wang RH. Treatment adherence among patients with schizophrenia treated with atypical and typical antipsychotics. Psychiatry Res 2006;144(2-3):177-89.

35. Gianfrancesco FD, Rajagopalan K, Sajatovic M, Wang RH. Treatment adherence among patients with bipolar or manic disorder taking atypical and typical antipsychotics. J Clin Psychiatry 2006;67(2):222-32.

36. Rawson NS, Malcolm E, D'Arcy C. Reliability of the recording of schizophrenia and depressive disorder in the Saskatchewan health care datafiles. Soc Psychiatry Psychiatr Epidemiol 1997;32(4):191-9.

37. Kilzieh N, Todd-Stenberg JA, Kennedy A, Wood AE, Tapp AM. Time to discontinuation and self-discontinuation of olanzapine and risperidone in patients with schizophrenia in a naturalistic outpatient setting. J Clin Psychopharmacol 2008;28(1):74-7.

38. Zhang Y, Baicker K, Newhouse JP. Geographic variation in the quality of prescribing. N Engl J Med 2010;363(21):1985-8.

39. Buckley PF, Correll CU. Strategies for dosing and switching antipsychotics for optimal clinical management. J Clin Psychiatry 2008;69 Suppl 1:4-17.

40. Baandrup L, Allerup P, Nordentoft M, Lublin H, Glenthoj BY. Exploring regional variation in antipsychotic coprescribing practice: a Danish questionnaire survey. J Clin Psychiatry 2010;71(11):1457-64.

41. Acosta FJ, Bosch E, Sarmiento G, Juanes N, Caballero-Hidalgo A, Mayans T. Evaluation of noncompliance in schizophrenia patients using electronic monitoring (MEMS) and its relationship to sociodemographic, clinical and psychopathological variables. Schizophr Res 2009;107(23):213-7. 
CHAPER 2

\section{ADHERENCE TO ANTIPSYCHOTIC TREATMENTS IN A COMMERCIALLY INSURED POPULATION DIAGNOSED WITH SCHIZOPHRENIA}

Formatted for submission to the Journal of Managed Care Pharmacy (JMCP), not yet submitted. 


\section{Abstract:}

\section{Background}

Adherence and persistence to medications for schizophrenia is typically less than that seen in other classes of medication. Additionally, studies of adherence to antipsychotics are often completed in populations with a high prevalence of schizophrenia, which may not be generalizable to the commercially insured population. The purpose of this analysis was to determine the factors associated with adherence to therapy in a commercially insured population.

\section{Methods}

A retrospective cohort study was completed in order to determine if demographic, clinical, or employment characteristics described in administrative claims data are associated with adherence and persistence in this population. Adherence was calculated based on a medication possession ratio of greater than $80 \%$, and persistence was based on a gap of 90 days or more in therapy.

\section{Results}

There were 1,086 individuals identified with an ICD-9 code indicating schizophrenia and at least 2 dispensings of the same medication. The adherence rate observed in this population was $61.3 \%(\mathrm{~N}=666)$, with $70.4 \%$ ( $\mathrm{N}=765)$ experiencing no 90 day gaps in therapy. After adjusting using logistic regression, good adherence was associated with documentation of diabetes (OR $0.691,95 \% \mathrm{Cl} 0.501-0.952)$ or mental health comorbidities (OR $0.587,95 \% \mathrm{Cl}$ $0.457-0.755)$. Poor persistence on therapy was associated with anxiety (OR 
$0.691,95 \% \mathrm{Cl} 0.501-0.952$ ) or bipolar disorder (OR $0.587,95 \% \mathrm{Cl} 0.457$ -

$0.755)$.

Conclusion

Several factors drive an individual's adherence and persistence to medication regimens. Adherence and persistence were both decreased in individuals with comorbid mental health conditions such as bipolar disorder or anxiety.

Demographic and employment characteristics were not significant predictors of adherence or persistence. 


\section{Background:}

\section{Prevalence of Schizophrenia}

Treatment of Mental health disorders can be difficult and expensive, and these conditions occur fairly commonly in the United States. The lifetime prevalence of schizophrenia is between $0.3 \%$ and $1.6 \%,{ }^{1}$ with the period prevalence of schizophrenia between $0.13 \%$ and $0.82 \%{ }^{2}$ Although less common in commercially insured populations, the prevalence of schizophrenia in that group is still not negligible at about $0.13 \% .^{3}$ Despite being less prevalent in the commercial population overall, people in this group make up a significant portion $(16 \%)$ of the schizophrenic population. ${ }^{3}$

Antipsychotic Treatment

Adherence to treatment is a key stumbling block for many patients receiving antipsychotics. A review of the literature by Llorca found that several studies demonstrate a significant relationship between low adherence and relapses and hospitalization. ${ }^{4}$ The difficult side effects of antipsychotics, which include extrapyramidal effects in first generation antipsychotics and metabolic effects in second generation antipsychotics, alone are a barrier to adherence. A study by Bulloch found that $35 \%$ of individuals were non-adherent to their antipsychotics, ${ }^{5}$ and Second Generation Antipsychotics were associated with a 
better likelihood of adherence than First Generation Antipsychotics in several studies. $^{6,7}$

Less complicated regimens ${ }^{8}$, levels of social support, ${ }^{9}$ and patient attitude towards treatment are additional areas associated with patient adherence. ${ }^{10}$ It has also been demonstrated that treatment naïve patients are less likely than those who have switched from another medication to be adherent and persistent ${ }^{11}$ demonstrating the difficulty in selecting a first medication.

In the schizophrenia population, it is clear that decreased adherence leads to a decreased treatment response, ${ }^{12}$ a higher rate of relapse, ${ }^{13,14}$ and greater risk of hospitalization. ${ }^{15-17}$ The Law study in particular found that within 10 days of a missed refill, the risk of hospitalization increases significantly. ${ }^{17}$ In schizophrenic patients, adherence was better on second generation antipsychotics, ${ }^{18}$ with Rabinovitch finding that $59.4 \%$ of second generation users were adherent, compared to $34.5 \%$ of first generation users. ${ }^{9}$ Studies have been mixed in their assessment of factors leading to better adherence to antipsychotics in the schizophrenic population, with Acosta, et al, finding no relationship between sociodemographic, clinical, or treatment related variables and adherence, ${ }^{19}$ while Valenstein et al found that demographic factors such as younger age and non-white race were associated with poorer adherence, as were clinical factors such as using a second generation antipsychotic. ${ }^{20}$

Similar trends emerge among populations of patients having Bipolar disorder. Such patients utilizing second generation antipsychotics were more likely to be both adherent and persistent, and also less likely to switch. ${ }^{21}$ Several 
studies of patients having bipolar disorder demonstrate a decrease in hospitalization risk in adherent groups..$^{22,23}$ Bipolar individuals with a medication possession ratio (MPR) greater than $80 \%$ decreased their risk of hospitalization by $18 \%$, compared to those considered non-adherent. ${ }^{23}$ Barriers such as lacking social support also affect adherence in this population. ${ }^{24}$

\section{Study Purpose and Justification}

There have been many studies conducted to better understand factors influencing adherence to antipsychotics. The vast majority of the literature identified above focuses on specific populations with a high incidence of schizophrenia, those individuals utilizing Medicaid and Veteran's Administration (VA) programs. The commercial population likely differs significantly from the Medicaid and VA groups where patients are typically older, and (especially in the VA) more likely to be male. ${ }^{7,25}$ This population is also different from those used in prospective open-label trials such as CATIE, in which $85 \%$ of the population was unemployed. ${ }^{26}$ It is critical to gain a better understanding of medication utilization patterns the commercial population. Sixteen percent of schizophrenic patients receive services through private insurance, and represent a fairly significant cost in this population. ${ }^{3}$ Programs designed to better manage these populations will utilize the improved information to better understand their participants, leading to more targeted interventions. ${ }^{27,28}$ 
In addition to better understanding this population, there are also a wide variety of methods utilized to measure adherence to antipsychotics described in the literature, although the MPR method is most common. ${ }^{17,29,30}$ MPR and proportion of days covered (PDC) have both been shown to be associated with poor outcomes such as hospitalization. ${ }^{29}$ Additionally, evaluating large gaps in therapy as a proxy for discontinuation provides insight into longer drug free periods and may be associated with different factors than MPR and PDC. ${ }^{17}$

The goal of this analysis was to evaluate factors that may be associated with medication adherence among commercially insured patients utilizing antipsychotic medications, considering both MPR results and drug discontinuation. These factors include: the use of first or second generation agents, switching treatments, use of combination treatments, and the demographic, clinical, and employment characteristics of the population. 


\section{Methods:}

Study Design:

Data from the Thompson MarketScan database were utilized to conduct a retrospective cohort analysis of medication adherence in the schizophrenic population utilizing antipsychotics. The outcome of interest in this analysis is the Medication Possession Ratio (MPR), indicating how closely a patient complies with the medication regimen during treatment periods. The association between clinical, demographic, and employment factors on MPR are evaluated based on multivariate statistical analysis.

\section{Data Source:}

The data source for this analysis is the Thomson MarketScan commercial claims dataset, including employees and their dependents working for large companies spread across the United States, and insured by roughly 100 different payers. This data set contains comprehensive medical, demographic, and employment data for roughly 5.9 million individuals between 2000 and 2001. The data is provided in cleaned data sets, but it was still examined in order to ensure that variables were complete and distributed as expected. 
Inclusion Criteria:

From the overall eligible population ( $N=1,428,349), 2,156$ individuals $(0.15 \%)$ were identified as schizophrenic, and 1,361 of those had at least one treatment episode where MPR could be calculated. Inclusion criteria for this analysis require that a patient be continuously enrolled for the entire study period (24 months), and be between 18 and 65 years of age at the beginning and end of the study. The individuals must also have at least 1 ICD-9 code indicating schizophrenia (295.xx), and 2 dispensings for the same antipsychotic medication occurring within the period. Figure II-1 demonstrates the sample selection criteria.

Operational Definitions:

Continuous enrollment was defined as having 366 days of continuous enrollment in 2000, and 365 days of continuous enrollment in 2001 with both medical and pharmacy coverage. This data was abstracted from the enrollment data sets provided.

Diagnoses for specific conditions were identified through the presence of one or more ICD-9 codes in the inpatient or outpatient records. Anxiety, Bipolar Disorder, Depression, Schizophrenia, and Other Mental Health Disorders not included above (such as substance abuse) were identified. Documentation of Diabetes was also identified due to the association between second generation 
antipsychotics and an increased risk of metabolic outcomes. The specific list of ICD-9 codes used to identify these conditions is provided in table II-1. This methodology is similar to that used in a variety of other studies, ${ }^{3,18,21,32}$ and validated by Rawson, et al, in $1997 .^{32}$

Therapy with a given treatment was defined as receipt of at least 2 dispensings of that medication within the study period. The "therapeutic period" for a treatment is the time from the first fill, to the date of the last fill plus the last days supply, and any days spent in the hospital. "Combination Therapy" is defined as two treatments overlapping by a minimum of 90 days. A "switch" in therapy was defined as a change from one treatment to another where there is no more than a 90 day gap in therapy, and no more than 90 days of overlap in therapy. A discontinuation in treatment is defined as a period of 90 days or more without therapy following the end of a therapeutic period, excluding any days in the hospital. Studies have typically used periods of 30 to 90 days to define gaps in therapy. ${ }^{18,21,33}$ This study utilized the 90 day period to match the longest days supply routinely received by patients.

Adherence was calculated utilizing the Medication Possession Ratio (MPR), calculated utilizing equation 1 below..$^{20}$ Although a variety of methodologies for measuring adherence are available, several methods such as electronic monitoring (MEMS caps), or patient questionnaires are not feasible. Although electronic monitoring is considered the gold standard, ${ }^{19}$ use of medical records or claims databases are considered more accurate than patient selfreport. ${ }^{19,34,35}$ The decision to use MPR rather than Proportion of Days Covered 
(PDC) was based on several studies supporting its use, ${ }^{6,36,37}$ as well as it being the most common measure reported in the literature, and therefore the best for comparison amongst studies. Any days spent in the hospital were removed from the time period between the first and last fills.

$$
\begin{aligned}
& \text { Equation 1: } \\
& \qquad M P R=\frac{\left(\sum d a y_{-} q t y\right)-\text { last_day_qty }}{\text { Last_fill_date }- \text { First_fill_date }}
\end{aligned}
$$

Therapy duration was calculated as the difference between the end of the treatment period and the first fill date, similar to several studies reported in the literature..$^{18,21,38}$ One treatment period was identified for each individual based on whichever medication, or combination of medications, they were using as of January 1,2001 . Discontinuation was defined as having a therapy end date prior to September 30, 2001, and no other antipsychotic treatments between that date and the end of the study period.

Demographic variables were cleaned and defined as well. An individual's age was defined as the difference between their birth year, and the year 2000 . There were no instances in the data where an individual had more than 1 gender on record. Employment and geographic variables were defined for each individual as the value that turned up most often for that individual (if more than one value was available). Employment characteristics included full time vs. part time or unemployed status, primary vs. dependent coverage status, and salary vs. hourly pay. Geographic variables were coded as rural or non-rural based on 
Metropolitan Statistical Area, and Region (North East, North Central, South, and West).

Bivariate analysis

Because of the typical left skewed, truncated nature of the distribution of MPR, each individual treatment episode was categorized as adherent (MPR $\geq 80 \%$ ) or non-adherent (MPR $<80 \%$ ). The $80 \%$ cut-off has been utilized as the threshold in several publications describing adherence rates and outcomes due to poor adherence in populations treated for psychiatric conditions including schizophrenia. ${ }^{18,21,38}$ Treatment gap of 90 days or more was treated as a dichotomous variable. The relationship between the outcomes of interest (adherence and discontinuation) and the clinical and demographic variables (first or second generation antipsychotic utilization, treatment combination or switch, demographic, and employment variables) was tested using the chi-square analysis. The association between age, the only continuous explanatory variable, and adherence and discontinuation was also tested utilizing the student's T-test.

\section{Multivariate Analysis:}

Two separate Logistic regression models were used in order to adjust for multiple factors influencing MPR and discontinuation. Adherence to therapy was modeled against first or second generation medication choice, switching, combination use, demographic, clinical, and employment factors. Interaction 
terms including the various combinations of age group, gender, and comorbidities were also included if they were associated with the dependent variable as measured by the chi-square test with a significant $p$-value $(<0.2)$. Chi-square analysis was also used to assess several potential associations amongst independent variables to determine if they were independent. If the variables were not independent (chi-square value was less than 0.05 ), the less important variable was dropped from consideration for the model. Stepwise backwards elimination was used to optimize the model, using the -2 log likelihood to test the significance of changes. Multicollinearity was assessed based on the variation inflation factor (VIF), and eignevalues. These were calculated utilizing a separate model with the proc reg function in SAS with the VIF, TOL, and collin options. If the condition number was greater than 30 , or the VIF was greater than 5 , increased scrutiny was given to the affected variables. HosmerLemeshow was used to assess goodness of fit. 


\section{Results:}

Univariate results:

In the first year of data, $2,156(0.2 \%$ of those meeting demographic criteria) individuals were identified with at least 1 ICD-9 code indicating schizophrenia, of them 1,086 (50.3\%) individuals that had at least 2 dispensings of the same medication within 90 days of each other to create a treatment episode including January 1, 2001. The demographic, clinical, and employment characteristics of the population are described in table II-2. Of the 1,086 individuals that had treatments, $666(61.3 \%)$ were considered adherent. Most of the treatment episodes in this analysis were for second generation antipsychotics, with $15.1 \%$ following a switch in therapies, and $13.8 \%$ received in combination. Table II-3 provides a description of the therapies observed in this population.

The mean duration of treatment without any gaps over 90 days between January 1, 2000 and December 31, 2001 was 579.2 (sd 173.1) days. Duration had a bimodal distribution due to the short time period of the data, with peaks at 450 and 750 days (figure II-2). 698 (64.2\%) episodes were likely began therapy prior to the earliest records in the data, 765 (70.4\%) likely continued therapy beyond the study period, and 541 (49.8\%) were began prior to and ended after the study period. The minority, $164(15.1 \%)$ of episodes occur completely within the study period. 
Bivariate results:

The bivariate analyses demonstrated that older age was associated with greater adherence: (46.9 [sd 11.3] in the adherent group vs. 45.2 [sd 11.9] in the non-adherent group, $p=0.014)$. Age groupings did not show any statistically significant difference in adherence. Gender was not associated with adherence. Patients also having diabetes were significantly less likely to be adherent to therapy than non-diabetics $(55.0 \%$ vs. $62.8 \%$ respectively, $p=0.042)$. Hourly workers were more likely than others to be adherent $(67.1 \%$ vs $59.5 \%$ salaried and $58.9 \%$ others, $\mathrm{p}=0.0487$ ). The remaining results are listed in table II-4.

Discontinuation was identified in 321 (29.6\%) individuals. These individuals tended to be younger, with 18 to 44 year olds discontinuing $33.4 \%$ vs $27.3 \%$ in 45 to 64 year olds $(p=0.033)$. Individuals with additional mental health diagnoses were also significantly more likely to discontinue therapy ( $36.0 \%$ vs $23.1 \%[p<0.001]$ for those with no comorbid mental health conditions documented). Individuals who combined medications (47.3\% vs. $26.7 \%$ $[p<0.001]$ for those that did not combine) or switched between medications (37.8\% vs. $28.1 \%$ [ $=0.012]$ for those that did not switch) were also more likely to discontinue therapy. Table II-5 provides the percent of individuals who discontinued and the $p$-values for all of the variables examined. 
Multivariate results:

The multivariate analysis found several associations between adherence and clinical, demographic, and employment related factors. Table II-6 provides the diagnostic data utilized in fitting the final model. Adherence was modeled against age, gender, comorbid diagnoses, use of a second generation antipsychotic, switching, combination use, and payer type. All variables remained in the final model. This model had a good fit, with $\mathrm{c}=0.842$, and Hosmer-Lemeshow $\mathrm{p}$-value $=0.401$. Individuals with a comorbid diagnosis of diabetes (OR $0.691,95 \% \mathrm{Cl} 0.501-0.952)$ or other mental health conditions such as substance abuse (OR $0.587,95 \% \mathrm{Cl} 0.457-0.755)$ were both less likely to be adherent to their antipsychotic treatments. Other variables did not result in significant differences in MPR. Table II-7 provides the odds ratios associated with the remaining variables.

There were fewer significant associations between discontinuation and the demographic, clinical, and employment characteristics tested. The full model included age, gender, diagnosis of anxiety, bipolar disorder, depression, other mental health diagnoses, first or second generation antipsychotic use, switching, combination use, and insurance coverage type (primary vs. dependent). The final model included age, gender, comorbid diagnoses, and use of combinations (table II-8). Goodness-of-fit for this model was adequate with c-statistic $=0.747$, and Hosmer-Lemeshow $p$-value $=0.495$. Documentation of bipolar disorder (OR $0.587,95 \% \mathrm{Cl} 0.457-0.755)$ and anxiety (OR $0.691,95 \% \mathrm{Cl} 0.501-0.952)$ were 
both associated with less likelihood to be persistent. Table II-9 provides the odds ratios from the final model. 


\section{Discussion:}

This analysis demonstrates the importance of comorbidities in the likelihood that a patient will be adherent to and persistent on therapy. Observed decreases in adherence associated with a diabetes or other mental health diagnoses may lead to treatment being ineffective, with resultant increases in the need for medical care, as well as increases in the indirect costs of schizophrenia. This analysis gives caregivers, providers, and insurers new insight into the factors that increase the risk of non-adherence and non-persistence in the commercial population, and these can be utilized to identify the patients who would be the best targets for outreach attempting to improve adherence.

\section{Factors Associated with MPR}

Adherence measured by MPR is the most commonly utilized methodology in literature addressing claims based studies. The adherence rate found in our study (61.3\% of the population having an MPR above $80 \%)$ is higher than that seen in other studies, for example Ascher-Svanum found that $58 \%$ of participants in the US Schizophrenia Care and Assessment Program (US-SCAP) had an MPR above $80 \%$, Valenstein found that $60 \%$ of the VA population studied had an MPR greater than $80 \%$, and Gilmer found that only $41 \%$ of the Medicaid population they studied was adherent using the same criteria. ${ }^{20,38,39}$ There are a number of potential explanations for this finding. First, studies have shown that 
social support is a key driver of adherence, ${ }^{9}$ in this analysis dependents tended to be more adherent than primary policy holders, thus dependent status may be an indicator of the social support available to these individuals. In addition to differences in the population, there may also be differences in the methodology used to calculate MPR, where some studies do not exclude days in the hospital from the denominator, or use the entire study period as the denominator, rather than just the treatment period.

The multivariate results show that certain clinical characteristics are key drivers associated with adherence. There are differing reports on superior adherence rates in first vs. second generation antipsychotic users, with a VA population having lower adherence to second generation antipsychotics $(62.2 \%$ and $58.8 \%$ with an MPR $>80 \%$ in first vs. second generation antipsychotics respectively) ${ }^{20}$ and a study based on patients with a first episode of psychosis in the community found that second generation antipsychotics resulted in better adherence (MPR $=59.4 \%$ vs. $34.5 \%$ in first generation users); $;, 9,20$ in the study described here, we found that there was no significant difference in adherence for second generation antipsychotic users as compared to first generation antipsychotic users.

Individuals with other mental health disorders also had lower adherence rates, which correlate with the existing literature..$^{40} \mathrm{~A}$ study by Lang et al found that combination users were more likely to be adherent than those using single treatments $(71 \%$ in combination users vs. $70 \%$ in first generation users and $64 \%$ in second generation users), agreeing with our study that found that combination 
users trended towards higher adherence than single medication users (OR $1.361,95 \% \mathrm{Cl} 0.939-1.972) .{ }^{40}$ There was also lower adherence among patients having diabetes in our study, which may be indicative of concern about metabolic adverse events, or associated with increased complexity of care in general. ${ }^{41}$ Other studies have also found limited associations between demographic, economic / work, and clinical variables and adherence. ${ }^{19}$

\section{Factors Associated with Persistence}

Persistence indicates the length of time an individual is able to remain on treatment. Due to the relatively short timeframe available for this study, most individuals were already on a treatment at the beginning of the study, and still taking it at the end. Therefore we were unable to calculate a true estimation of treatment duration in this population, but with nearly $50 \%$ of the population receiving therapy without more than a 90 day gap at the beginning and end of the study, the commercially insured population performs significantly better than the CATIE population, where $74 \%$ of new users discontinued therapy by 18 months ${ }^{26}$ as well as a VA population where the median time to discontinuation was 120 days. ${ }^{33}$ Being persistent on therapy is crucial as the risk for poor outcomes such as hospitalization can begin to increase in as little as 10 days after discontinuing therapy. ${ }^{17}$

Our study demonstrated an increased risk for discontinuation in populations with comorbid bipolar disorder or anxiety. These conditions likely 
complicate therapeutic regimens due to their episodic nature, leading to discontinuations due to changes in overall disease states, but also due to confusion on the part of the individual. ${ }^{8}$ Overall, there were very few variables associated with discontinuation following adjustment with logistic regression. This is in agreement with the literature where Gianfrancesco et al found that there was no difference in persistence between first and second generation antipsychotics in a commercial population. ${ }^{18}$ In an evaluation of the VA population, there was less likelihood of discontinuation in second generation antipsychotic users as compared to first generation antipsychotic users. Several issues may be causing this difference in outcomes. First, the VA study did not control for comorbid conditions in their analysis. Additionally there are some substantial differences in the populations, with the VA consisting largely of older male patients at the time, and the Medicaid population likely having significant differences in sociodemographic characteristics such as income and social support that could not be measured in either study.

\section{Limitations}

Studies utilizing claims records to measure adherence are prone to several well documented limitations. For instance, without observing an individual taking a medication one cannot be sure that it is being taken. Pharmacy claims can also be incomplete if patients receive samples from their 
physician, or pay cash rather than their copay for inexpensive generics, resulting in underestimates of adherence.

The short time period available in our data also limited the ability to follow patients over a long period of time based on trade-offs with population size. Future studies using a broader population, and longer timeframe may also be able to identify more significant drivers of adherence and persistence than those seen in our population. The age of this data may also limit generalizability due to the addition of new treatments and changes in guidelines over time. Generalizability is also limited to the commercially insured population represented by the data.

The limitations of claims data might also help to explain why full time workers are less likely to be adherent to therapy. Although our methodology for identifying schizophrenia in the population is in line with several other published studies, ${ }^{3,18,32}$ requiring only one ICD-9 code for schizophrenia may be allowing some false positives. Although uncommon (Rawson et al found $97 \%$ agreement between computerized records and medical charts), ${ }^{32}$ if those false positives are represented disproportionately in full time workers, it might be the case that those individuals are more likely to be using these antipsychotics for off-label purposes, ${ }^{42}$ such as the use of low dose quetiapine for sleep, which in turn could be lowering their overall possession ratios. Further research to validate the coding of schizophrenia in commercial databases would be necessary to confirm or reject this hypothesis. 


\section{Conclusions}

Several factors drive an individual's adherence and persistence to medication regimens. Adherence and persistence were both decreased in individuals with comorbid bipolar disorder or anxiety. Demographic and employment characteristics were not significant predictors of adherence or persistence. 
Figures:

Figure II-1: Inclusion and exclusion criteria flowchart

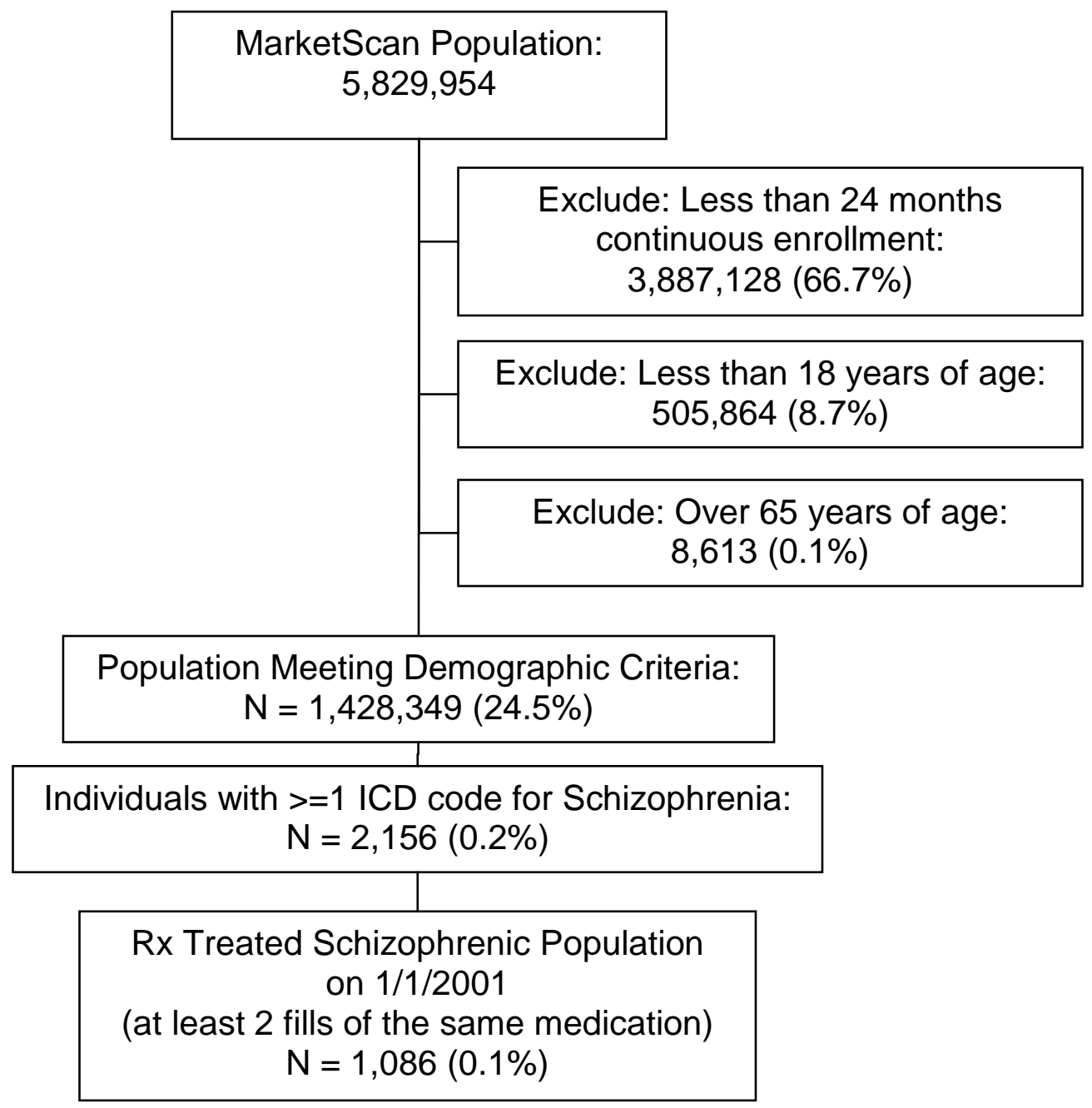


Figure II-2: Histogram of frequency of days of continual antipsychotic treatment among patients with a diagnosis of schizophrenia

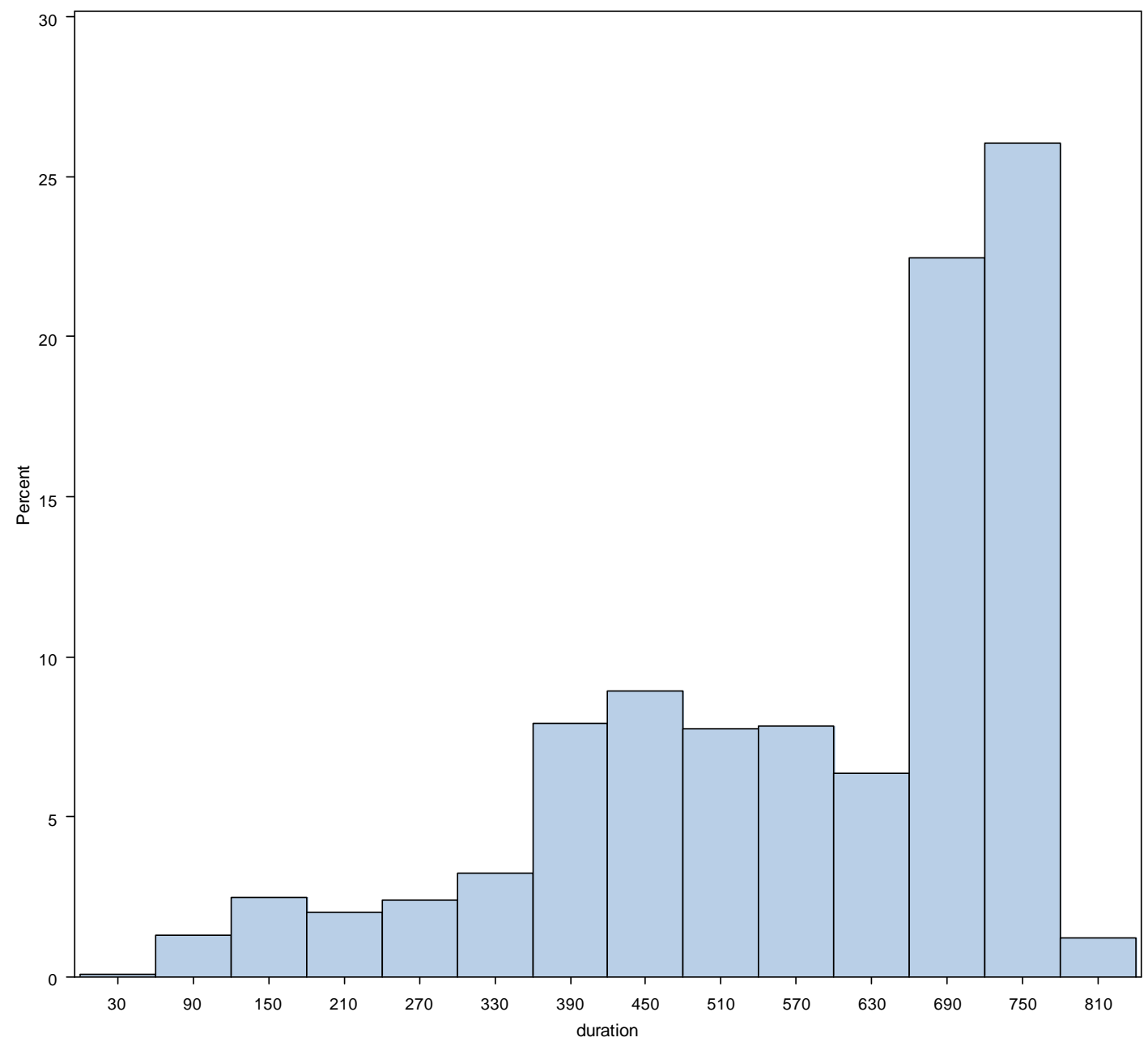




\section{Tables:}

Table II-1: ICD-9 Codes used for identifying diagnoses with primary conditions and comorbidities

\begin{tabular}{lc}
\hline Condition & ICD-9 Codes Included \\
\hline Schizophrenia & $295-295.95$ \\
\hline Bipolar Disorder & $296-296.99$ \\
\hline Anxiety & $300-300.09$ \\
\hline Depression & $311,300.4$ \\
\hline Other Mental Health & $290-319$, except for those listed above \\
\hline Diabetes & $250.00-250.99$ \\
\hline
\end{tabular}


Table II-2: Demographic characteristics of the study population

\begin{tabular}{|c|c|c|c|}
\hline & & \multicolumn{2}{|c|}{$\begin{array}{c}\text { Total } \\
(\mathrm{N}=1086)\end{array}$} \\
\hline & & $\mathrm{N}$ & $\begin{array}{l}\% \text { of } \\
\text { Total }\end{array}$ \\
\hline \multirow[t]{2}{*}{ Age } & $18-44$ & 401 & 36.9 \\
\hline & $45-64$ & 685 & 63.1 \\
\hline \multirow[t]{2}{*}{ Gender } & Male & 441 & 40.6 \\
\hline & Female & 645 & 59.4 \\
\hline \multirow[t]{6}{*}{ Location } & Rural & 203 & 18.7 \\
\hline & Non-Rural & 883 & 81.3 \\
\hline & North East & 306 & 28.2 \\
\hline & North Central & 306 & 28.2 \\
\hline & South & 427 & 39.3 \\
\hline & West & 47 & 4.3 \\
\hline \multirow[t]{10}{*}{ Diagnoses } & Bipolar Disorder & 333 & 30.7 \\
\hline & No Bipolar Disorder & 753 & 69.3 \\
\hline & Anxiety & 107 & 9.9 \\
\hline & No Anxiety & 979 & 90.1 \\
\hline & Depression & 239 & 22.0 \\
\hline & No Depression & 847 & 78.0 \\
\hline & Other Mental Health & 545 & 50.2 \\
\hline & No Other Mental Health & 541 & 49.8 \\
\hline & Diabetes & 200 & 18.4 \\
\hline & No Diabetes & 886 & 81.6 \\
\hline \multirow{8}{*}{$\begin{array}{l}\text { Medication } \\
\text { Utilization }\end{array}$} & Second Generation & & \\
\hline & Antipsychotic & 710 & 65.4 \\
\hline & First Generation Antipsychotic & 282 & 26.0 \\
\hline & Both (combination) & 94 & 8.7 \\
\hline & Switched To & 164 & 15.1 \\
\hline & Not post switch & 913 & 84.1 \\
\hline & Combined & 150 & 13.8 \\
\hline & Not Combined & 936 & 86.2 \\
\hline \multirow[t]{7}{*}{ Employment } & Full Time & 569 & 52.4 \\
\hline & $\begin{array}{l}\text { Part Time / Retired / } \\
\text { Unemployed }\end{array}$ & 517 & 47.6 \\
\hline & Primary Policy Holder & 527 & 48.5 \\
\hline & Dependent & 559 & 51.5 \\
\hline & Salary & 227 & 20.9 \\
\hline & Hourly & 307 & 28.3 \\
\hline & No Pay / Unknown & 552 & 50.8 \\
\hline
\end{tabular}


Table II-3: Treatments observed in the study population

\begin{tabular}{|c|c|c|c|}
\hline & & $\mathbf{N}$ & $\%$ \\
\hline \multicolumn{2}{|l|}{ Total Population } & 1086 & $100.0 \%$ \\
\hline \multirow{5}{*}{$\begin{array}{l}\text { Second } \\
\text { Generation } \\
\text { Antipsychotics }\end{array}$} & Any SGA monotherapy & 665 & $61.2 \%$ \\
\hline & Clozapine (Clozaril) & 60 & $5.5 \%$ \\
\hline & Risperidone (Risperdal) & 251 & $23.1 \%$ \\
\hline & Quetiapine (Seroquel) & 85 & $7.8 \%$ \\
\hline & Olanzapine (Zyprexa) & 269 & $24.8 \%$ \\
\hline \multirow{12}{*}{$\begin{array}{l}\text { First } \\
\text { Generation } \\
\text { Antipsychotics }\end{array}$} & Any FGA monotherapy & 271 & $25.0 \%$ \\
\hline & Haloperidol (Haldol) & 49 & $4.5 \%$ \\
\hline & Loxipine (Loxitane) & 13 & $1.2 \%$ \\
\hline & Thioridazine (Mellaril) & 31 & $2.9 \%$ \\
\hline & Molindone (Mobane) & 3 & $0.3 \%$ \\
\hline & Thiothixene (Navane) & 39 & $3.6 \%$ \\
\hline & Pimozide (Orap) & 2 & $0.2 \%$ \\
\hline & Fluphenazine (Prolixin) & 30 & $2.8 \%$ \\
\hline & Mesoridazine (Serentil) & 3 & $0.3 \%$ \\
\hline & Trifluoperazine (Stelazine) & 46 & $4.2 \%$ \\
\hline & Chlorpromazine (Thorazine) & 19 & $1.7 \%$ \\
\hline & Perphenazine (Trilafon) & 36 & $3.3 \%$ \\
\hline \multirow[t]{4}{*}{ Combinations } & Any Combination & 150 & $13.8 \%$ \\
\hline & 2 or more Second Generations & 45 & $4.1 \%$ \\
\hline & 2 or more First Generations & 11 & $1.0 \%$ \\
\hline & First and Second Generation & 94 & $8.7 \%$ \\
\hline
\end{tabular}


Table II-4: Bivariate associations between adherence and demographic, clinical, and employment characteristics

\begin{tabular}{|c|c|c|c|c|c|c|}
\hline & & \multicolumn{2}{|c|}{$\begin{array}{l}\text { Adherent } \\
(\mathrm{N}=666)\end{array}$} & \multicolumn{2}{|c|}{$\begin{array}{l}\text { Non-Adherent } \\
(\mathrm{N}=420)\end{array}$} & \multirow{2}{*}{$p$-value } \\
\hline & & $\mathrm{N}$ & $\begin{array}{c}\% \\
\text { Adherent }\end{array}$ & $\mathrm{N}$ & $\begin{array}{l}\% \text { Non- } \\
\text { Adherent }\end{array}$ & \\
\hline \multirow[t]{2}{*}{ Age } & $18-44$ & 238 & 59.4 & 163 & 40.6 & \multirow{2}{*}{0.3067} \\
\hline & $45-64$ & 428 & 62.5 & 257 & 37.5 & \\
\hline \multirow[t]{2}{*}{ Gender } & Male & 266 & 60.3 & 175 & 39.7 & \multirow{2}{*}{0.573} \\
\hline & Female & 400 & 62.0 & 245 & 38.0 & \\
\hline \multirow[t]{6}{*}{ Location } & Rural & 120 & 59.1 & 83 & 40.9 & \multirow{2}{*}{0.473} \\
\hline & Non-Rural & 546 & 61.8 & 337 & 38.2 & \\
\hline & North East & 195 & 63.7 & 111 & 36.3 & \multirow{4}{*}{0.726} \\
\hline & North Central & 183 & 59.8 & 123 & 40.2 & \\
\hline & South & 258 & 60.4 & 169 & 39.6 & \\
\hline & West & 30 & 63.8 & 17 & 36.2 & \\
\hline \multirow[t]{10}{*}{ Diagnoses } & Bipolar Disorder & 200 & 60.1 & 133 & 39.9 & \multirow{2}{*}{0.569} \\
\hline & No Bipolar Disorder & 466 & 61.9 & 287 & 38.1 & \\
\hline & Anxiety & 60 & 56.1 & 47 & 43.9 & \multirow{2}{*}{0.240} \\
\hline & No Anxiety & 606 & 61.9 & 373 & 38.1 & \\
\hline & Depression & 140 & 58.6 & 99 & 41.4 & \multirow{2}{*}{0.323} \\
\hline & No Depression & 526 & 62.1 & 321 & 37.9 & \\
\hline & Other Mental Health & 298 & 54.7 & 247 & 45.3 & \multirow[b]{2}{*}{$<0.001$} \\
\hline & $\begin{array}{l}\text { No Other Mental } \\
\text { Health }\end{array}$ & 368 & 68.0 & 173 & 32.0 & \\
\hline & Diabetes & 110 & 55.0 & 90 & 45.0 & \multirow{2}{*}{0.042} \\
\hline & No Diabetes & 330 & 37.2 & 556 & 62.8 & \\
\hline \multirow[t]{7}{*}{$\begin{array}{l}\text { Medication } \\
\text { Utilization }\end{array}$} & $\begin{array}{l}\text { Second Generation } \\
\text { Antipsychotic }\end{array}$ & 433 & 61.0 & 277 & 39.0 & \multirow{3}{*}{0.2435} \\
\hline & $\begin{array}{l}\text { First Generation } \\
\text { Antipsychotic }\end{array}$ & 168 & 59.6 & 114 & 40.4 & \\
\hline & Both (combination) & 65 & 69.1 & 29 & 30.9 & \\
\hline & Switched To & 90 & 54.9 & 74 & 45.1 & \multirow{2}{*}{0.066} \\
\hline & Not post switch & 567 & 62.1 & 346 & 37.9 & \\
\hline & Combined & 101 & 67.3 & 49 & 32.7 & \multirow{2}{*}{0.104} \\
\hline & Not Combined & 565 & 60.4 & 371 & 39.6 & \\
\hline \multirow[t]{7}{*}{ Employment } & Full Time & 339 & 59.6 & 230 & 40.4 & \multirow[b]{2}{*}{0.215} \\
\hline & $\begin{array}{l}\text { Part Time / Retired / } \\
\text { Unemployed }\end{array}$ & 327 & 63.2 & 190 & 36.8 & \\
\hline & $\begin{array}{l}\text { Primary Policy } \\
\text { Holder }\end{array}$ & 316 & 60.0 & 211 & 40.0 & \multirow[t]{2}{*}{0.370} \\
\hline & Dependent & 350 & 62.6 & 209 & 37.4 & \\
\hline & Salary & 135 & 59.5 & 92 & 40.5 & \multirow{3}{*}{0.049} \\
\hline & Hourly & 206 & 67.1 & 101 & 32.9 & \\
\hline & No Pay / Unknown & 325 & 58.9 & 227 & 41.1 & \\
\hline
\end{tabular}


Table II-5: Bivariate associations between discontinuation and demographic, clinical, and employment characteristics

\begin{tabular}{|c|c|c|c|c|c|c|}
\hline & & \multicolumn{2}{|c|}{$\begin{array}{l}\text { No Discontinuation } \\
\quad(\mathrm{N}=765)\end{array}$} & \multicolumn{2}{|c|}{$\begin{array}{l}\text { Discontinued } \\
(\mathrm{N}=321)\end{array}$} & \multirow{2}{*}{$p$-value } \\
\hline & & $\mathrm{N}$ & $\%$ & $\mathrm{~N}$ & $\%$ & \\
\hline \multirow[t]{2}{*}{ Age } & $18-44$ & 267 & 66.6 & 134 & 33.4 & \multirow{2}{*}{0.033} \\
\hline & $45-64$ & 498 & 72.7 & 187 & 27.3 & \\
\hline \multirow[t]{2}{*}{ Gender } & Male & 313 & 71.0 & 128 & 29.0 & \multirow[b]{2}{*}{0.7502} \\
\hline & Female & 452 & 70.1 & 193 & 29.9 & \\
\hline \multirow[t]{6}{*}{ Location } & Rural & 140 & 69.0 & 63 & 31.0 & \multirow{2}{*}{0.609} \\
\hline & Non-Rural & 625 & 70.8 & 258 & 29.2 & \\
\hline & North East & 213 & 69.6 & 93 & 30.4 & \multirow{4}{*}{0.329} \\
\hline & North Central & 225 & 73.5 & 81 & 26.5 & \\
\hline & South & 291 & 68.1 & 136 & 31.9 & \\
\hline & West & 36 & 76.6 & 11 & 23.4 & \\
\hline \multirow[t]{10}{*}{ Diagnoses } & Bipolar Disorder & 211 & 63.4 & 122 & 36.6 & \multirow[b]{2}{*}{0.001} \\
\hline & $\begin{array}{l}\text { No Bipolar } \\
\text { Disorder }\end{array}$ & 554 & 73.6 & 199 & 26.4 & \\
\hline & Anxiety & 58 & 54.2 & 49 & 45.8 & \multirow{2}{*}{0.000} \\
\hline & No Anxiety & 707 & 72.2 & 272 & 27.8 & \\
\hline & Depression & 145 & 60.7 & 94 & 39.3 & \multirow{2}{*}{0.000} \\
\hline & No Depression & 620 & 73.2 & 227 & 26.8 & \\
\hline & $\begin{array}{l}\text { Other Mental } \\
\text { Health }\end{array}$ & 349 & 64.0 & 196 & 36.0 & \multirow{2}{*}{$<0.0001$} \\
\hline & $\begin{array}{l}\text { No Other Mental } \\
\text { Health }\end{array}$ & 416 & 76.9 & 125 & 23.1 & \\
\hline & Diabetes & 146 & 73.0 & 54 & 27.0 & \multirow{2}{*}{0.380} \\
\hline & No Diabetes & 619 & 69.9 & 267 & 30.1 & \\
\hline Medication & Second & & & & & \multirow{4}{*}{0.000} \\
\hline \multirow[t]{7}{*}{ Utilization } & $\begin{array}{l}\text { Generation } \\
\text { Antipsychotic }\end{array}$ & 505 & 71.1 & 205 & 28.9 & \\
\hline & $\begin{array}{l}\text { First Generation } \\
\text { Antipsychotic }\end{array}$ & 211 & 74.8 & 71 & 25.2 & \\
\hline & Both (combination) & 49 & 52.1 & 45 & 47.9 & \\
\hline & Switched To & 102 & 62.2 & 62 & 37.8 & \multirow{2}{*}{0.012} \\
\hline & Not post switch & 663 & 71.9 & 259 & 28.1 & \\
\hline & Combined & 79 & 52.7 & 71 & 47.3 & \multirow{2}{*}{$<0.0001$} \\
\hline & Not Combined & 686 & 73.3 & 250 & 26.7 & \\
\hline \multirow[t]{7}{*}{ Employment } & Full Time & 408 & 71.7 & 161 & 28.3 & \multirow[b]{2}{*}{0.339} \\
\hline & $\begin{array}{l}\text { Part Time / Retired } \\
\text { / Unemployed }\end{array}$ & 358 & 69.1 & 160 & 30.9 & \\
\hline & $\begin{array}{l}\text { Primary Policy } \\
\text { Holder }\end{array}$ & 381 & 72.3 & 146 & 27.7 & \multirow[t]{2}{*}{0.194} \\
\hline & Dependent & 384 & 68.7 & 175 & 31.3 & \\
\hline & Salary & 163 & 71.8 & 64 & 28.2 & \multirow{3}{*}{0.472} \\
\hline & Hourly & 208 & 67.8 & 99 & 32.2 & \\
\hline & No Pay / Unknown & 394 & 71.4 & 158 & 28.6 & \\
\hline
\end{tabular}


Table II-6: Logistic regression model optimization for factors associated with adherence

\begin{tabular}{|c|c|c|c|c|c|c|}
\hline Iteration & Description & $\begin{array}{l}\log \\
\text { Likelihood }\end{array}$ & $\begin{array}{l}\text { Difference } \\
\text { in -2 Log } \\
\text { Likelihood }\end{array}$ & $\begin{array}{l}\text { Model } \\
\text { DF }\end{array}$ & $\begin{array}{c}x^{2} \\
\text { critical } \\
\text { value }\end{array}$ & P-value \\
\hline 1 & Full Model ${ }^{* *}$ & 1416.211 & & 9 & & \\
\hline 2 & Full Model - Pay Type & 1418.950 & 5.478 & 8 & 3.84 & $<0.05$ \\
\hline \multicolumn{7}{|c|}{$\begin{array}{l}\text { *Full model Includes: Age, gender, diagnoses, use of a second generation antipsychotic, } \\
\text { switching, combination, insurance coverage, and full time employment }\end{array}$} \\
\hline \multicolumn{7}{|c|}{${ }^{\star \star}$ Final model includes all variables from the full model } \\
\hline
\end{tabular}


Table II-7: Odds ratios for the likelihood that an individual will be adherent to treatment

\begin{tabular}{llccc}
\hline \multirow{2}{*}{ Demographic } & \multicolumn{1}{c}{$\begin{array}{c}\text { Point } \\
\text { Estimate }\end{array}$} & \multicolumn{2}{c}{ 95\%Confidence Limits } \\
\cline { 2 - 5 } & Male vs. female & 0.919 & 0.712 & 1.187 \\
\cline { 2 - 5 } & $\begin{array}{l}\text { Age 45-64 vs. } \\
18-44\end{array}$ & 1.11 & 0.849 & 1.451 \\
\hline & $\begin{array}{l}\text { Other Mental } \\
\text { Health vs. none }\end{array}$ & 0.587 & 0.457 & 0.755 \\
\cline { 2 - 5 } & $\begin{array}{l}\text { Diabetes vs. no } \\
\text { diabetes }\end{array}$ & 0.691 & 0.501 & 0.952 \\
\hline $\begin{array}{lllll}\text { Switch vs. no } \\
\text { switch }\end{array}$ & 0.806 & 0.572 & 1.137 \\
\hline $\begin{array}{l}\text { Combination vs. } \\
\text { no combination }\end{array}$ & 1.361 & 0.939 & 1.972 \\
\hline Employment & $\begin{array}{l}\text { Salary vs. Hourly } \\
\text { Wages }\end{array}$ & 0.903 & 0.664 & 1.228 \\
\hline
\end{tabular}


Table II-8: Logistic regression model optimization for factors associated with discontinuation

\begin{tabular}{|c|c|c|c|c|c|c|}
\hline Iteration & Description & $\begin{array}{c}\text { Log } \\
\text { Likelihood }\end{array}$ & $\begin{array}{l}\text { Difference } \\
\text { in -2 Log } \\
\text { Likelihood }\end{array}$ & $\begin{array}{l}\text { Model } \\
\text { DF }\end{array}$ & $\begin{array}{c}x^{2} \\
\text { critical } \\
\text { value }\end{array}$ & P-value \\
\hline 1 & Full Model* & 1244.158 & & 11 & & \\
\hline 2 & $\begin{array}{l}\text { Full Model - } \\
\text { Antipsych Type }\end{array}$ & 1244.56 & 0.804 & 9 & 3.84 & $>0.05$ \\
\hline 3 & $\begin{array}{l}\text { Full Model - } \\
\text { Antipsych } \\
\text { Type,Insurance }\end{array}$ & 1245.14 & 1.16 & 8 & 3.84 & $>0.05$ \\
\hline 4 & $\begin{array}{l}\text { Full Model - } \\
\text { Antipsych Type, } \\
\text { Insurance, Switch** }\end{array}$ & 1246.541 & 2.802 & 7 & 3.84 & $>0.05$ \\
\hline 5 & $\begin{array}{l}\text { Full Model - } \\
\text { Antipsychotic Type, } \\
\text { Insurance, Switch, } \\
\text { Anxiety }\end{array}$ & 1249.458 & 5.834 & 6 & 3.84 & $<0.05$ \\
\hline $\begin{array}{l}{ }^{*} \text { Full moc } \\
\text { switching } \\
{ }^{* \star} \text { The fina } \\
\text { generatio }\end{array}$ & $\begin{array}{l}\text { ludes: Age, gender, } \\
\text { ination, and insuranc } \\
\text { el includes all variable } \\
\text { osychotic, insurance c }\end{array}$ & $\begin{array}{l}\text { agnoses, us } \\
\text { coverage } t \text { ) } \\
\text { from the fu } \\
\text { verage type }\end{array}$ & $\begin{array}{l}\text { of a secon } \\
\text { model exc } \\
\text { and switch }\end{array}$ & generat & $\begin{array}{l}\text { n antips } \\
\text { second }\end{array}$ & chotic, \\
\hline
\end{tabular}


Table II-9: Odds ratios for the likelihood that an individual will be persistent on treatment

\begin{tabular}{llccc}
\hline & & $\begin{array}{c}\text { Point } \\
\text { Estimate }\end{array}$ & \multicolumn{2}{c}{ 95\%Confidence Limits } \\
\hline Demographic & Male vs. female & 1.042 & 0.787 & 1.381 \\
\cline { 2 - 5 } & $\begin{array}{l}\text { Age 45-64 vs 18- } \\
\text { 44 }\end{array}$ & 1.222 & 0.922 & 1.619 \\
\hline Clinical & $\begin{array}{l}\text { Bipolar vs. no } \\
\text { bipolar }\end{array}$ & 0.587 & 0.457 & 0.755 \\
\hline $\begin{array}{l}\text { Anxiety vs. no } \\
\text { anxiety }\end{array}$ & 0.691 & 0.501 & 0.952 \\
\hline $\begin{array}{l}\text { Depression vs. } \\
\text { no depression }\end{array}$ & 0.806 & 0.572 & 1.137 \\
\hline $\begin{array}{l}\text { other mental } \\
\text { health diagnosis } \\
\text { vs. none }\end{array}$ & 1.361 & 0.939 & 1.972 \\
\hline $\begin{array}{l}\text { Combination vs. } \\
\text { monotherapy }\end{array}$ & 0.903 & 0.664 & 1.228 \\
\hline
\end{tabular}




\section{References:}

1. Kessler RC, Birnbaum H, Demler O, Falloon IR, Gagnon E, Guyer M et al. The prevalence and correlates of nonaffective psychosis in the National Comorbidity Survey Replication (NCS-R). Biol Psychiatry 2005;58(8):66876.

2. Saha S, Chant D, Welham J, McGrath J. A systematic review of the prevalence of schizophrenia. PLoS Med 2005;2(5):e141.

3. Wu EQ, Shi L, Birnbaum H, Hudson T, Kessler R. Annual prevalence of diagnosed schizophrenia in the USA: a claims data analysis approach. Psychol Med 2006;36(11):1535-40.

4. Llorca PM. Partial compliance in schizophrenia and the impact on patient outcomes. Psychiatry Res 2008;161(2):235-47.

5. Bulloch AG, Patten SB. Non-adherence with psychotropic medications in the general population. Soc Psychiatry Psychiatr Epidemiol 2010;45(1):4756 .

6. Ren XS, Herz L, Qian S, Smith E, Kazis LE. Measurement of treatment adherence with antipsychotic agents in patients with schizophrenia. Neuropsychiatr Dis Treat 2009;5:491-8.

7. Menzin J, Boulanger L, Friedman M, Mackell J, Lloyd JR. Treatment adherence associated with conventional and atypical antipsychotics in a large state Medicaid program. Psychiatr Serv 2003;54(5):719-23.

8. Pfeiffer PN, Ganoczy D, Valenstein M. Dosing frequency and adherence to antipsychotic medications. Psychiatr Serv 2008;59(10):1207-10.

9. Rabinovitch M, Bechard-Evans L, Schmitz N, Joober R, Malla A. Early predictors of nonadherence to antipsychotic therapy in first-episode psychosis. Can J Psychiatry 2009;54(1):28-35.

10. Schennach-Wolff R, Jager M, Seemuller F, Obermeier M, Messer T, Laux $G$ et al. Attitude towards adherence in patients with schizophrenia at discharge. J Psychiatr Res 2009;43(16):1294-301.

11. Vanelli M, Coca-Perraillon M. Role of patient experience in antidepressant adherence: a retrospective data analysis. Clin Ther 2008;30(9):1737-45.

12. Lindenmayer JP, Liu-Seifert H, Kulkarni PM, Kinon BJ, Stauffer V, Edwards SE et al. Medication nonadherence and treatment outcome in 
patients with schizophrenia or schizoaffective disorder with suboptimal prior response. J Clin Psychiatry 2009;70(7):990-6.

13. Masand PS, Roca M, Turner MS, Kane JM. Partial adherence to antipsychotic medication impacts the course of illness in patients with schizophrenia: a review. Prim Care Companion J Clin Psychiatry 2009;11(4):147-54.

14. Ascher-Svanum H, Zhu B, Faries DE, Salkever D, Slade EP, Peng X et al. The cost of relapse and the predictors of relapse in the treatment of schizophrenia. BMC Psychiatry 2010;10(1):2.

15. Ascher-Svanum H, Zhu B, Faries DE, Furiak NM, Montgomery W. Medication adherence levels and differential use of mental-health services in the treatment of schizophrenia. BMC Res Notes 2009;2:6.

16. Damen J, Thuresson PO, Heeg B, Lothgren M. A pharmacoeconomic analysis of compliance gains on antipsychotic medications. Appl Health Econ Health Policy 2008;6(4):189-97.

17. Law MR, Soumerai SB, Ross-Degnan D, Adams AS. A longitudinal study of medication nonadherence and hospitalization risk in schizophrenia. $J$ Clin Psychiatry 2008;69(1):47-53.

18. Gianfrancesco FD, Rajagopalan K, Sajatovic M, Wang RH. Treatment adherence among patients with schizophrenia treated with atypical and typical antipsychotics. Psychiatry Res 2006;144(2-3):177-89.

19. Acosta FJ, Bosch E, Sarmiento G, Juanes N, Caballero-Hidalgo A, Mayans $T$. Evaluation of noncompliance in schizophrenia patients using electronic monitoring (MEMS) and its relationship to sociodemographic, clinical and psychopathological variables. Schizophr Res 2009;107(23):213-7.

20. Valenstein M, Blow FC, Copeland LA, McCarthy JF, Zeber JE, Gillon L et al. Poor antipsychotic adherence among patients with schizophrenia: medication and patient factors. Schizophr Bull 2004;30(2):255-64.

21. Gianfrancesco FD, Rajagopalan K, Sajatovic M, Wang RH. Treatment adherence among patients with bipolar or manic disorder taking atypical and typical antipsychotics. J Clin Psychiatry 2006;67(2):222-32.

22. Gianfrancesco FD, Sajatovic M, Rajagopalan K, Wang RH. Antipsychotic treatment adherence and associated mental health care use among individuals with bipolar disorder. Clin Ther 2008;30(7):1358-74. 
23. Lage MJ, Hassan MK. The relationship between antipsychotic medication adherence and patient outcomes among individuals diagnosed with bipolar disorder: a retrospective study. Ann Gen Psychiatry 2009;8:7.

24. Sajatovic M, Biswas K, Kilbourne AK, Fenn H, Williford W, Bauer MS. Factors associated with prospective long-term treatment adherence among individuals with bipolar disorder. Psychiatr Serv 2008;59(7):753-9.

25. Yang M, Barner JC, Lawson KA, Rascati KL, Wilson JP, Crismon ML et al. Antipsychotic medication utilization trends among Texas veterans: 19972002. Ann Pharmacother 2008;42(9):1229-38.

26. Lieberman JA, Stroup TS, McEvoy JP, Swartz MS, Rosenheck RA, Perkins DO et al. Effectiveness of antipsychotic drugs in patients with chronic schizophrenia. N Engl J Med 2005;353(12):1209-23.

27. Valenstein M, Kavanagh J, Lee T, Reilly P, Dalack GW, Grabowski J et al. Using A Pharmacy-Based Intervention To Improve Antipsychotic Adherence Among Patients With Serious Mental Illness. Schizophr Bull 2009;

28. Constantine RJ, Andel R, Tandon R. Trends in Adult Antipsychotic Polypharmacy: Progress and Challenges in Florida's Medicaid Program. Community Ment Health J 2010;

29. Karve S, Cleves MA, Helm M, Hudson TJ, West DS, Martin BC. Prospective validation of eight different adherence measures for use with administrative claims data among patients with schizophrenia. Value Health 2009;12(6):989-95.

30. Svarstad BL, Shireman TI, Sweeney JK. Using drug claims data to assess the relationship of medication adherence with hospitalization and costs. Psychiatr Serv 2001;52(6):805-11.

31. Perron BE, Howard MO, Nienhuis JK, Bauer MS, Woodward AT, Kilbourne AM. Prevalence and burden of general medical conditions among adults with bipolar I disorder: results from the National Epidemiologic Survey on Alcohol and Related Conditions. J Clin Psychiatry 2009;70(10):1407-15.

32. Rawson NS, Malcolm E, D'Arcy C. Reliability of the recording of schizophrenia and depressive disorder in the Saskatchewan health care datafiles. Soc Psychiatry Psychiatr Epidemiol 1997;32(4):191-9.

33. Kilzieh N, Todd-Stenberg JA, Kennedy A, Wood AE, Tapp AM. Time to discontinuation and self-discontinuation of olanzapine and risperidone in patients with schizophrenia in a naturalistic outpatient setting. J Clin Psychopharmacol 2008;28(1):74-7. 
34. Cassidy CM, Rabinovitch M, Schmitz N, Joober R, Malla A. A comparison study of multiple measures of adherence to antipsychotic medication in firstepisode psychosis. J Clin Psychopharmacol 2010;30(1):64-7.

35. Kikkert MJ, Barbui C, Koeter MW, David AS, Leese M, Tansella M et al. Assessment of medication adherence in patients with schizophrenia: the Achilles heel of adherence research. J Nerv Ment Dis 2008;196(4):274-81.

36. Choudhry NK, Shrank WH, Levin RL, Lee JL, Jan SA, Brookhart MA et al. Measuring concurrent adherence to multiple related medications. Am J Manag Care 2009;15(7):457-64.

37. Martin BC, Wiley-Exley EK, Richards S, Domino ME, Carey TS, Sleath BL. Contrasting measures of adherence with simple drug use, medication switching, and therapeutic duplication. Ann Pharmacother 2009;43(1):36-44.

38. Ascher-Svanum H, Zhu B, Faries DE, Lacro JP, Dolder CR, Peng X. Adherence and persistence to typical and atypical antipsychotics in the naturalistic treatment of patients with schizophrenia. Patient Prefer Adherence 2008;2:67-77.

39. Gilmer TP, Dolder CR, Lacro JP, Folsom DP, Lindamer L, Garcia P et al. Adherence to treatment with antipsychotic medication and health care costs among Medicaid beneficiaries with schizophrenia. Am J Psychiatry 2004;161(4):692-9.

40. Lang K, Meyers JL, Korn JR, Lee S, Sikirica M, Crivera C et al. Medication adherence and hospitalization among patients with schizophrenia treated with antipsychotics. Psychiatr Serv 2010;61(12):1239-47.

41. Dolder CR, Lacro JP, Jeste DV. Adherence to antipsychotic and nonpsychiatric medications in middle-aged and older patients with psychotic disorders. Psychosom Med 2003;65(1):156-62.

42. Leslie DL, Mohamed S, Rosenheck RA. Off-label use of antipsychotic medications in the department of Veterans Affairs health care system. Psychiatr Serv 2009;60(9):1175-81. 


\section{CHAPTER 3}

\section{ASSOCIATION BETWEEN ADHERENCE AND HOSPITALIZATION IN A COMMERCIALLY INSURED POPULATION RECEIVING ANTIPSYCHOTICS}

Formatted for submission to the Journal of Managed Care Pharmacy (JMCP), not yet submitted. 


\section{Abstract}

\section{Background}

Adherence to treatments for schizophrenia are associated with significant adverse events that often lead to poor adherence and discontinuation of therapy. The lack of adherence to therapy may limit its effectiveness and be associated with poor outcomes. The purpose of this analysis is to determine if there is a significant difference in mental health associated hospitalization rates for those individuals with high adherence as compared to those with lower rates of adherence.

\section{Methods}

This study utilized a matched retrospective cohort design. Data were obtained from the MarketScan database between 2000 and 2001, and included 1,361 schizophrenia patients treated with antipsychotics. Propensity score matching was utilized to control for differences in sociodemographic and clinical factors between the adherent and non-adherent populations. Adherence was defined based on the Medication Possession Ratio (MPR) being greater than or equal to $80 \%$.

\section{Results}

Matching was successful in selecting a non-adherent comparison group for $76.5 \%$ of the adherent population, with significant support across the full range of propensity scores. The matching process was successful in limiting the differences in demographic and clinical characteristics between the groups. The risk of hospitalization was higher in the non-adherent population (RR 1.55, 95\% 
$\mathrm{Cl} 1.07-2.25)$ than the adherent population after matching. This is slightly lower than the relative risk seen in the unmatched group (RR 1.74, 95\% Cl $1.22-2.49$ in the adherent population vs. the non-adherent population).

\section{Conclusion}

Adherence to antipsychotic treatment has a significant association with a lower likelihood of hospitalization in the schizophrenia population. Additional analysis is necessary to understand the impact of persistence, and other medication taking behaviors such as switching or polytherapy. 


\section{Background}

Schizophrenia

Mental health disorders are prevalent in the United States, and treating these conditions can be difficult and expensive. A study conducted by Kessler, et al, found that the lifetime prevalence of schizophrenia is between $0.3 \%$ and $1.6 \%{ }^{1}$ A systematic review of the literature found that the period prevalence of schizophrenia is between $0.13 \%$ and $0.82 \%{ }^{2}$ An evaluation of a commercially insured population found that the prevalence of schizophrenia in that group is near the lower end of the range, at about $0.13 \% .^{3}$ Despite being less prevalent in the commercial population, people in this group make up a significant portion $(16 \%)$ of the schizophrenic population. ${ }^{3}$

Treatments and Adherence

Adherence to treatment is a key stumbling block for many patients receiving antipsychotics. It can take up to 16 weeks for a treatment regimen to become effective for relieving symptoms, but adverse events can occur far earlier. ${ }^{4}$ A review of the literature by Llorca found that several studies demonstrate a significant relationship between low adherence and poor outcomes. ${ }^{5}$ The side effects of antipsychotics alone are a barrier to adherence. These adverse events are largely metabolic for second generation antipsychotics, while first generation antipsychotics are associated with 
extrapyramidal side effects. A study by Bulloch found that $35 \%$ of individuals were non-adherent to their antipsychotics, ${ }^{6}$ and second generation antipsychotics were associated with a better likelihood of adherence than first generation antipsychotics in several studies. ${ }^{7,8}$

Less complicated regimens, ${ }^{9}$ levels of social support, ${ }^{10}$ and patient attitude towards treatment are additional areas associated with improved patient adherence. ${ }^{11}$ It has also been demonstrated that treatment naïve patients are less likely than those who have switched from another medication to be adherent and persistent, ${ }^{12}$ demonstrating the difficulty in selecting a first medication.

Adherence rates in the literature vary substantially depending on the population, and methods used to measure it. The medication possession ratio (MPR) is based on the sum of the days supply divided by the duration of therapy, whereas the proportion of days covered (PDC) is the number of days with therapy available divided by the length of the study. ${ }^{13}$ Individuals with a diagnosis of schizophrenia and a medication possession ratio (MPR) greater than $80 \%$ range between $35 \%$ and $60 \%,{ }^{6,14-17}$ coincidentally, the average MPR or PDC also ranged between $35 \%$ and $60 \%$ in different studies. ${ }^{8,10}$ This demonstrates the importance of ensuring that results are interpreted with population differences in mind, as results from one group may not be generalizable to another. 


\section{Impact of Poor Adherence}

Non-adherence to medications leads increasingly poor outcomes over

time. ${ }^{5}$ Poor adherence is a key driver of relapses in schizophrenia, leading to costs that are 3 times higher than non-relapsers. ${ }^{18}$ One key driver of this cost is hospitalization. A Canadian study in 2006 found that individuals who had a medication possession ratio (MPR) of greater than $80 \%$ had $63 \%$ fewer hospitalizations. ${ }^{19}$ A Medicaid population in Wisconsin had twice as many hospitalizations in the non-adherent group, and costs were 4 times higher. ${ }^{20}$ The risk of hospitalization increases quickly following discontinuation, with a study by Law et.al. observing the risk increase in as little as 10 days. ${ }^{21}$

Medication therapy choice regarding switching, combination therapy, and use of first vs. second generation antipsychotics might also impact hospitalization rates. In a Medicare population, second generation antipsychotic users and those on combination therapy were more likely to be hospitalized as compared with those utilizing first generation antipsychotics without combining, although the impact of adherence was not addressed in this analysis. ${ }^{22}$

\section{Study Purpose and Justification}

It has been estimated that hospitalizations could be decreased by $12.3 \%$ in the Medicaid population, saving $\$ 103$ million per year in the United States if gaps in therapy of longer than 15 days could be eliminated. ${ }^{23}$ Interventions have 
been successful in improving adherence rates, but additional information regarding the causes of adherence, and the populations where non-adherence is most likely could make these programs more effective. ${ }^{24} \mathrm{~A}$ key to making this information useful is ensuring that it is generalizable to the population where these programs are implemented.

There have been many studies conducted to better understand the factors leading to hospitalizations in the schizophrenia population. The vast majority of the literature identified above focuses on specific populations with a high incidence of schizophrenia, those individuals utilizing Medicaid and VA programs. The commercial population likely differs significantly from the Medicaid and VA groups where patients are typically older, and (especially in the VA) more likely to be male. ${ }^{22,23,25}$ This population is also different from that identified in Clinical Antipsychotic Trials of Intervention Effectiveness (CATIE), a prospective comparative effectiveness trial, in which $85 \%$ of the population was unemployed. ${ }^{26} \mathrm{~A}$ better understanding of medication use within the commercial population is critical. Sixteen percent of schizophrenics receive services through private insurance, and represent a fairly significant cost in this population. ${ }^{3}$

The purpose of this study is to determine the association between adherence to antipsychotics and decreased rates of hospitalization, while controlling for other medication taking behaviors and patient characteristics that could be associated with increased hospitalization rates in the commercially insured population receiving antipsychotics. 


\section{Methods}

Study Design

A matched retrospective cohort study was conducted. Individuals who were adherent to antipsychotics were matched to non-adherent individuals based on propensity scores measuring the likelihood of adherence to medication. Medication taking characteristics were examined for 1 year prior to the admission date of the hospitalized patient and in their non-hospitalized match.

\section{Data}

Data for this analysis was made available through the Thomson Medstat dissertation support program. This program provides access to de-identified data in the MarketScan database from years 2000 and 2001. This database contains enrollment and demographics data, as well as medical and pharmacy claims for nearly 5.9 million individuals.

Inclusion Criteria

Individuals were considered for inclusion in this study if they have at least 1 ICD-9 code indicating schizophrenia, 24 months of continuous enrollment, at least 2 fills of an antipsychotic medication in year 1 , and are between 18 and 64 
years old in the year 2000. Individuals were excluded if they were hospitalized for a mental health condition any time during the first year of the study. Figure III-1 describes the inclusion waterfall.

\section{Operational Definitions}

Operational definitions have largely been carried over from the work done previously to describe the antipsychotic using population. Continuous enrollment was defined as having 366 days of continuous enrollment in 2000, and 365 days of continuous enrollment in 2001 with both medical and pharmacy coverage. This data was abstracted from the enrollment data sets provided.

Hospitalizations were based on those individuals hospitalized for a mental health condition as defined by any inpatient record with a Major Diagnostic Category of 19, indicating treatment was for "Mental Diseases and Disorders." The hospitalization date was based on the related first hospital admission in 2001. Non-hospitalized patients were any individuals that did not have any hospitalizations for a mental health condition as defined above during the study period.

Diagnoses for specific conditions were identified through the presence of ICD-9 codes in the inpatient or outpatient records. Anxiety, Bipolar Disorder, Depression, Schizophrenia, Other Mental Health Disorders not included above, and Diabetes were all identified. The specific list of ICD-9 codes used to identify these conditions is provided in table III-1. The use of documentation of ICD-9 
codes to identify schizophrenia and comorbidities matches the methodology used in a variety of other studies, ${ }^{3,27,28}$ and is similar to methodology utilizing hospitalization billing records validated by Rawson, et al, in $1997 .{ }^{29}$

Therapy with a given treatment was defined as receipt of at least 2 fills within the study period. The "therapeutic period" for a treatment is the time from the first fill, to the date of the last fill plus the last days supply. "Combination Therapy" is defined as two treatments overlapping by a minimum of 90 days. A "switch" in therapy is defined as a change from one treatment to another where there is no more than a 90 day gap in therapy, and no more than 90 days of overlap in therapy. A "gap" in treatment is defined as a period of 90 days or more following the end of a therapeutic period, plus any days in the hospital (for non-mental health reasons). Studies have typically used periods of 30 to 90 days to define gaps in therapy $27,28,30$. This study utilized the 90 day period to match the longest days supply likely to be received by patients.

Demographic variables were cleaned and defined as well. Individual's age was defined as the difference between their birth year, and the year 2000 . There were no instances in the data where an individual had more than 1 gender on record. Employment and geographic variables were defined for each individual as the value that turned up most often for that individual (if more than one value was available).

Adherence was calculated utilizing the Medication Possession Ratio (MPR), calculated utilizing equation 1 below. Although a variety of methodologies for measuring adherence are available, several such as electronic 
monitoring (MEMS caps), or patient questionnaires are not feasible. Although electronic monitoring is considered the gold standard ${ }^{17}$, use of medical records

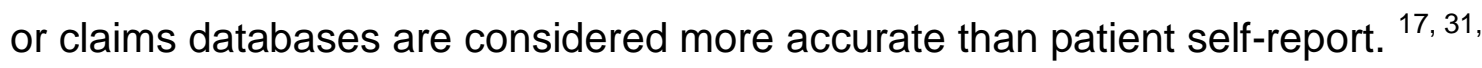
32 The decision to use MPR rather than Proportion of Days Covered (PDC) was based on several studies supporting its use, ${ }^{7,13,33,34}$ as well as it being the most common measure reported in the literature, and therefore the best for comparison amongst studies. Individuals were defined as adherent to therapy if their MPR was above $80 \%$.

Equation 1:

$$
M P R=\frac{\left(\sum d a y_{-} q t y\right)-l a s t_{-} d a y_{-} q t y}{\text { Last_fill_date }- \text { First_fill_date }}
$$

\section{Propensity Scores}

Propensity scores were developed for the likelihood that a patient will be adherent given their demographic, clinical, and employment characteristics (see table III-2 for a list of specific variables). Chi-square analysis was conducted in order to identify key characteristics based on a p-value greater than 0.2 . The full logistic regression model was then optimized using backwards stepwise regression. The log-likelihood test was used to determine if there were significant differences in the models. Correlations were utilized to identify risk of collinearity, and the Hosmer-Lemeshow test was used to assess goodness-of-fit. 


\section{Matching and Statistical Analysis}

Individuals with an MPR greater than $80 \%$ were matched $1: 1$ to nonadherent individuals based on the propensity scores. A nearest neighbor matching algorithm was used, utilizing calipers set to $1 / 2$ of a standard deviation of the propensity scores. Standardized differences were used to assess balance in variables before and after matching. This methodology is the same at that used by Bangelore et. al. ${ }^{35}$ in their analysis of the impact of beta-blocker use on clinical outcomes. The difference in hospitalization risk between adherent and non-adherent individuals was also assessed using the Chi-square test. Logistic regression was also utilized to control for factors differing between the hospitalized and non-hospitalized populations following matching. This model was optimized and tested in the same manner as the propensity score models described above. 


\section{Results}

Population:

This population examined in this study is described in table III-2. The mean age of the population was higher in the pre-match population than the post-match population (46.7 vs. 46.3 ) prior to matching, but the difference was not clinically significant. The population contained fewer males both before and after matching (41.2\% pre, $39.9 \%$ post). The percent of individuals living in rural areas increased slightly from $19.1 \%$ to $19.6 \%$, with a slight increase in the proportion of individuals living in the South and West. There were also slight increases in the number of full time and salaried workers. The number of individuals with other mental health conditions increased by about $4.2 \%$, but other comorbidities remained similar. Overall, the matched group is representative of the population from which it was produced.

\section{Propensity Scores:}

The propensity score model was successfully optimized (see table III-3) based on changes in -2 log likelihood. Goodness-of-fit was adequate based on a c-statistic $=0.782$, and Hosmer-Lemeshow $p$-value $=0.482$. The key drivers of adherence based on this model were age, gender, region, anxiety, other mental health diagnoses, diabetes, full time employment, and salary vs. hourly pay. 
There was support for matching adherent to non-adherent individuals across nearly the full range of assigned propensity scores (see figure III-2).

\section{Matching:}

Matching was successful in limiting the differences in key variables associated with adherence between the adherent and non-adherent populations. A match was identified for $76.5 \%$ of the adherent individuals, utilizing $91.6 \%$ of the non-adherent individuals. Figure III-3 describes the standardized differences in key variables before and after matching.

Prior to matching, age was significantly higher in the adherent population than the non-adherent population ( 47.7 vs. $45.5, \mathrm{p}-0.002$ ), but after matching the difference was no longer statistically significant (45.8 vs $46.9, p-0.169$ in the adherent and non-adherent groups respectively). Differences between the adherent and non-adherent populations based on gender remained insignificant at the alpha $=0.05$ level, as was the case for location and most of the comorbidities evaluated. There was a statistically significant difference before matching in other mental health disorders, which did not exist following matching. The variables that were significant at the alpha $=0.2$ level prior to matching were also no longer significant after matching. Table III-2 provides the details of these results. The details of the model fitting procedure are provided in table III-3. 
Impact of Adherence on Hospitalization:

The impact of adherence on hospitalization rates was apparent in the unmatched population, as well as the matched only and matched and statistically controlled groups. The relative risk of hospitalization in the matched nonadherent group was 55\% higher than in the adherent population (RR $1.55,95 \%$ Cl $1.07-2.25)$. In the unmatched population, the relative risk of hospitalization in the non-adherent group was $74 \%$ higher than in the adherent population (RR $1.7441,95 \% \mathrm{Cl} 1.22-2.49)$. Hospitalization rates in each group are described in table III-4.

There were also significant differences in a variety of clinical, demographic, and employment characteristics between hospitalized and nonhospitalized individuals both before and after matching. Table III-5 describes these characteristics in the hospitalized and non-hospitalized populations before and after matching. The strongest drivers of hospitalization in addition to adherence in both cases were comorbid bipolar disorder, anxiety, depression, and other mental health conditions, and therapy characteristics including choice of first vs. second generation antipsychotic, switching, and combination use. After controlling for confounders using logistic regression, adherence was still a significant predictor of hospitalization avoidance (OR $0.627,95 \% \mathrm{Cl} 0.394$ 0.999). Individuals with bipolar disorder, depression, and other mental health 
conditions also had significantly higher rates of hospitalization. See table III-6 for model diagnostics, and table III-7 for odds ratios generated by the logistic model. The difference in hospitalization rates between users of first and second generation antipsychotics were not significant, but those who used combinations or switched therapies were significantly more likely to be hospitalized. Table III-8 describes the differences in hospitalization rates between the matched and unmatched populations, and table III-9 describes the differences in odds ratios between methods. 


\section{Discussion:}

Poor adherence is a significant predictor of increased hospitalization risk for individuals with schizophrenia. This analysis clarifies the risk of nonadherence to therapy in a commercially insured population, and provides a clear incentive for patients, providers, caregivers, and insurers to ensure that those patients receiving antipsychotics remain true to their regimen. Identifying those individuals at risk for non-adherence and ensuring they are receiving support to overcome their barriers to adherence could lead to significantly lower numbers of hospitalizations, which in turn could lead to lower costs and essentially pay for the support programs.

Impact of adherence on hospitalizations

A variety of studies have looked at the association between adherence and hospitalizations due to mental health disorders, and many of them have found that hospitalization rates were nearly reduced by half between those who

were adherent and those who were not. ${ }^{19,20,36}$ This study found a more modest difference in hospitalization rates, with a relative risk of hospitalization of 1.55 $(95 \% \mathrm{Cl} 1.07-2.25)$ in the non-adherent population, as compared to adherent populations. Although adherence to medication is an important factor in avoiding hospitalizations, several other key factors emerged as well, with comorbidities, 
polypharmacy, and treatment switches increasing the likelihood of hospitalization.

The hospitalization rates seen in this population are below those seen in Medicaid populations ${ }^{20}$ ( $42 \%$ in the Medicaid non-adherent population vs. $14.5 \%$ in the commercial non-adherent population). This reinforces the need for population specific studies, as the severity of disease in this population is significantly lower as measured by hospitalizations.

\section{Meaning of different methodologies}

The importance of properly controlling comorbidities was also evident after examining the results of this analysis. Although the same conclusion holds throughout the unmatched, matched, and matched with logistic regression analyses, the magnitude of the impact decreases significantly with stronger controls for selection bias and potential confounders. Many of the studies performed in the literature did not control as carefully for these biases, and may be over-estimating the impact of adherence on hospitalization rates. Although adherence is important in avoiding hospitalizations, inflating the impact may divert limited funds from managed care outreach programs that address polypharmacy and other therapeutic issues to those focused more directly on adherence. In the end, it would be ideal to address all of a patient's medication taking behaviors, but the statistical analysis in this study shows that getting 
people settled on a suitable monotherapeutic regimen might result in a lower rate of hospitalizations.

\section{Limitations}

This study is limited to inferences that can be made from claims databases. A matched cohort study cannot be used to assess causality, although every attempt was made to address potential confounders, issues known to impact adherence and risk of hospitalization such as social support and disease severity could not be observed based on claims data. The limited timeframe of the study also made it difficult to assess the impact of persistence on outcomes. Users of depot medications were excluded from the study, potentially eliminating individuals with more severe, or long-term illness. The age of the data utilized in this study may also lead to limited generalizability due to changes in available therapies and differences in guidelines. The results are also limited in generalizability to the commercially insured population, and differ significantly for similar studies of Medicare, Medicaid, and Veterans populations.

Studies utilizing claims records to measure adherence are prone to several well documented limitations. For instance, without observing an individual taking a medication one cannot be sure that it is being taken. Pharmacy claims can also be incomplete if patients receive samples from their physician, or pay cash rather than their copay for inexpensive generics, resulting in underestimates of adherence. Severity of illness is also a confounder that is 
difficult to control for based on claims data, but may have biased the results if individuals with more severe disease were also less likely to be adherent to therapy.

Conclusions

Regardless of methodology, there risk of hospitalization increases substantially if individuals are not adherent to therapy as prescribed. Although adherence is a significant issue, polypharmacy and switching between treatments are also closely tied to hospitalization, and future studies should assess their impact. 


\section{Figures:}

Figure III-1: Inclusion and exclusion criteria flowchart

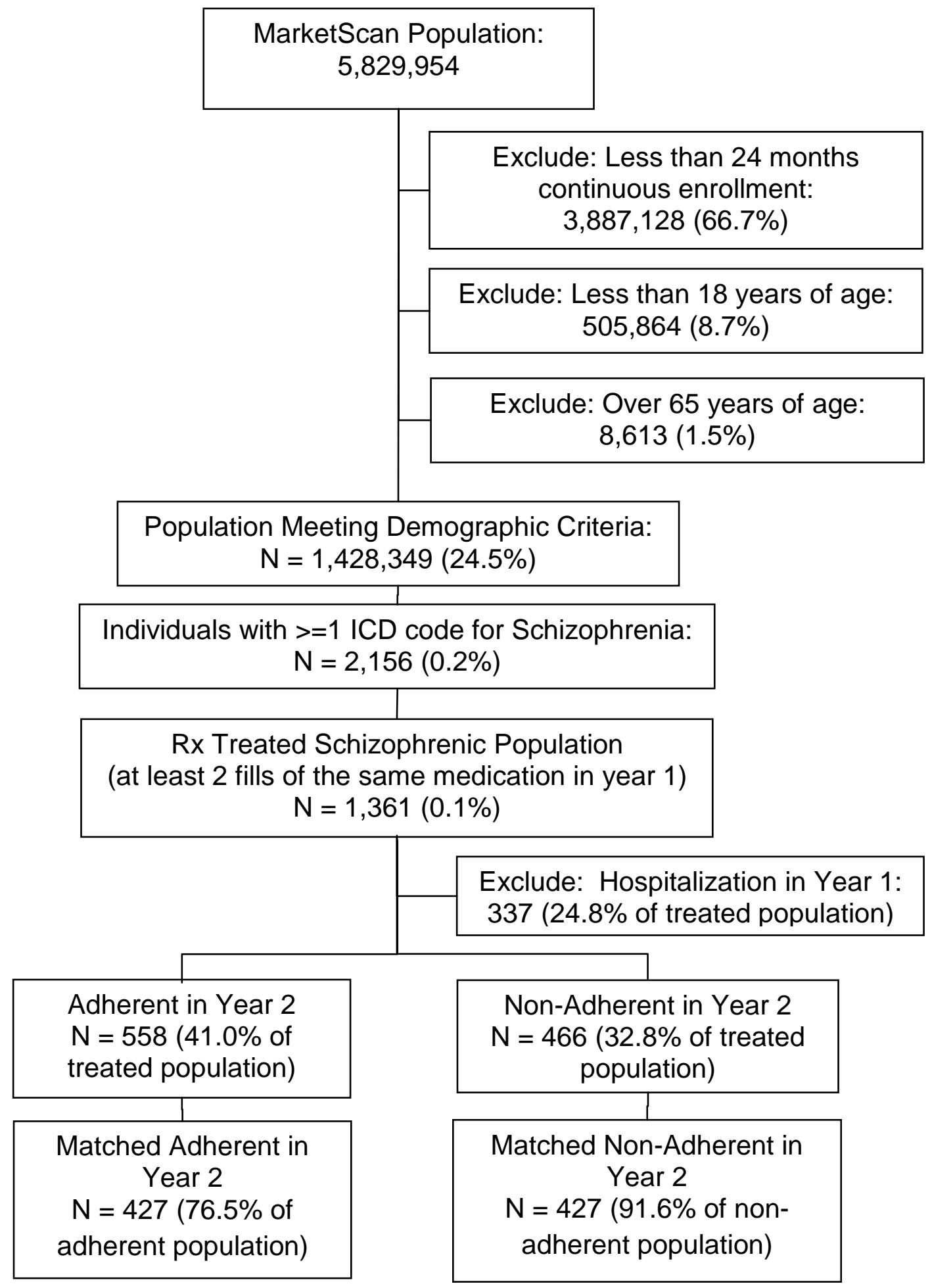


Figure III-2: Matching support for propensity scores in adherent vs. nonadherent populations

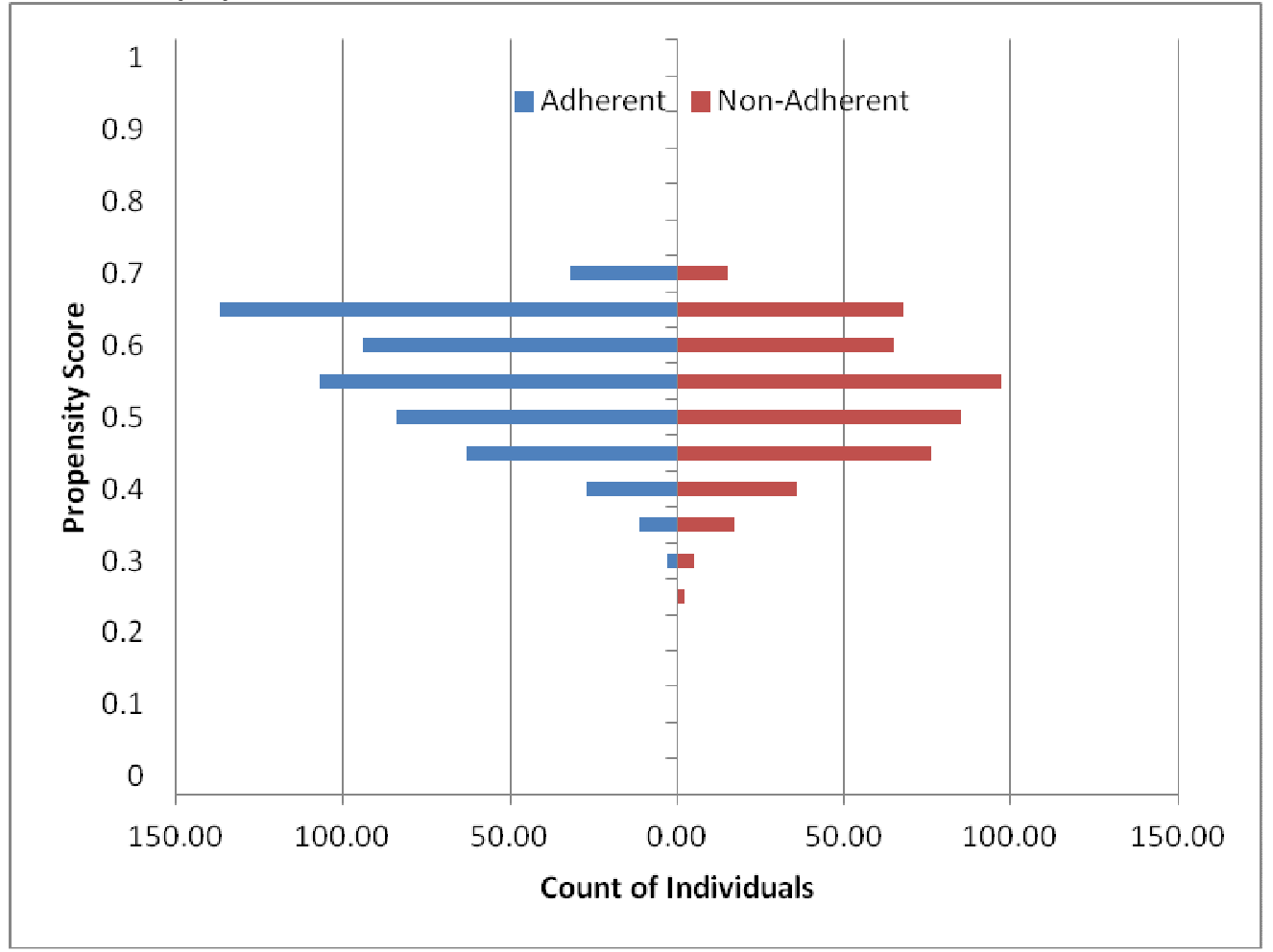


Figure III-3: Absolute standardized differences in matched variables before and after matching

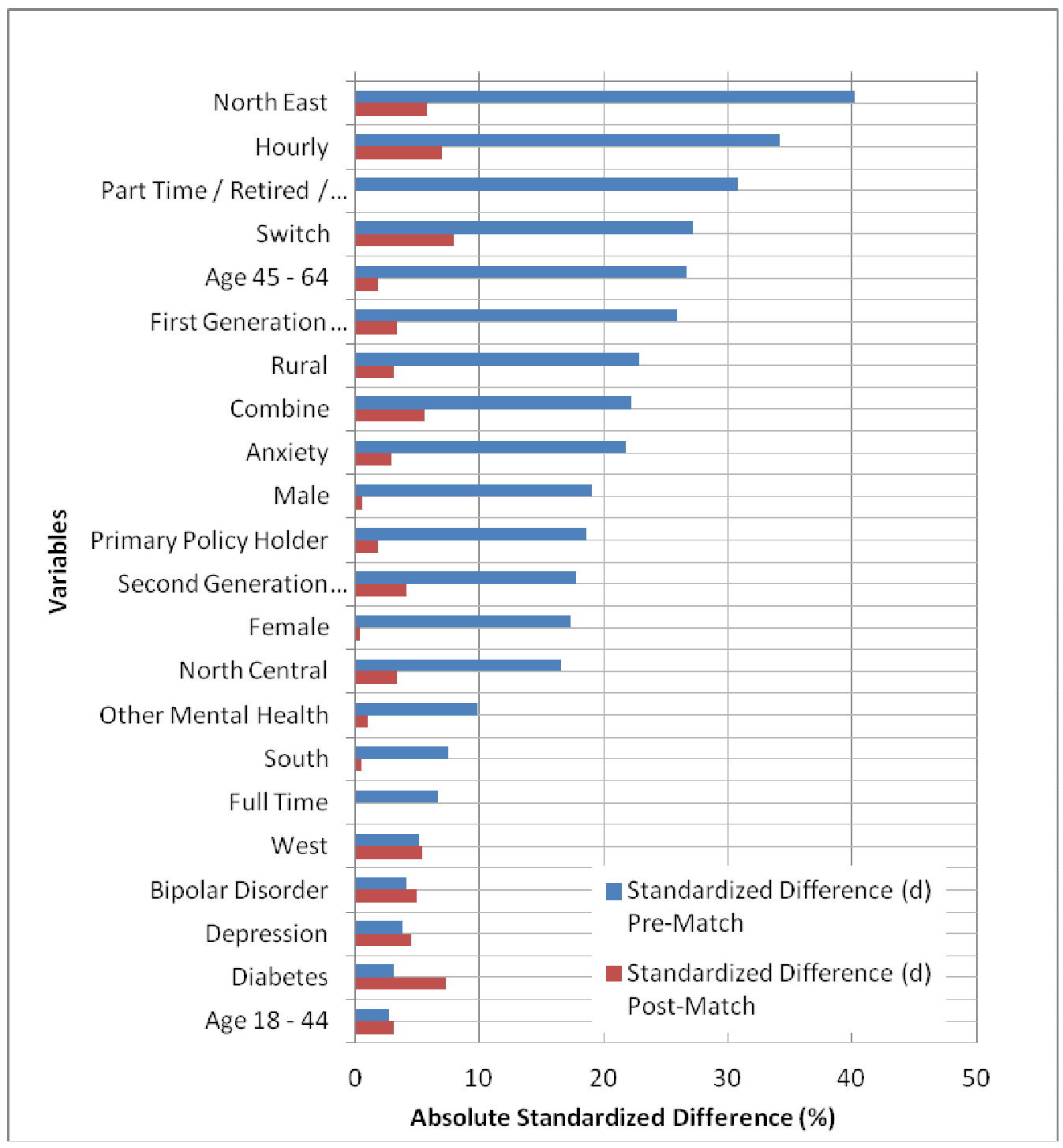




\section{Tables:}

Table III-1: ICD-9 Codes used for identifying diagnoses with primary conditions and comorbidities

\begin{tabular}{lc}
\hline Condition & ICD-9 Codes Included \\
\hline Schizophrenia & $295-295.95$ \\
\hline Bipolar Disorder & $296-296.99$ \\
\hline Anxiety & $300-300.09$ \\
\hline Depression & $311,300.4$ \\
\hline Other Mental Health & $290-319$, except for those listed above \\
\hline Diabetes & $250.00-250.99$ \\
\hline
\end{tabular}


Table III-2: Bivariate analysis of clinical, demographic, and employment factors potentially associated with adherence before and after matching

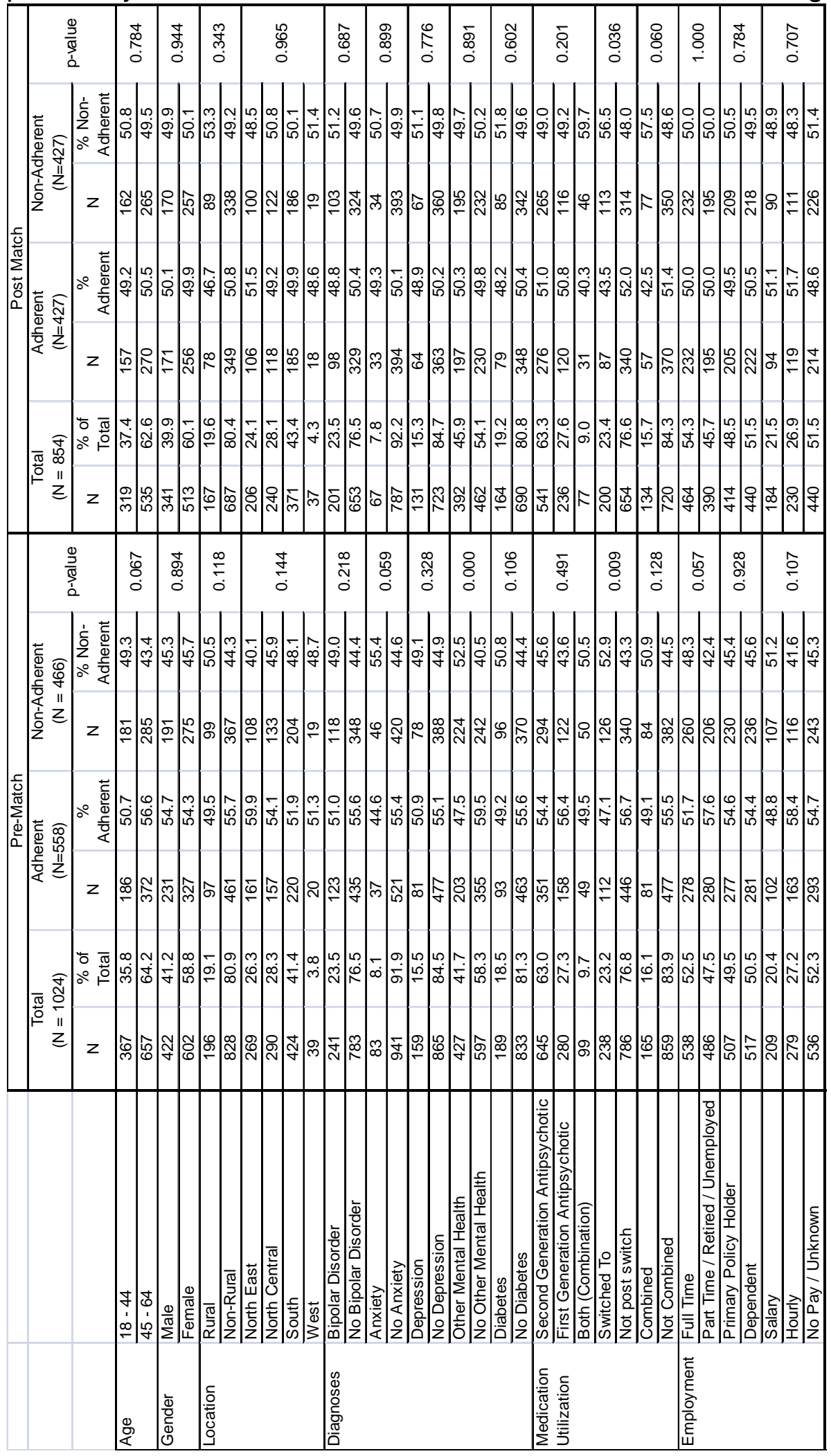


Table III-3: Model fitting diagnostics for propensity score, modeling likelihood of hospitalization among adherent and non-adherent groups, controlling for other covariates.

\begin{tabular}{|c|c|c|c|c|c|c|}
\hline Iteration & Description & $\begin{array}{c}\text { Log } \\
\text { Likelihood }\end{array}$ & $\begin{array}{c}\text { Difference } \\
\text { in -2 Log } \\
\text { Likelihood }\end{array}$ & $\begin{array}{c}\text { Model } \\
\text { DF }\end{array}$ & $\begin{array}{c}\text { critical } \\
\text { value } \\
\left(x^{2}\right) \\
\end{array}$ & $\mathrm{P}$-value \\
\hline 1 & Full Model $^{*}$ & 1376.41 & & 11 & & \\
\hline 2 & $\begin{array}{l}\text { Full Model } \\
\text { - Rural }{ }^{\star *}\end{array}$ & 1377.705 & 2.59 & 10 & 3.84 & $>0.05$ \\
\hline 3 & $\begin{array}{l}\text { Full Model } \\
\text { - Rural, } \\
\text { Anxiety }\end{array}$ & 1379.704 & 3.998 & 9 & 3.84 & $<0.05$ \\
\hline
\end{tabular}


Table III-4: Hospitalization rates in the adherent and non-adherent populations before and after matching

\begin{tabular}{lcc}
\hline & \multicolumn{2}{c}{ \% Hospitalized } \\
& Un-Matched & Matched \\
\hline Adherent & 8.2 & 9.4 \\
\hline Non-Adherent & 14.38 & 14.5 \\
\hline Relative Risk & 1.74 & 1.55 \\
\hline 95\% Cl for RR & $1.22-2.49$ & $1.07-2.25$ \\
\hline
\end{tabular}


Table III-5: Demographic, clinical, and employment characteristics in the hospitalized and non-hospitalized populations before and after matching

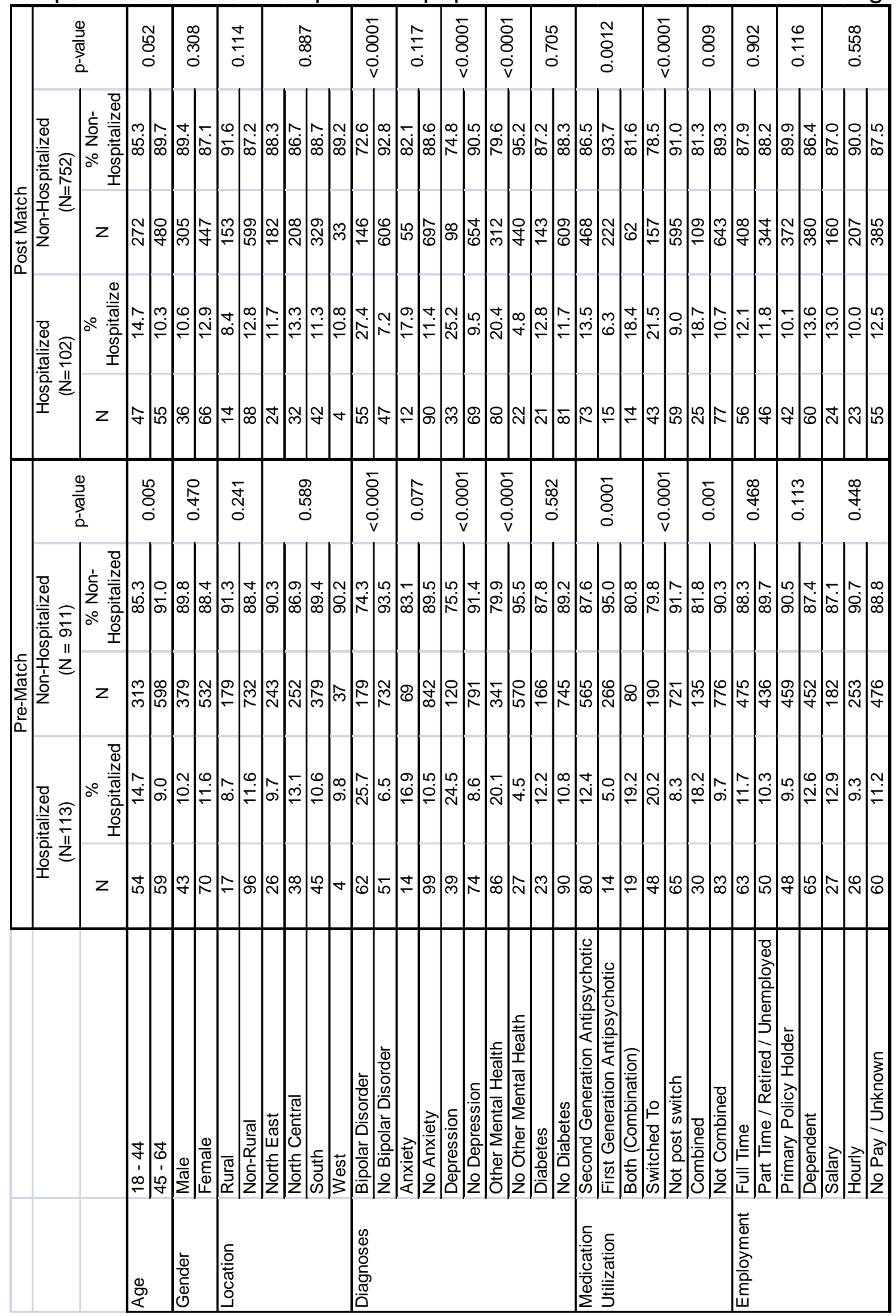


Table III-6: Model fitting diagnostics for the likelihood of hospitalization, modeling the likelihood of hospitalization among adherent and non-adherent groups, controlling for other covariates following within the matched population

\begin{tabular}{|c|c|c|c|c|c|c|}
\hline Iteration & Description & $\begin{array}{c}\text { Log } \\
\text { Likelihood }\end{array}$ & $\begin{array}{l}\text { Difference } \\
\text { in -2 Log } \\
\text { Likelihood }\end{array}$ & $\begin{array}{l}\text { Model } \\
\text { DF }\end{array}$ & $\begin{array}{c}\text { Critical } \\
\text { Value } \\
\left(x^{2}\right)\end{array}$ & P-value \\
\hline 1 & Full Model* & 498.14 & & 13 & & \\
\hline 2 & $\begin{array}{l}\text { Full Model - } \\
\text { Anxiety }\end{array}$ & 498.154 & 0.028 & 12 & 3.84 & $>0.05$ \\
\hline 3 & $\begin{array}{l}\text { Full Model - } \\
\text { Anxiety, Comb }\end{array}$ & 498.366 & 0.424 & 11 & 3.84 & $>0.05$ \\
\hline 4 & $\begin{array}{l}\text { Full Model - } \\
\text { Anxiety, Comb, } \\
\text { Rural }^{* *}\end{array}$ & 499.658 & 2.584 & 10 & 3.84 & $>0.05$ \\
\hline 5 & $\begin{array}{l}\text { Full Model - } \\
\text { Anxiety, Comb, } \\
\text { Rural, Atyp }\end{array}$ & 508.198 & 17.08 & 9 & 3.84 & $<0.05$ \\
\hline \multicolumn{7}{|c|}{$\begin{array}{l}{ }^{\star} \text { Full model Includes: Adherence, Age, gender, rural, bipolar, anxiety, depression, other } \\
\text { mental health diagnosis, atypical use, combination, switching, and primary coverage } \\
\star{ }^{\star *} \text { Final model includes all variables from the full model except anxiety, combination use, and } \\
\text { rural location }\end{array}$} \\
\hline
\end{tabular}


Table III-7: Odds ratios for the likelihood of hospitalization

\begin{tabular}{|c|c|c|c|c|}
\hline \multirow{2}{*}{ Adherence } & \multirow[b]{2}{*}{ Adherent vs. non-adherent } & \multirow{2}{*}{$\begin{array}{c}\begin{array}{c}\text { Point } \\
\text { Estimate }\end{array} \\
0.627\end{array}$} & \multicolumn{2}{|c|}{$\begin{array}{l}\text { 95\%Confidence } \\
\text { Limits }\end{array}$} \\
\hline & & & 0.394 & 0.999 \\
\hline \multirow[t]{2}{*}{ Demographic } & Male vs. Female & 0.826 & 0.506 & 1.346 \\
\hline & Over 45 vs. Under 45 & 0.769 & 0.470 & 1.260 \\
\hline \multirow[t]{6}{*}{ Clinical } & Bipolar vs. No Bipolar & 3.673 & 2.311 & 5.840 \\
\hline & Depression vs. No Depression & 2.285 & 1.363 & 3.832 \\
\hline & Other Mental Health vs. None & 3.511 & 2.064 & 5.972 \\
\hline & SGA vs. FGA & 1.764 & 0.915 & 3.401 \\
\hline & FGA / SGA Combo vs. FGA & 3.910 & 1.628 & 9.388 \\
\hline & Switch vs. no switch & 2.138 & 1.329 & 3.441 \\
\hline Employment & $\begin{array}{l}\text { Responsible for coverage vs. } \\
\text { Dependent }\end{array}$ & 0.626 & 0.388 & 1.010 \\
\hline
\end{tabular}


Table III-8: Hospitalization rates in the adherent and non-adherent populations before and after matching

\begin{tabular}{lcc}
\hline & \multicolumn{2}{c}{ \% Hospitalized } \\
& Un-Matched & Matched \\
\hline Adherent & 8.2 & 9.4 \\
\hline Non-Adherent & 14.38 & 14.5 \\
\hline Relative Risk & 1.74 & 1.55 \\
\hline $\mathbf{9 5 \%}$ Cl for RR & $1.22-2.49$ & $1.07-2.25$ \\
\hline
\end{tabular}


Table III-9: Odds of hospitalization in the unmatched, matched, and matched with logistic regression

\begin{tabular}{|c|c|c|c|}
\hline & \multicolumn{3}{|c|}{$\%$ Hospitalized } \\
\hline & Un-Matched & Matched & $\begin{array}{c}\text { Match w/ } \\
\text { Statistical Mode }\end{array}$ \\
\hline Odds Ratio & 0.535 & 0.609 & 0.627 \\
\hline p-value & 0.0018 & 0.0203 & 0.0493 \\
\hline 95\% Cl for OR & $0.36-0.80$ & $0.40-0.93$ & $0.39-0.999$ \\
\hline
\end{tabular}




\section{References:}

1. Kessler RC, Birnbaum H, Demler O, Falloon IR, Gagnon E, Guyer M et al. The prevalence and correlates of nonaffective psychosis in the National Comorbidity Survey Replication (NCS-R). Biol Psychiatry 2005;58(8):66876.

2. Saha S, Chant D, Welham J, McGrath J. A systematic review of the prevalence of schizophrenia. PLoS Med 2005;2(5):e141.

3. Wu EQ, Shi L, Birnbaum H, Hudson T, Kessler R. Annual prevalence of diagnosed schizophrenia in the USA: a claims data analysis approach. Psychol Med 2006;36(11):1535-40.

4. Stahl SM, Grady MM. A critical review of atypical antipsychotic utilization: comparing monotherapy with polypharmacy and augmentation. Curr Med Chem 2004;11(3):313-27.

5. Llorca PM. Partial compliance in schizophrenia and the impact on patient outcomes. Psychiatry Res 2008;161(2):235-47.

6. Bulloch AG, Patten SB. Non-adherence with psychotropic medications in the general population. Soc Psychiatry Psychiatr Epidemiol 2010;45(1):4756.

7. Ren XS, Herz L, Qian S, Smith E, Kazis LE. Measurement of treatment adherence with antipsychotic agents in patients with schizophrenia. Neuropsychiatr Dis Treat 2009;5:491-8.

8. Menzin J, Boulanger L, Friedman M, Mackell J, Lloyd JR. Treatment adherence associated with conventional and atypical antipsychotics in a large state Medicaid program. Psychiatr Serv 2003;54(5):719-23.

9. Pfeiffer PN, Ganoczy D, Valenstein M. Dosing frequency and adherence to antipsychotic medications. Psychiatr Serv 2008;59(10):1207-10.

10. Rabinovitch M, Bechard-Evans L, Schmitz N, Joober R, Malla A. Early predictors of nonadherence to antipsychotic therapy in first-episode psychosis. Can J Psychiatry 2009;54(1):28-35.

11. Schennach-Wolff R, Jager M, Seemuller F, Obermeier M, Messer T, Laux $G$ et al. Attitude towards adherence in patients with schizophrenia at discharge. J Psychiatr Res 2009;43(16):1294-301.

12. Vanelli M, Coca-Perraillon M. Role of patient experience in antidepressant adherence: a retrospective data analysis. Clin Ther 2008;30(9):1737-45. 
13. Karve S, Cleves MA, Helm M, Hudson TJ, West DS, Martin BC. Prospective validation of eight different adherence measures for use with administrative claims data among patients with schizophrenia. Value Health 2009;12(6):989-95.

14. Gilmer TP, Dolder CR, Lacro JP, Folsom DP, Lindamer L, Garcia P et al. Adherence to treatment with antipsychotic medication and health care costs among Medicaid beneficiaries with schizophrenia. Am J Psychiatry 2004;161(4):692-9.

15. Valenstein M, Kavanagh J, Lee T, Reilly P, Dalack GW, Grabowski J et al. Using A Pharmacy-Based Intervention To Improve Antipsychotic Adherence Among Patients With Serious Mental Illness. Schizophr Bull 2009;

16. Valenstein M, Blow FC, Copeland LA, McCarthy JF, Zeber JE, Gillon L et al. Poor antipsychotic adherence among patients with schizophrenia: medication and patient factors. Schizophr Bull 2004;30(2):255-64.

17. Acosta FJ, Bosch E, Sarmiento G, Juanes N, Caballero-Hidalgo A, Mayans T. Evaluation of noncompliance in schizophrenia patients using electronic monitoring (MEMS) and its relationship to sociodemographic, clinical and psychopathological variables. Schizophr Res 2009;107(23):213-7.

18. Ascher-Svanum H, Zhu B, Faries DE, Salkever D, Slade EP, Peng X et al. The cost of relapse and the predictors of relapse in the treatment of schizophrenia. BMC Psychiatry 2010;10(1):2.

19. Ward A, Ishak K, Proskorovsky I, Caro J. Compliance with refilling prescriptions for atypical antipsychotic agents and its association with the risks for hospitalization, suicide, and death in patients with schizophrenia in Quebec and Saskatchewan: a retrospective database study. Clin Ther 2006;28(11):1912-21.

20. Svarstad BL, Shireman TI, Sweeney JK. Using drug claims data to assess the relationship of medication adherence with hospitalization and costs. Psychiatr Serv 2001;52(6):805-11.

21. Law MR, Soumerai SB, Ross-Degnan D, Adams AS. A longitudinal study of medication nonadherence and hospitalization risk in schizophrenia. $J$ Clin Psychiatry 2008;69(1):47-53.

22. Kennedy J, Tien YY, Cohen LJ, Sclar DA, Liu D, Blodgett EG et al. The association between class of antipsychotic and rates of hospitalization: results of a retrospective analysis of data from the 2005 medicare current beneficiary survey. Clin Ther 2009;31(12):2931-9. 
23. Marcus SC, Olfson M. Outpatient antipsychotic treatment and inpatient costs of schizophrenia. Schizophr Bull 2008;34(1):173-80.

24. Cook PF, Emiliozzi S, Waters C, El Hajj D. Effects of telephone counseling on antipsychotic adherence and emergency department utilization. Am J Manag Care 2008;14(12):841-6.

25. Lang K, Meyers JL, Korn JR, Lee S, Sikirica M, Crivera C et al. Medication adherence and hospitalization among patients with schizophrenia treated with antipsychotics. Psychiatr Serv 2010;61(12):1239-47.

26. Lieberman JA, Stroup TS, McEvoy JP, Swartz MS, Rosenheck RA, Perkins DO et al. Effectiveness of antipsychotic drugs in patients with chronic schizophrenia. N Engl J Med 2005;353(12):1209-23.

27. Gianfrancesco FD, Rajagopalan K, Sajatovic M, Wang RH. Treatment adherence among patients with schizophrenia treated with atypical and typical antipsychotics. Psychiatry Res 2006;144(2-3):177-89.

28. Gianfrancesco FD, Rajagopalan K, Sajatovic M, Wang RH. Treatment adherence among patients with bipolar or manic disorder taking atypical and typical antipsychotics. J Clin Psychiatry 2006;67(2):222-32.

29. Rawson NS, Malcolm E, D'Arcy C. Reliability of the recording of schizophrenia and depressive disorder in the Saskatchewan health care datafiles. Soc Psychiatry Psychiatr Epidemiol 1997;32(4):191-9.

30. Kilzieh N, Todd-Stenberg JA, Kennedy A, Wood AE, Tapp AM. Time to discontinuation and self-discontinuation of olanzapine and risperidone in patients with schizophrenia in a naturalistic outpatient setting. J Clin Psychopharmacol 2008;28(1):74-7.

31. Cassidy CM, Rabinovitch M, Schmitz N, Joober R, Malla A. A comparison study of multiple measures of adherence to antipsychotic medication in first-episode psychosis. J Clin Psychopharmacol 2010;30(1):64-7.

32. Kikkert MJ, Barbui C, Koeter MW, David AS, Leese M, Tansella M et al. Assessment of medication adherence in patients with schizophrenia: the Achilles heel of adherence research. J Nerv Ment Dis 2008;196(4):274-81.

33. Choudhry NK, Shrank WH, Levin RL, Lee JL, Jan SA, Brookhart MA et al. Measuring concurrent adherence to multiple related medications. Am J Manag Care 2009;15(7):457-64.

34. Martin BC, Wiley-Exley EK, Richards S, Domino ME, Carey TS, Sleath $\mathrm{BL}$. Contrasting measures of adherence with simple drug use, medication switching, and therapeutic duplication. Ann Pharmacother 2009;43(1):3644. 
35. Bangalore S, Steg G, Deedwania P, Crowley K, Eagle KA, Goto S et al. beta-Blocker use and clinical outcomes in stable outpatients with and without coronary artery disease. JAMA 2012;308(13):1340-9.

36. Novick D, Haro JM, Suarez D, Perez V, Dittmann RW, Haddad PM. Predictors and clinical consequences of non-adherence with antipsychotic medication in the outpatient treatment of schizophrenia. Psychiatry Res 2010;176(2-3):109-13. 